US Army Corps

of Engineers ${ }_{\circledast}$

Engineer Research and

Development Center

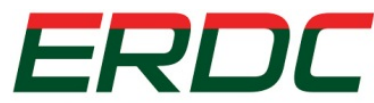

INNOVATIVE SOLUTIONS for a safer, better world

\title{
Emissions Reductions Associated with the Use of Warm-Mix Asphalt as Compared to Hot-Mix Asphalt
}

Mariely Mejías-Santiago and Linda V. Osborn

June 2014

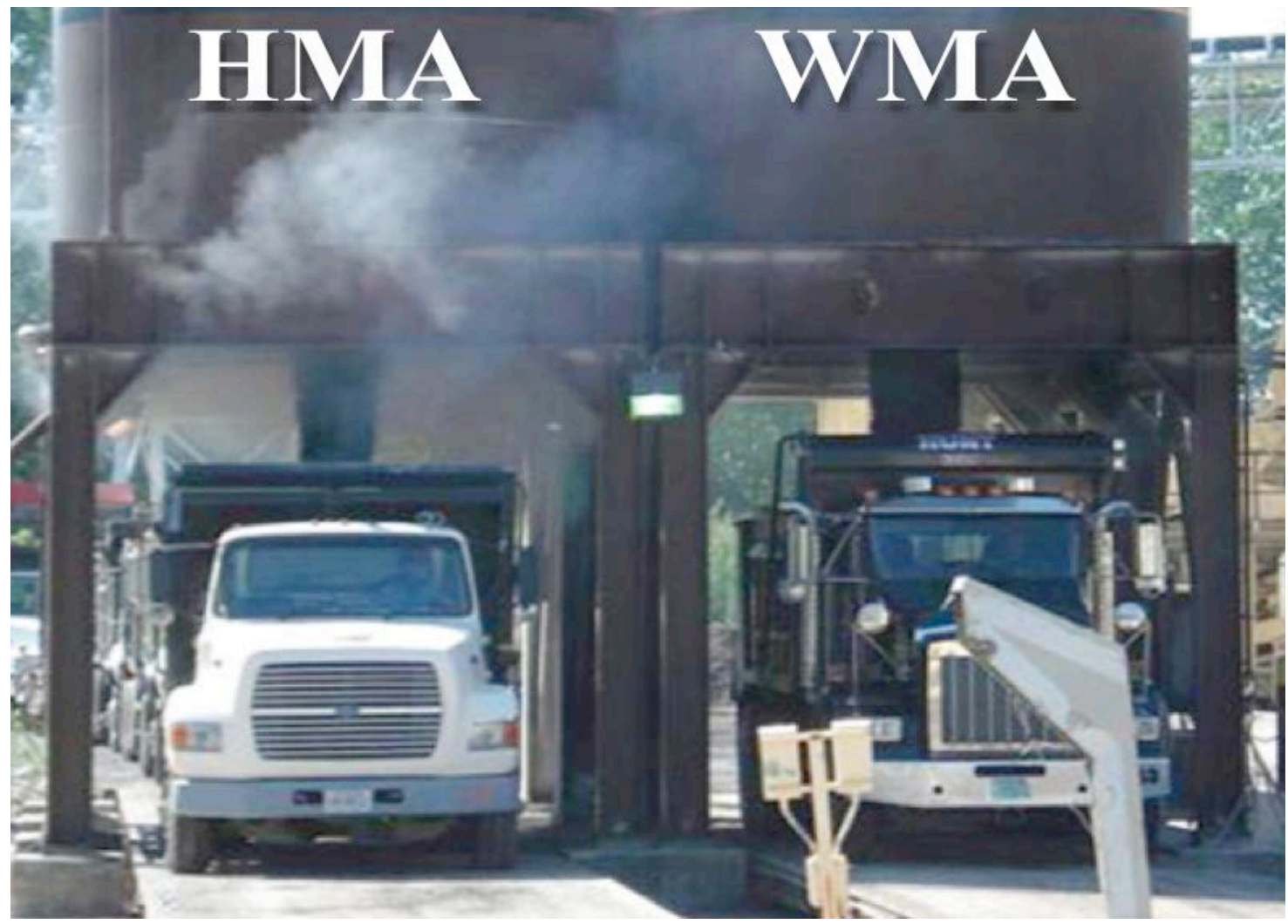


The US Army Engineer Research and Development Center (ERDC) solves the nation's toughest engineering and environmental challenges. ERDC develops innovative solutions in civil and military engineering, geospatial sciences, water resources, and environmental sciences for the Army, the Department of Defense, civilian agencies, and our nation's public good. Find out more at www.erdc.usace.army.mil.

To search for other technical reports published by ERDC, visit the ERDC online library at http://acwc.sdp.sirsi.net/client/default. 


\title{
Emissions Reductions Associated with the Use of Warm-Mix Asphalt as Compared to Hot-Mix Asphalt
}

\author{
Mariely Mejías-Santiago \\ Geotechnical and Structures Laboratory \\ U.S. Army Engineer Research and Development Center \\ 3909 Halls Ferry Road \\ Vicksburg, MS 39180-6199 \\ Linda V. Osborn \\ Heritage Research Group \\ 7901 W. Morris St. \\ Indianapolis, IN 46231
}

Final report

Approved for public release; distribution is unlimited.

\author{
Prepared for U.S. Air Force Civil Engineer Center \\ 139 Barnes Drive, Suite 1 \\ Tyndall AFB, FL 32403-5319
}




\section{Abstract}

This report presents results from a literature review and field testing that were conducted with the main objective of developing guidance for documenting the reduction in emissions associated with the use of warmmix asphalt (WMA) as compared to conventional hot-mix asphalt (HMA). The literature review presents current methods for estimating emissions during asphalt production, current protocols to measure and control emissions, and case studies where WMA emissions were measured and compared to HMA. Field testing was conducted during asphalt paving at two locations where a given mixture was placed as HMA and WMA. Workers' exposures to asphalt emissions were measured at each test site for both HMA and WMA. Data from both the literature and field testing provide averaged emissions reductions that range up to $70 \%$ for plant emissions and up to $50 \%$ for asphalt emissions during placement.

DISCLAIMER: The contents of this report are not to be used for advertising, publication, or promotional purposes. Citation of trade names does not constitute an official endorsement or approval of the use of such commercial products. All product names and trademarks cited are the property of their respective owners. The findings of this report are not to be construed as an official Department of the Army position unless so designated by other authorized documents. 


\section{Contents}

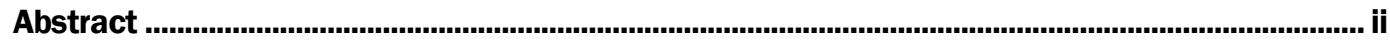

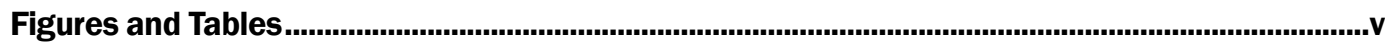

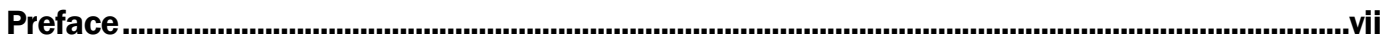

Unit Conversion Factors ..................................................................................................................... vili

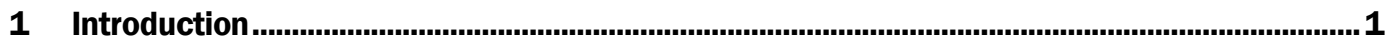

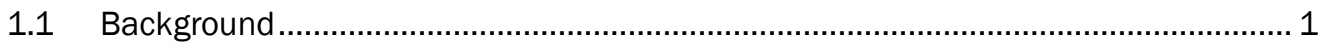

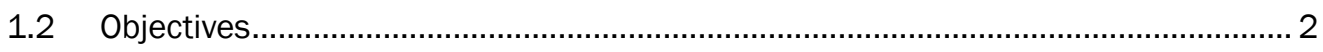

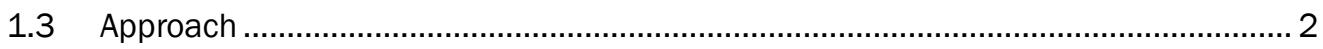

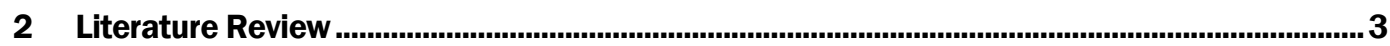

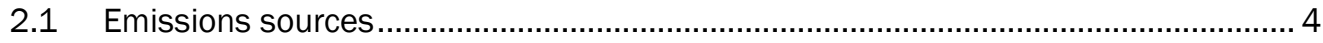

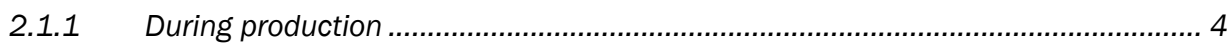

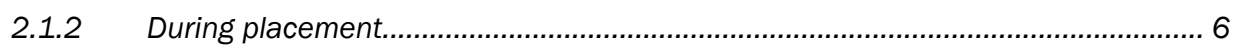

2.2 Emissions control technologies ........................................................................... 7

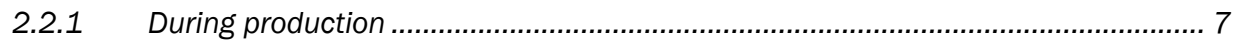

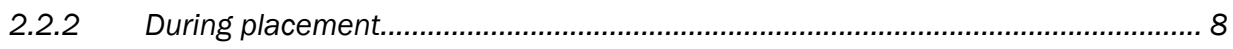

2.3 WMA potential to reduce emissions .................................................................. 8

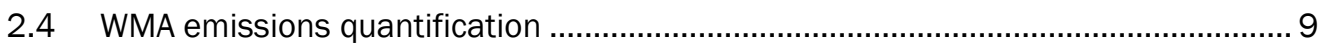

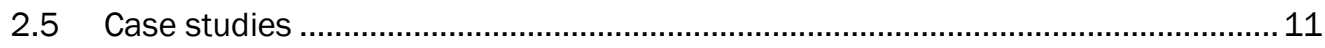

2.5.1 Emissions during asphalt production ............................................................ 11

2.5.2 Emissions during asphalt placement............................................................... 12

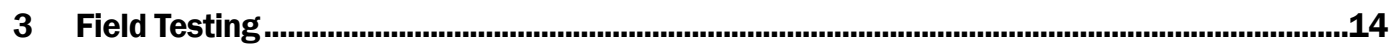

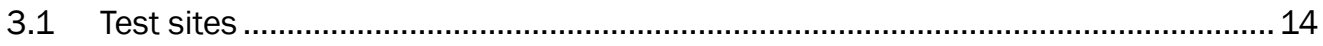

3.2 Monitoring equipment and procedures............................................................. 16

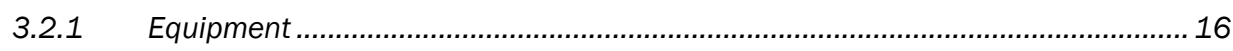

3.2.2 Monitoring procedures ................................................................................... 18

S.3 Sample analysis procedures........................................................................... 20

3.3.1 Total Particulates and Benzene Soluble Fraction ................................................ 20

3.3.2 Total Organic Matter ......................................................................................... 22

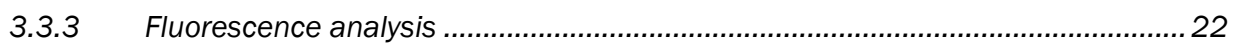

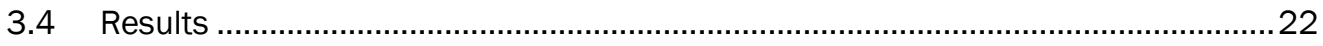

3.4.1 Total Particulates and Benzene Soluble Fraction ............................................... 23

3.4.2 Total Organic Matter .................................................................................... 26

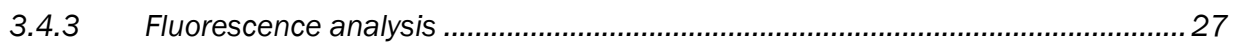

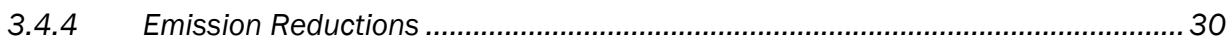

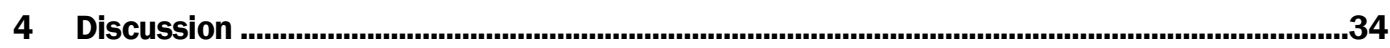

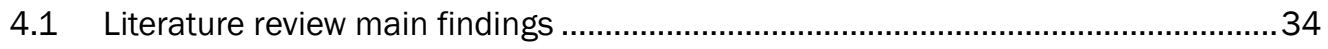




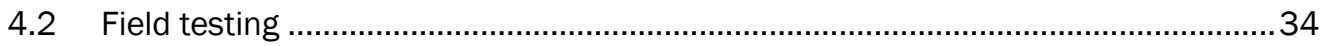

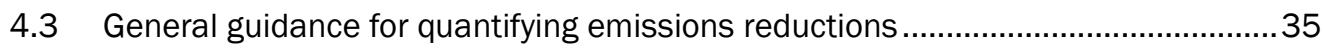

5 Conclusions and Recommendations ................................................................................37

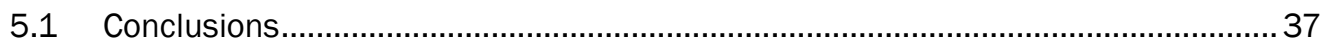

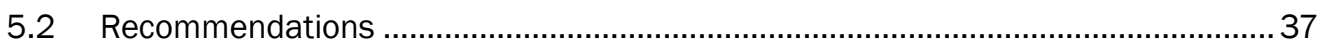

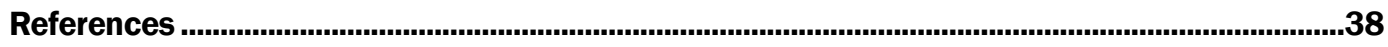

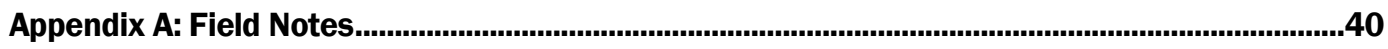

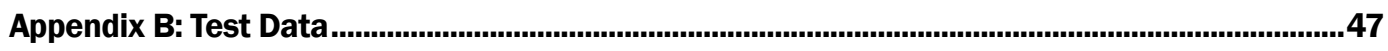

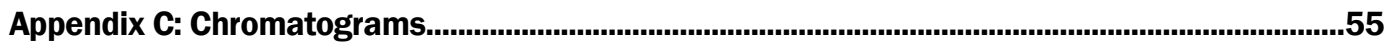

Report Documentation Page 


\section{Figures and Tables}

\section{Figures}

Figure 1. Basic process steps for batch-mix asphalt plants............................................................

Figure 2. Basic process steps for drum-mix asphalt plants. ……........................................................ 5

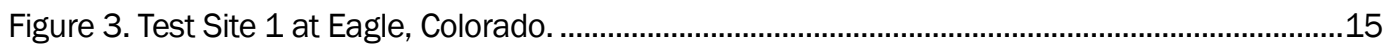

Figure 4. Test Site 2 at Okolona, Mississippi........................................................................................15

Figure 5. Sampling equipment: a) air pump and b) electronic calibrator.........................................16

Figure 6. NIOSH 5042 sampler: a) filter assembled and b) detailed assembly.................................17

Figure 7. Sorbent tube sampler. .............................................................................................17

Figure 8. Sampling train connected in series.........................................................................18

Figure 9. Typical sampler configuration on worker. ............................................................................19

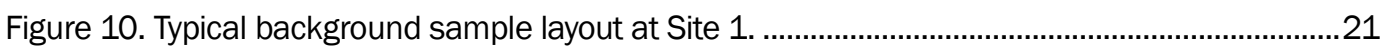

Figure 11. Background sample set up at Test Site 2 ……...............................................................21

Figure 12. Worker exposure to TP during WMA and HMA placement at Test Site 1. .......................24

Figure 13. Worker exposure to TP during WMA and HMA placement at Test Site 2. .......................24

Figure 14. Worker exposure to BSF during WMA and HMA placement at Test Site 1......................25

Figure 15. Worker exposure to BSF during WMA and HMA placement at Test Site 2......................25

Figure 16. Worker exposure to TOM during WMA and HMA placement at Test Site 1......................26

Figure 17. Worker exposure to TOM during WMA and HMA placement at Test Site 2. ......................27

Figure 18. FLU-PACs reported as $\mu \mathrm{g} / \mathrm{m}^{3}$ as DPA for WMA and HMA at Test Site 1...........................28

Figure 19. FLU-PACs reported as $\mu \mathrm{g} / \mathrm{m}^{3}$ as DPA for WMA and HMA at Test Site 2...........................28

Figure 20. FLU-PACs reported as (EU/g ADJ) for WMA and HMA at Test Site 1.................................29

Figure 21. FLU-PACs reported as (EU/g ADJ) for WMA and HMA at Test Site 2 ................................29

Figure 22. Average site results comparing TP emissions of WMA and HMA ...................................30

Figure 23. Average site results comparing BSF emissions of WMA and HMA. ................................31

Figure 24. Average site results comparing TOM emissions of WMA and HMA................................31

Figure 25. Average site results comparing fluorescence results $\left(\mu \mathrm{g} / \mathrm{m}^{3}\right.$ as DPA) of WMA and HMA.

Figure 26. Average site results comparing fluorescence results (EU/g ADs) of WMA and HMA.............32

Figure 27. Average emission reductions comparing WMA and HMA per test site. ..............................33

Table 7. Important factors to consider when monitoring asphalt emissions. ......................................36

Figure C1. GC/FID chromatogram of a kerosene calibration standard............................................55

Figure C2. GC/FID chromatogram of a simulated distillation standard showing straight chain hydrocarbons from C-6 through C-44. ..............................................................................56

Figure C3. GC/FID chromatogram of a blank extract.................................................................57

Figure C4. GC/FID chromatogram of TOM from one worker from Test Site 1. .................................58

Figure C5. GC/FID chromatogram of TOM from one worker from Test Site 2. ..................................59 


\section{Tables}

Table 1. Typical asphalt plant emission control techniques.............................................................. 7

Table 2. Stack emission test parameters and methods (adapted from NCHRP 9-47a) ...................10

Table 3. Comparison of WMA and HMA stack emissions data from the literature...........................11

Table 4. Data summary on worker exposure to asphalt fumes from the literature. ..........................13

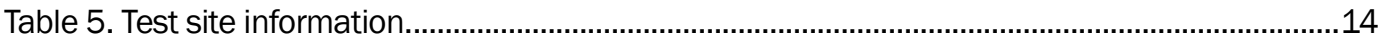

Table 6. Average mix temperatures for both test sites...................................................................23

Table 7. Important factors to consider when monitoring asphalt emissions. ....................................36

Table B1. Total particulate (TP) data from Test Site 1. ......................................................................4

Table B2. Total particulate (TP) data from Test Site 2 . ....................................................................48

Table B3. Benzene soluble fraction (BSF) data from Test Site 1.....................................................49

Table B4. Benzene soluble fraction (BSF) data from Test Site 2 ......................................................50

Table B5. Total organic matter (TOM) data from Test Site 1 ..............................................................51

Table B6. Total organic matter (TOM) data from Test Site 2 ...............................................................52

Table B7. Fluorescence data from Test Site 1.................................................................................53

Table B8. Fluorescence data from Test Site 2 ....................................................................................54 


\section{Preface}

This study was conducted for the U.S. Air Force Civil Engineer Center as part of the Warm-Mix Asphalt Evaluation Project. The Technical Monitor was Dr. David A. Horner.

The work was performed by the Airfields and Pavements Branch (GM-A), Engineering Systems and Materials Division (GM), U.S. Army Engineer Research and Development Center, Geotechnical and Structures Laboratory (ERDC-GSL), and Heritage Research Group. At the time of publication, Dr. Gary L. Anderton was Chief, CEERD-GM-A; Dr. Larry N. Lynch was Chief, CEERD-GM; and Dr. David A. Horner, CEERD-GV-T, was the Technical Director for Force Projection and Maneuver Support. The Deputy Director of ERDC-GSL was Dr. William P. Grogan, and the Director was Dr. David W. Pittman.

COL J effrey R. Eckstein was the Commander of ERDC, and Dr. J effery P. Holland was the Director. 


\section{Unit Conversion Factors}

\begin{tabular}{|l|l|l|}
\hline Multiply & By & To Obtain \\
\hline degrees Celsius & $1.8 \mathrm{C}+32$ & degrees Fahrenheit \\
\hline meters & 3.2808399 & feet \\
\hline kilograms & 35.273962 & ounces (mass) \\
\hline
\end{tabular}




\section{Introduction}

\subsection{Background}

Emissions from the production and placement of hot-mix asphalt (HMA) are being increasingly scrutinized. The introduction of a range of warm-mix asphalt (WMA) technologies could potentially lead to a reduction in these emissions. WMA is a general description for asphalt concrete that is produced at lower temperatures than conventional HMA. Many techniques have been developed to produce WMA, including chemical additives, organic wax additives, and foaming. WMA is produced at temperatures typically $40-70^{\circ} \mathrm{F}$ lower than conventional HMA (Prowell et al. 2012).

The measurement of emissions during asphalt production and placement is both complex and expensive. Limited guidance is available for accurately measuring surface emissions during HMA and WMA paving operations. The National Cooperative Highway Research Program (NCHRP) funded project 9-47a to update the Protocol for Documenting Emissions and Energy Reductions of WMA and Conventional HMA during Plant and Paving Operations, originally developed by the WMA Technical Working Group (TWG). However, available data on emissions during WMA production and placement using this protocol are very limited. Additional research is needed to provide sufficient data to accurately quantify the reduction in emissions associated with the use of WMA compared to HMA.

In support of the U.S. Air Force Civil Engineer Center (AFCEC), the U.S. Army Engineer Research and Development Center (ERDC) was tasked to collect information from literature and from asphalt paving projects in order to develop guidance for documenting the reduction in emissions associated with the use of WMA compared to HMA. Such guidance would provide military engineers with a practical tool for quantifying the environmental impacts of these technologies and would help in the decisions for using alternative materials. 


\subsection{Objectives}

The objective of this project was to develop guidance for documenting the reduction in emissions associated with the use of WMA compared to conventional HMA.

\subsection{Approach}

The general approach to this project was to conduct a literature review to search for current methods for estimating emissions during asphalt production, state DOTs' current protocols to measure and control emissions, and case studies where WMA emissions were measured and compared to those from HMA. Field testing was conducted during asphalt paving to measure asphalt emissions. Two projects consisting of matching HMA and WMA mixes were visited to collect workers' exposures to asphalt emissions in order to quantify the reduction in emissions of WMA compared to that from conventional HMA. 


\section{Literature Review}

Asphalt-fume emissions have been studied for years due to the increasing concern about how they affect the environment and the health and safety of workers during mix production and laydown operations. The United States has significant regulations pertaining to emissions that must be followed under the provisions of the Clean Air Act of 1990. These provisions are largely administered through implementation plans devised by state and local air authorities under the support of the U.S. Environmental Protection Agency (EPA). Restrictions often target volatile organic compounds (VOCs), nitrogen oxides $\left(\mathrm{NO}_{\mathrm{x}}\right)$, carbon monoxide $(\mathrm{CO})$, sulfur dioxide $\left(\mathrm{SO}_{2}\right)$, and various other pollutants, including those labeled as hazardous air pollutants (HAPs) (Prowell et al. 2012). Therefore, air authorities constantly emphasize the need for reducing emissions during asphalt production and placement operations.

Research results from NCHRP project 9-47a suggested that since stack emissions are largely the result of combusted fuel, reduced fuel usage combined with proper burner tuning should reduce $\mathrm{CO}_{2}$ emissions during asphalt production (Prowell et al. 2009). On the other hand, the National Institute for Occupational Safety and Health (NIOSH) recommends the use of engineering controls on paving machinery, proper work practices during asphalt placement, and reduction in the asphalt-mix temperature to minimize worker exposure to asphalt fumes (NIOSH 2001). Recent studies have shown that reduced asphalt application temperature is predictive of reduced inhalation exposures (Cavallari et al. 2011) and the total absorbed dose of polycyclic aromatic compounds (PACs) (MoClean et al. 2011).

Produced at lower temperatures than conventional HMA, WMA provides a potential solution for the asphalt emissions problem. Reducing emissions through the use of WMA depends on several factors, including temperature reduction, type of fuel used during production, the plant's design and operation, aggregate moisture content, and use of recycled asphalt pavement (RAP) and recycled asphalt shingles (RAS).

The following sections discuss the different sources of emissions that occur during asphalt production and placement and the different technologies 
that are available to control or mitigate asphalt emissions. The WMA's potential for reducing emissions is then discussed, followed by a summary of some emissions quantification techniques. Finally, a summary of data obtained from case studies found in the literature is presented.

\subsection{Emissions sources}

\subsubsection{During production}

The process of producing hot-mix asphalt involves drying and heating the aggregate to prepare it for the bitumen coating. In the drying process, the aggregate is dried in a rotating, slightly inclined, direct-fired drum dryer. The aggregate is introduced into the higher end of the dryer. The interior of the dryer is equipped with flights that veil the aggregate through the hot exhaust as the dryer rotates. After drying, the aggregate is generally heated to temperatures ranging from 250 to $300{ }^{\circ} \mathrm{C}$ and then coated with bitumen in one of two ways. In most drum-mix plants, the bitumen is introduced directly into the dryer chamber to coat the aggregate. In batch-mix plants, the mixing of aggregate and asphalt takes place in a separate mixing chamber called a pug mill.

There are several sources of emissions throughout the entire asphalt production process; i.e., material handling, diesel generators, storage tanks, dryer, and others, but they can be classified mainly as process emissions and fugitive dust emissions. Process emissions are those generated during the production process, and fugitive dust emissions are those generated by activities at the asphalt plant not related to the production equipment. Examples of process emissions are combustion emissions generated by the aggregate dryer. Process emissions can be gaseous (G) or particulate matter (PM). Examples of fugitive dust emissions could be those generated when trucks drive on unpaved surfaces or the dust that is generated during handling of aggregates.

The amount of emissions produced by process or fugitive sources depends on the type of asphalt plant, i.e., batch or drum, and the type of process used, i.e., parallel flow or counter flow in drum plants. Figure 1 is a schematic of a typical batch-mix asphalt plant and highlights the likely emission points. Figure 2 gives a general description of a drum-mix process and the emission points. 
Figure 1. Basic process steps for batch-mix asphalt plants.

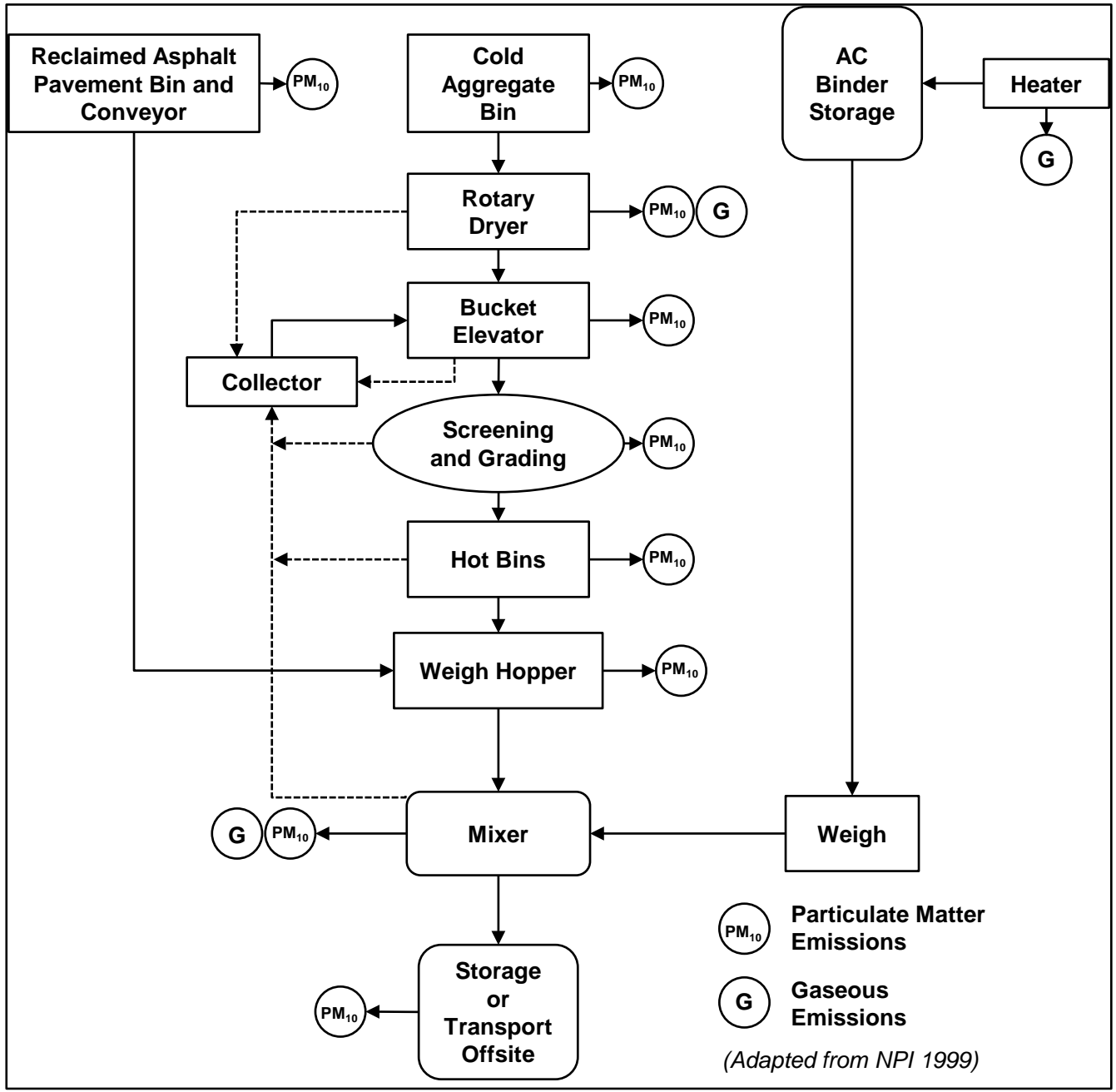

Figure 2. Basic process steps for drum-mix asphalt plants.

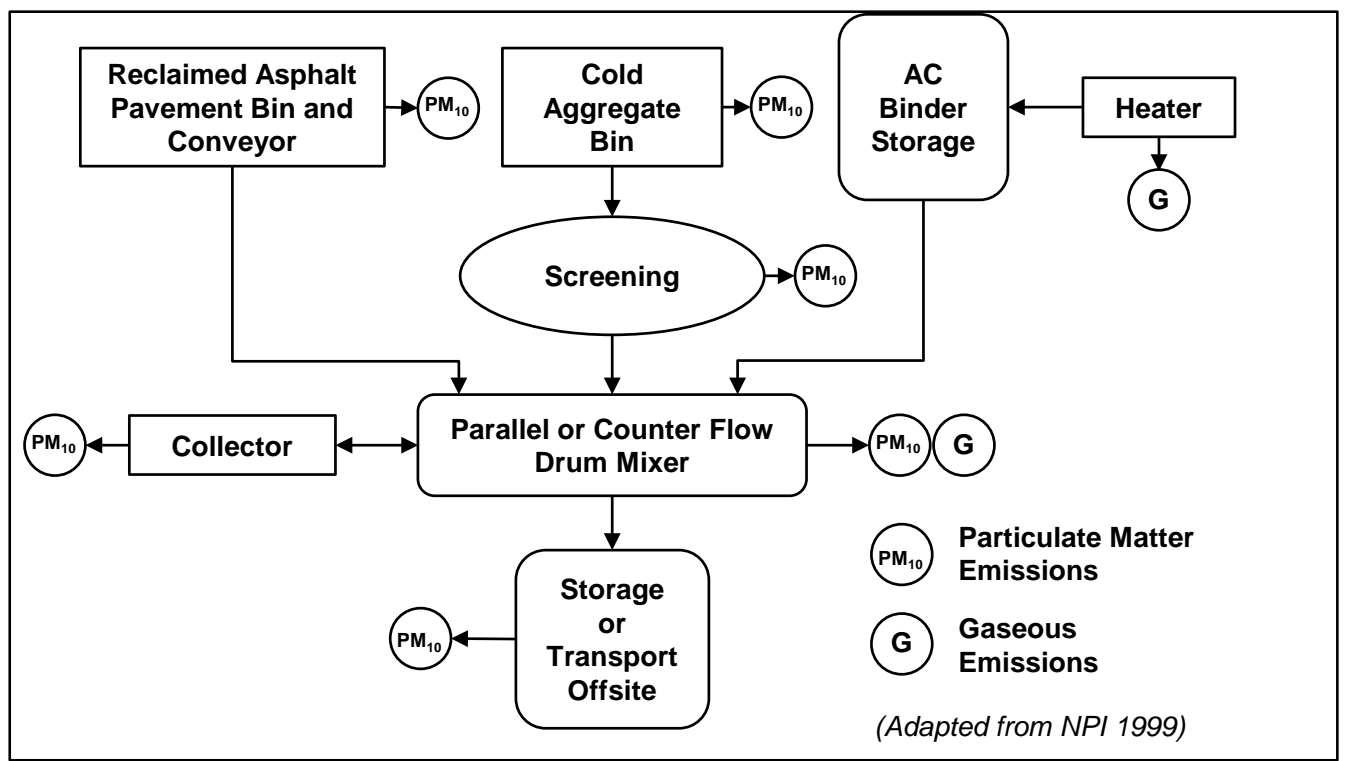


The most significant source of emissions during asphalt-mix production is the aggregate dryer, which includes combustion and non-combustion emissions. Combustion emissions include $\mathrm{NO}_{\mathrm{x}}, \mathrm{SO}_{2}, \mathrm{CO}_{2}, \mathrm{CO}$, and VOCs. Non-combustion emissions include water, particulate matter $\left(\mathrm{PM}_{10}\right)$, small amounts of VOCs, polycyclic aromatic hydrocarbons (PAHs), aldehydes, hazardous organics from the volatile fraction of the bitumen, and organic residues that are commonly found in RAP. The extent of these emissions will depend on the combustion process and equipment used, and the type of fuel used, i.e., natural gas, liquefied petroleum gas, light fuel oils, or waste fuel oils and its sulfur content (NPI 1999).

In counter-flow drum-mix plants, the liquid asphalt, aggregate, and RAP are mixed in a zone that is not in contact with the hot exhaust gas stream. Consequently, counter-flow drum-mix plants will likely have lower VOC emissions than parallel-flow drum-mix plants. $\mathrm{PM}_{10}$ emissions from parallel-flow drum-mix plants are reduced because the aggregate and asphalt cement mix for a longer time. The amount of $\mathrm{PM}_{10}$ generated within the dryer in this process is usually lower than that generated within batch dryers. However, since the asphalt is heated to higher temperatures for a longer period of time, organic emissions (gaseous and hydrocarbons) are generally greater in drum plants than in batch plants. In batch plants, the amount of hydrocarbons produced depends on the temperature of the asphalt cement and aggregate entering the pug mill (NPI 1999).

\subsubsection{During placement}

The paver's auger area is the greatest source of fume emissions during asphalt pavement placement (NIOSH 1997). At present, there are more than a half-million asphalt paving workers who are routinely exposed to asphalt fumes (OSHA 2014). The NIOSH summary of health effects of occupational exposure to asphalt fumes generally indicates that there are acute (immediate or short-term) and chronic (long-term) impacts to human health. While not all studies agree on the specific effects or their significance, there is generally strong enough evidence to show that such effects can be present. Given that, it is beneficial to reduce asphalt-fume exposure to paving workers even if it is below established limits. Other sources of emissions are diesel products that are used for power generation and as release agents for tools and equipment. 


\subsection{Emissions control technologies}

\subsubsection{During production}

The most common techniques used to control emissions during asphalt production are listed in Table 1. The table lists the techniques that are used to control each pollutant produced at each general emission source. For process-generated emissions, the most common and efficient control technique is the use of baghouses. Baghouses are used to filter particles through fabric filter systems (bags). The dust captured by these bags is usually returned to the production process. Several process modifications have been introduced to reduce the blue smoke (VOCs), including installation of flame shields, rearrangements of flights inside the drum, and adjustments of the asphalt injection point. Tuning up the burner periodically may reduce VOC emissions substantially (Prowell et al. 2009). The approach common for reducing $\mathrm{SO}_{2}$ emissions is using low sulfur fuels, which reduce the sulfur fed to the combustor. The use of limestone aggregate also reduces $\mathrm{SO}_{2}$ emissions because this alkaline aggregate absorbs sulfur compounds from the exhaust gas. Low-nitrogen fuels are commonly used to reduce some of the $\mathrm{NO}_{\mathrm{x}}$ emissions. Finally, to control fugitive particulate emissions, driving surfaces are usually maintained by using wet-down techniques or by covering unpaved roads with crushed RAP. Watering the aggregate stockpiles is not generally used to control fugitive particulate emissions because it increases the moisture content and puts a burden on the heating and drying process. Crusting agents or pre-washed aggregates are used instead.

Table 1. Typical asphalt plant emission control techniques.

\begin{tabular}{|l|l|l|}
\hline Emission Source & Pollutant & Control Technique \\
\hline Process & $\mathrm{PM}_{10}$ & $\begin{array}{l}\text { Cyclones } \\
\text { Settling Chamber } \\
\text { Baghouse } \\
\text { Venturi scrubber }\end{array}$ \\
\cline { 2 - 3 } & $\mathrm{VOCs}$ & Dryer and combustion process modifications \\
\cline { 2 - 3 } & $\mathrm{SO}_{2}$ & $\begin{array}{l}\text { Limestone } \\
\text { Low sulfur fuel }\end{array}$ \\
\cline { 2 - 3 } & $\mathrm{NO}_{x}$ & Low nitrogen fuel \\
\hline Fugitive Dust & $\mathrm{PM}_{10}$ & $\begin{array}{l}\text { Paving maintenance } \\
\text { Wetting and crusting agents } \\
\text { Crushed RAP material }\end{array}$ \\
\hline
\end{tabular}

Adapted from: NPI 1999. 


\subsubsection{During placement}

Asphalt paver engineering controls have been implemented by the National Asphalt Pavement Association (NAPA) and NIOSH to reduce workers' exposures to asphalt fumes during placement operations. The engineering control method includes ventilation systems, baffles, and enclosures to capture the generated contaminant within the paver's auger area and to exhaust it before it enters the workers' environment. The control systems capture up to $80 \%$ of fume emissions coming from the auger area (NIOSH 1997). The controls cover the auger area of the paver where fumes are generated. They then transport the fumes through a duct system and exhaust them through a stack away from the workers. This system significantly reduces worker's exposure to asphalt fumes. The use of non-diesel products for power generation or as release agents for tools and equipment can also reduce the production of some other emissions. Also, reducing the asphalt temperature to reduce emissions has been recommended by NIOSH; that is where WMA plays an important role.

\subsection{WMA potential to reduce emissions}

The first experiments with WMA in Europe were driven by a need to reduce emissions of processes generating greenhouse gases. The motivation was to meet strict emissions regulations set forth by the Kyoto Protocol (Prowell et al. 2012). National research has shown that lowering the plant-mix temperature can markedly reduce the production of emissions from asphalt mixtures (Lange and Stroup-Gardiner 2007; D'Angelo et al. 2008, Frank et al. 2011; Kriech et al. 2011; and others). Since WMA is produced at temperatures that are about $50{ }^{\circ} \mathrm{F}$ lower than conventional HMA, one of its most important benefits is the potential reduction in emissions during both production and placement operations. Some studies have compared emissions during WMA production to those produced during HMA production. Others have studied WMA emissions during placement operations and compared to HMA. In some cases, the data showed a clear reduction in emissions associated with the use of WMA, but the data showed mixed results in others. For example, while Frank et al. (2011) observed reductions in $\mathrm{CO}_{2}$ emissions, the $\mathrm{CO}$ and VOC emissions observed indicated that there were broader plant practices whose impacts overshadowed potential WMA reductions. Frank et al. also concluded that the plant type affects how much the emissions are reduced when using WMA as compared to HMA. As mentioned before, while asphalt temperature reduction potentially reduces the production of 
emissions, there are other factors during the production and placement processes that can affect emissions. As it is difficult enough to quantify emission production during asphalt production and placement, it is even more difficult to quantify the actual reduction in emissions associated with the use of WMA. The next section discusses a few techniques that have been developed for this purpose.

\subsection{WMA emissions quantification}

There are multiple techniques to measure or estimate emissions during asphalt production including sampling or direct measurement (by stack emissions testing), mass balance, fuel analysis, engineering estimates, and emission factors. Some of the emission estimation techniques are available online in a user-friendly format that accelerates the calculation process. Also, several studies have been dedicated to develop methods for assessing the workers' exposure to asphalt fumes during asphalt paving operations (Kriech et al. 2002; Osborn et al. 2001; Cavallari et al. 2011; McClean et al. 2011; and Kriech et al. 2011). Most of these methods consist of collecting air samples using personal and areal sampling pumps. What varies is the sampler type and the analysis method.

There is limited guidance to quantify the reduction in emissions associated with the use of WMA compared to HMA in the most efficient way. A few studies have been dedicated to measuring emissions during production and placement of WMA to compare emissions with those of HMA (Frank et al. 2011; Kriech et al. 2011; and Hurley et al. 2010). The National Cooperative Highway Research Program (NCHRP) conducted a study specifically to evaluate emissions and energy reductions of WMA with the purpose of developing numerical guidance and to update the protocol for documenting WMA and HMA emissions (Prowell et al. 2014). Similarly, state agencies have conducted research to quantify the main benefits of using WMA technologies.

A test protocol was developed by the WMA Technical Working Group (TWG) with the purpose of providing guidance for documenting emissions and energy reductions of WMA and conventional HMA. The protocol suggests two types of emissions measurements: 1) stack emissions testing and 2) measuring emissions during laydown operations. To conduct stack emissions testing, the protocol recommends following the EPA protocol used historically in the HMA industry. For measuring emissions surrounding laydown operations, the protocol recommends monitoring 
the paving crew for asphalt-fume emissions using NIOSH Method 5042 (NIOSH 1998) to measure Total Particulates (TP) and Benzene Soluble Fraction (BSF).

This protocol was recently revised by a group of researchers working under NCHRP Project 9-47a (Prowell et al. 2014). The updated version of the WMA TWG protocol includes a more detailed description of the stack emissions testing protocols, including recommended number of test runs per technology and the sampling and analytical methodologies for each emission parameter. This information is listed in Table 2. The updated version also recommends a new method for sampling and analyzing asphalt-fume emissions during laydown operations. During their investigation, Kriech et al. (2011) determined that the traditional gravimetric procedures used to quantify asphalt-fume emissions such as NIOSH Method 5042 generally prevent quantitative comparisons between HMA and WMA, since most readings were below detectable limits. The WMA TWG protocol now recommends an alternate procedure to measure total organic matter (TOM) (Kriech et al. 2002) in conjunction with NIOSH Method 5042.

The updated WMA TWG protocol was used in this study to measure emissions during asphalt paving operations. A detailed description of the method and the data collected are presented in Chapter 3.

Table 2. Stack emission test parameters and methods (adapted from NCHRP 9-47a)

\begin{tabular}{|l|l|l|}
\hline Emission Parameter & $\begin{array}{l}\text { Min. No. of Test } \\
\text { Runs per Technology }\end{array}$ & $\begin{array}{l}\text { Sampling and Analytical } \\
\text { Methodology }\end{array}$ \\
\hline Volumetric flow rate & a & U.S. EPA Methods 1 and 2 \\
\hline Oxygen $\left(\mathrm{O}_{2}\right)$ and carbon dioxide $\left(\mathrm{CO}_{2}\right)$ & a & U.S. EPA Method 3A \\
\hline Moisture content & a & U.S. EPA Method 4 \\
\hline Sulfur Dioxide $\left(\mathrm{SO}_{2}\right)$ & 2 & U.S. EPA Method 6 \\
\hline Nitrogen oxides $\left(\mathrm{NO}_{\mathbf{x}}\right)$ & 2 & U.S. EPA Method 7E \\
\hline Carbon monoxide $(\mathrm{CO})$ & 2 & U.S. EPA Method 10 \\
\hline Total hydrocarbons $(\text { volatile organic compounds }(\mathrm{VOC}))^{\text {b }}$ & 2 & U.S. EPA Method 25A \\
\hline Particulate Matter $(\mathrm{PM} 10)$ & 2 & U.S. EPA Methods 5/202 \\
\hline Formaldehyde & 2 & U.S. EPA Method 316 \\
\hline
\end{tabular}

a Determined concurrently with all emission parameters

${ }^{b}$ Reported as molecular weight of propane 


\subsection{Case studies}

This section summarizes the data that are available in the literature from case studies where emissions were measured for both WMA and corresponding HMA during asphalt production and paving operations. This summary helps understand what is available and what is needed in terms of data to support current emission measurement techniques and conclusions about WMA potential for reducing emissions.

\subsubsection{Emissions during asphalt production}

A summary of stack emissions data found in the literature is presented in Table 3. D'Angelo et al. (2008) published a report on the European WMA practices. The report includes a comparison of stack emissions between HMA and WMA and reported reductions with WMA as shown in Table 3. These data were provided by the Norwegian Public Roads Administration and the Laboratoire Central des Points et Chaussées in France. Davidson and Pedlow (2007) conducted stack emissions testing following the EPA protocols. Data from their study indicate a decrease of approximately $20 \%$ for $\mathrm{CO}, \mathrm{CO}_{2}$, and $\mathrm{NO}_{\mathrm{x}}$ and a slight increase in $\mathrm{SO}_{2}$ for WMA (Evotherm) compared to conventional HMA. It is important to note that in their study WMA data were generated after many process interruptions, while the HMA data were from continuous monitoring.

Table 3. Comparison of WMA and HMA stack emissions data from the literature.

\begin{tabular}{|l|l|l|l|l|l|}
\hline \multirow{2}{*}{ Emission } & \multicolumn{5}{|c|}{ Emission Reduction (\%)a.b } \\
\cline { 2 - 6 } & $\begin{array}{l}\text { Davidson and } \\
\text { Pedlow (2007) }\end{array}$ & $\begin{array}{l}\text { D'Angelo et al. } \\
(\mathbf{2 0 0 8 )}\end{array}$ & $\begin{array}{l}\text { Middleton and } \\
\text { Forfylow (2008) }\end{array}$ & $\begin{array}{l}\text { Hurley et al. } \\
(\mathbf{2 0 1 0})\end{array}$ & $\begin{array}{l}\text { Frank et al. } \\
(2011)\end{array}$ \\
\hline $\mathrm{CO}_{2}$ & 17 & $15-40$ & 11 & 5 & 19 \\
\hline $\mathrm{SO}_{2}$ & -17 & $18-35$ & -14 & $---c$ & 55 \\
\hline $\mathrm{NO}_{x}$ & 20 & $18-70$ & 8 & 14 & 18 \\
\hline $\mathrm{VOC}$ & $---\mathrm{c}$ & $19-50$ & $---c$ & -313 & -17 \\
\hline $\mathrm{CO}$ & 20 & $10-30$ & 10 & $---c$ & 19 \\
\hline
\end{tabular}

a Negative values indicate an increase in emissions when WMA was used

b Average reductions from multiple test sites

c Data were not provided

As with the data provided by Davidson and Pedlow, data from Middleton and Forfylow (2008) also showed a relatively consistent reduction in CO, $\mathrm{CO}_{2}$, and $\mathrm{NO}_{\mathrm{x}}$ for the WMA compared to the HMA and a slight increase in $\mathrm{SO}_{2}$. The authors indicated that the slight increase in $\mathrm{SO}_{2}$ could have been within testing variability. Similarly, Hurley et al. (2010) showed reductions 
in $\mathrm{CO}_{2}$ and $\mathrm{NO}_{\mathrm{x}}$; however, the VOCs were increased by 313\% during WMA production compared to HMA. The authors believed unburned fuel was released into the asphalt drum that increased the amount of VOCs emitted. This indicated a need for fine-tuning the burner.

Finally, Frank et al. (2011) conducted a study to evaluate emission reductions and energy savings associated with the use of WMA. As with the other studies, their data showed consistent reduction in $\mathrm{CO}, \mathrm{CO}_{2}$, and $\mathrm{NO}_{\mathrm{x}}$ for the WMA compared to HMA. However, their data showed a 55\% reduction in $\mathrm{SO}_{2}$, even though one of the test sites evaluated used recycled fuel oil (highest sulfur content). VOCs increased when WMA was used in two of the three test sites evaluated. Since the increase in VOCs was uniform across three very different WMA technologies, the authors concluded that factors other than WMA itself may have caused the increase.

\subsubsection{Emissions during asphalt placement}

D'Angelo et al. (2008) also provided information that indicated reduced worker exposure when placing WMA. Although direct comparisons are difficult because of various sampling and testing protocols used in different countries, the German Bitumen Forum (2006) indicated that asphalt aerosols/ fumes and polycyclic aromatic hydrocarbons (PAHs) were reduced by $30-50 \%$ for WMA compared to HMA. It is important to note that exposure data from corresponding HMA projects indicated values below the acceptable exposure limits. This general observation was confirmed in several other sources. For example, Diefenderfer et al. (2007) measured BSF and total particulate matter (TP) emissions from laydown operations in Virginia. They used personal sampling devices on the paver and screed operators to monitor asphalt-fume exposure for a control HMA and a WMA section. The data indicated that the exposures to airborne asphalt fumes were under non-detectable levels.

Kriech et al. (2011) presented internal data showing that the BSF concentrations, as measured by NIOSH 5042 method, were all below the limit of detection (LOD). However, the authors suggested the use of an alternate method that measured total organic matter (TOM) and showed data that were useful to make comparisons between WMA and HMA. Using this method, their data showed an average reduction in TOM of 33\% from using WMA as compared to HMA. Hurley et al. (2010) collected areal and personal fume samples during the construction of two WMA test sections (Evotherm ${ }^{\mathrm{TM}}$ and Sasobit ${ }^{\circledR}$ ) and one control HMA test section in 
Wisconsin. Areal data for the Sasobit ${ }^{\circledR}$ mix showed asphalt fumes 43-91\% lower than the HMA at the paver. For Evotherm ${ }^{\mathrm{TM}}$, the asphalt fumes were 22-82\% lower than the control HMA. The large reduction in fumes was attributed to the location of the fume collection devices. Personal sampling data from the same project were below the LOD. A summary of all of these findings is in Table 4.

Table 4. Data summary on worker exposure to asphalt fumes from the literature.

\begin{tabular}{|c|c|c|c|}
\hline Study & $\begin{array}{l}\text { Methods Used/ } \\
\text { Emissions Measured }\end{array}$ & $\begin{array}{l}\text { WMA } \\
\text { Technologies Used }\end{array}$ & \begin{tabular}{|l} 
Main \\
Findings
\end{tabular} \\
\hline $\begin{array}{l}\text { D'Angelo et al. } \\
\text { (2008) }\end{array}$ & $\begin{array}{l}\text { Method not specified. } \\
\text { VOCs and PAHs }\end{array}$ & Not specified & $\begin{array}{l}30-50 \% \text { reduction for WMA } \\
\text { compared to HMA }\end{array}$ \\
\hline $\begin{array}{l}\text { Diefenderfer et al. } \\
(2007)\end{array}$ & $\begin{array}{l}\text { NIOSH } 5042 \\
\text { (personal sampling) } \\
\text { BSF and TP }\end{array}$ & Evotherm ET & $\begin{array}{l}\text { All exposures were below the } \\
\text { LOD }\end{array}$ \\
\hline $\begin{array}{l}\text { Kriech et al. } \\
(2011)\end{array}$ & $\begin{array}{l}\text { Kriech et al. (2002) method } \\
\text { (personal sampling) } \\
\text { TOM }\end{array}$ & $\begin{array}{l}\text { BituTech PER, } \\
\text { Cecabase RT, } \\
\text { Evotherm DAT, Sonne } \\
\text { Warmix, Ultrafoam } \\
\text { GX2, and wax }\end{array}$ & $\begin{array}{l}\text { 33\% reduction for WMA } \\
\text { compared to HMA }\end{array}$ \\
\hline $\begin{array}{l}\text { Hurley at al. } \\
(2010)\end{array}$ & $\begin{array}{l}\text { NIOSH } 5042 \\
\text { (areal and personal sampling) } \\
\text { BSF }\end{array}$ & $\begin{array}{l}\text { Evotherm }{ }^{\mathrm{TM}} \text { and } \\
\text { Sasobit }\end{array}$ & $\begin{array}{l}43-91 \% \text { areal fume reduction } \\
\text { for Sasobit } \AA \text {; } 22-82 \% \text { areal } \\
\text { fume reduction for } \\
\text { Evotherm }{ }^{\mathrm{TM}} \text {; and personal } \\
\text { exposures below LOD }\end{array}$ \\
\hline
\end{tabular}




\section{Field Testing}

Field monitoring of asphalt emissions was conducted to collect quantitative data to determine the reduction in emissions associated with the use of WMA compared to HMA. The study only monitored emissions during asphalt paving operations. Therefore, no stack emissions testing data were collected in this field evaluation. The following sections describe the test sites, test methods, and the results of the field monitoring of emissions during WMA and HMA placement.

\subsection{Test sites}

Two test sites were selected for this evaluation and are described in Table 5. Test Site 1 was located in Eagle, Colorado, and Test Site 2 was at Okolona, Mississippi. Both projects consisted of highway pavement rehabilitation projects. General project information and field notes are in Appendix A. The project at Test Site 1 (Figure 3) consisted of milling and overlaying the eastbound lane of Interstate 70 from Eagle to Wolcott, Colorado. The project included four test sections, two HMA and two WMA, with varying RAP contents. For this study, only two of the four test sections were used and are described in Table 5. The binder grade used in both sections was PG 64-28. The project in Test Site 2 (Figure 4) consisted of approximately 4 miles of milling and replacing the top asphalt layer of U.S. 41 between U.S. 45 and U.S. 45 Alternate in Okolona. The asphalt mixture included 15\% RAP, and the binder grade was PG 67-22. This project used mainly WMA, but for the purposes of this study, the contractor agreed to switch the production temperature up to HMA temperature during the last paving day. Both projects used foaming processes to produce WMA.

Table 5. Test site information.

\begin{tabular}{|l|l|l|l|l|}
\hline $\begin{array}{l}\text { Test } \\
\text { Site }\end{array}$ & Location & $\begin{array}{l}\text { Test Section } \\
\text { Description }\end{array}$ & $\begin{array}{l}\text { Date } \\
\text { Monitored }\end{array}$ & $\begin{array}{l}\text { Average Placement } \\
\text { Temperature }\left({ }^{\circ} \mathrm{F}\right)\end{array}$ \\
\hline \multirow{2}{*}{1} & $\begin{array}{l}\text { Eagle, } \\
\text { Colorado }\end{array}$ & 20\% RAP HMA & May 16, 2013 & 138 \\
\cline { 3 - 5 } 2 & $\begin{array}{l}\text { Okolona, } \\
\text { Mississippi }\end{array}$ & 15\% RAP WMA & May 17, 2013 & 126 \\
\cline { 3 - 5 } & & 15\% RAP HMA & Jun 26, 2013 & 132 \\
\hline
\end{tabular}


Figure 3. Test Site 1 at Eagle, Colorado.

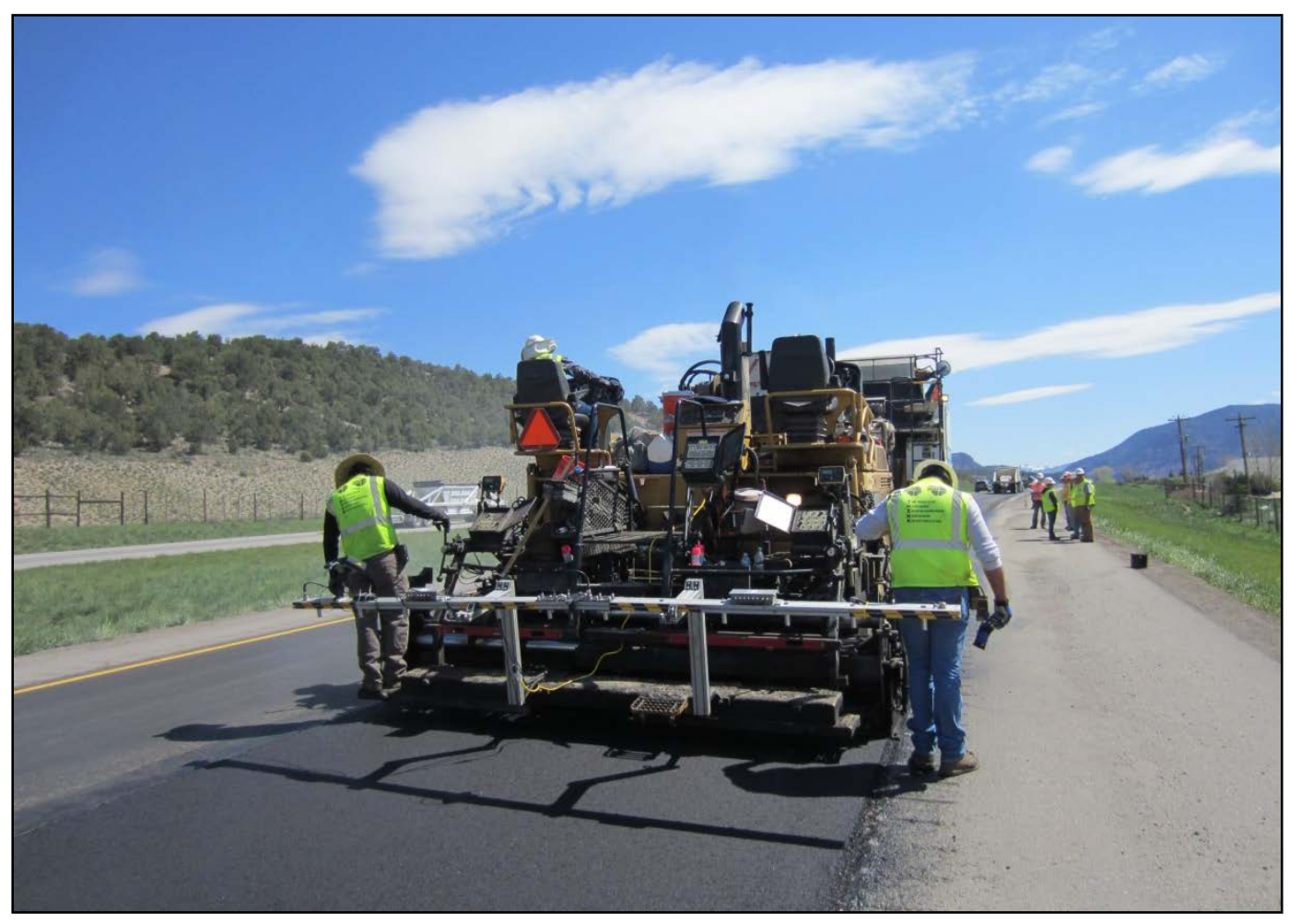

Figure 4. Test Site 2 at Okolona, Mississippi.

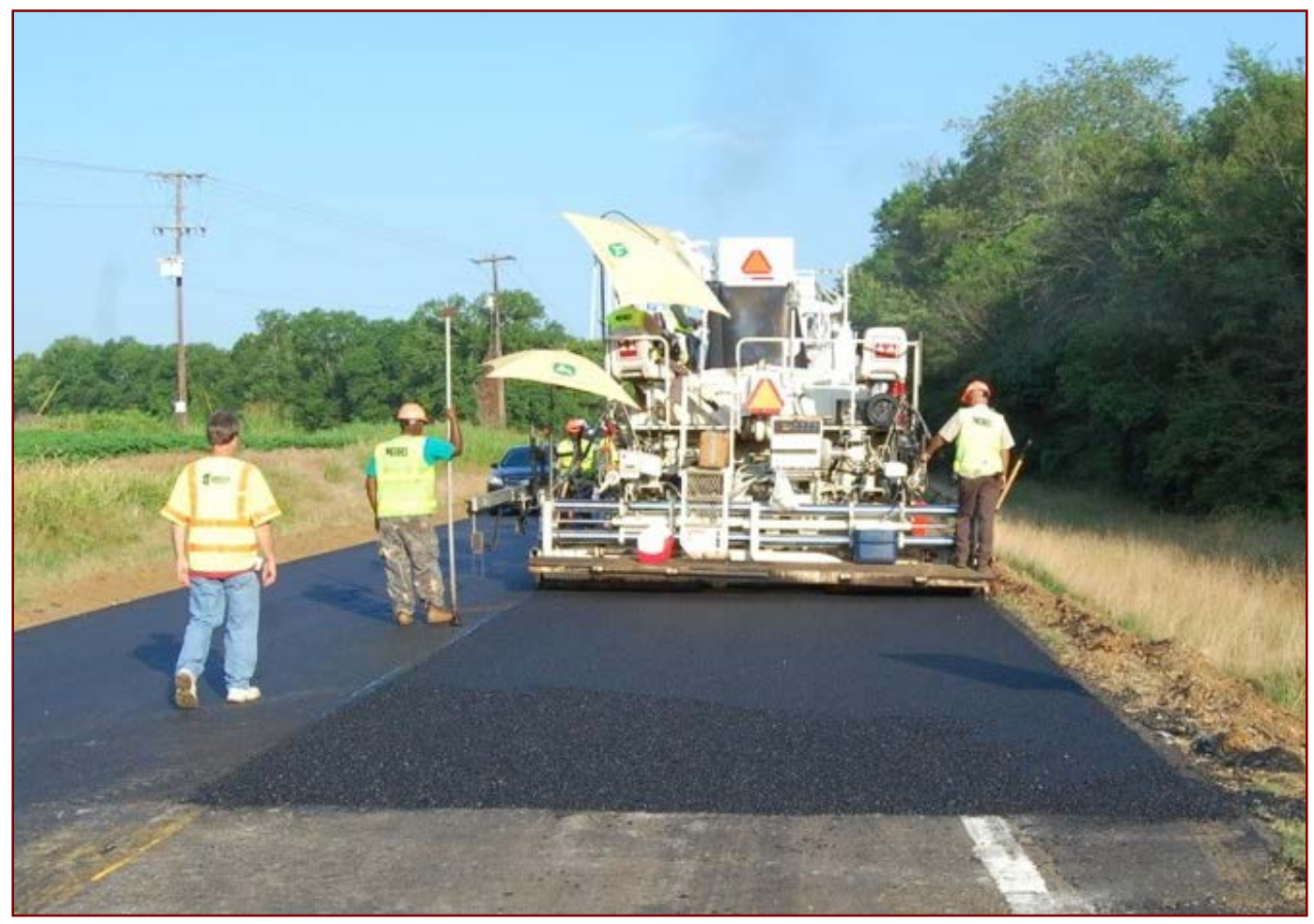




\subsection{Monitoring equipment and procedures}

\subsubsection{Equipment}

Paving crew members were monitored for asphalt-fume emissions using PCXR8 Universal Series Samplers shown in Figure 5a. These constant flow air samplers are manufactured and supplied by SKC, Inc., and are used for industrial hygiene studies and environmental testing. The air flow rate can be adjusted between 1.0 and $5.0 \mathrm{~L} / \mathrm{min}$. The flow rate on each pump was calibrated using a Defender Primary Standard Calibrator shown in Figure 5b. This electronic calibrator, manufactured by SKC, Inc., is designed exclusively for the occupational health and safety industry. It has two ports, a pressure port for pressure applications and a suction port for pump or suction applications. The settings allow for continuous or single flow readings for different applications.

Figure 5. Sampling equipment: a) air pump and b) electronic calibrator

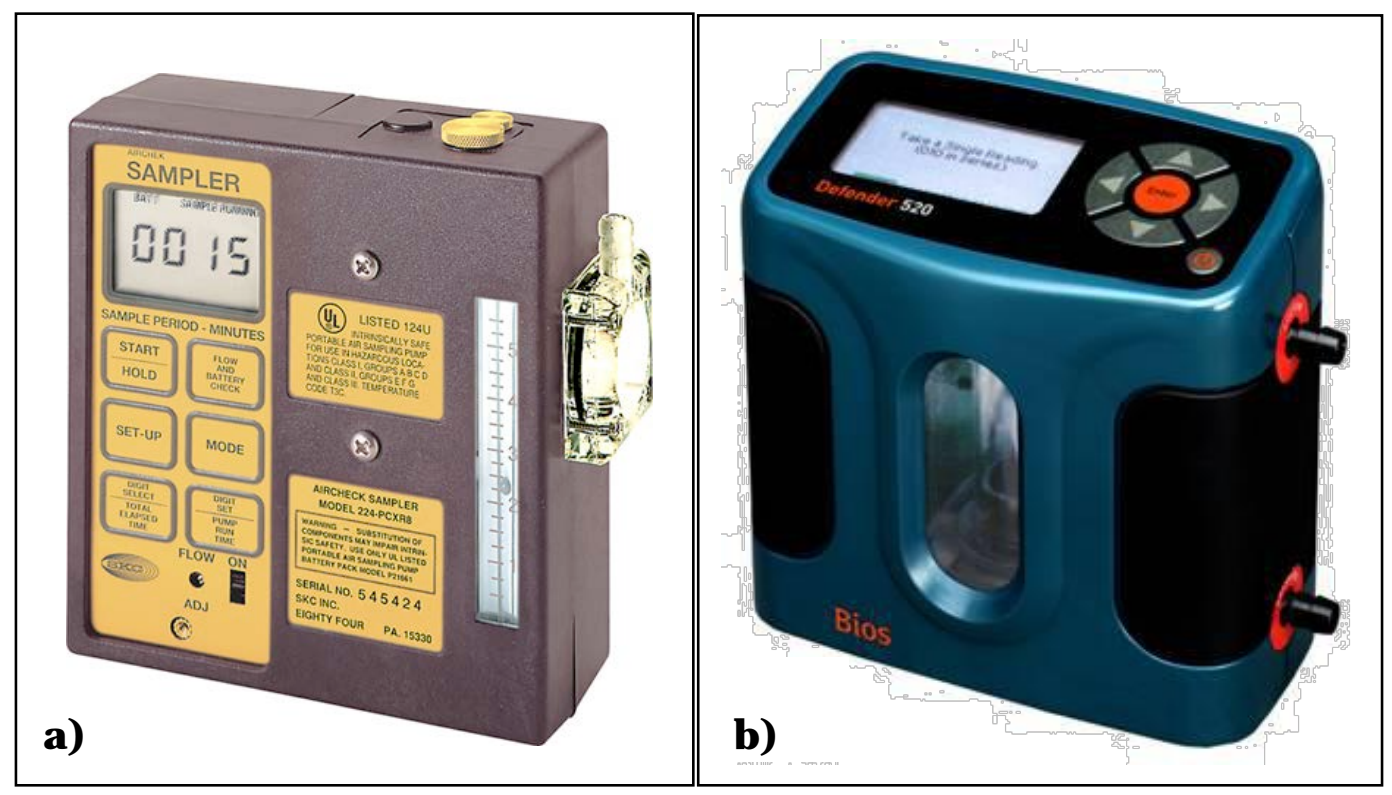

Each worker was equipped with one pump and two samplers, i.e., 1) the NIOSH 5042 sampler (Figure 6a), and 2) a sorbent tube (Figure 7). The NIOSH 5042 sampler consist of a 2- $\mu$ m PTFE 37-mm filter housed in a cassette with a 4-mm inlet and was assembled in accordance with method NIOSH 5042 as shown in Figure 6b. The sorbent tubes were custom ordered with SKC, Inc., using custom equipment order CPM040313-002. The tubes were 8-mm outside diameter by $110 \mathrm{~mm}$ in length and consisted of $50 \mathrm{mg}$ of XAD- 2 polymeric resin followed by another $100 \mathrm{mg}$ of XAD-2, followed by $50 \mathrm{mg}$ of activated charcoal, as shown in Figure 7. The separator material was glass wool, and the tubes were rinsed with dichloromethane. 
Figure 6. NIOSH 5042 sampler: a) filter assembled and b) detailed assembly.

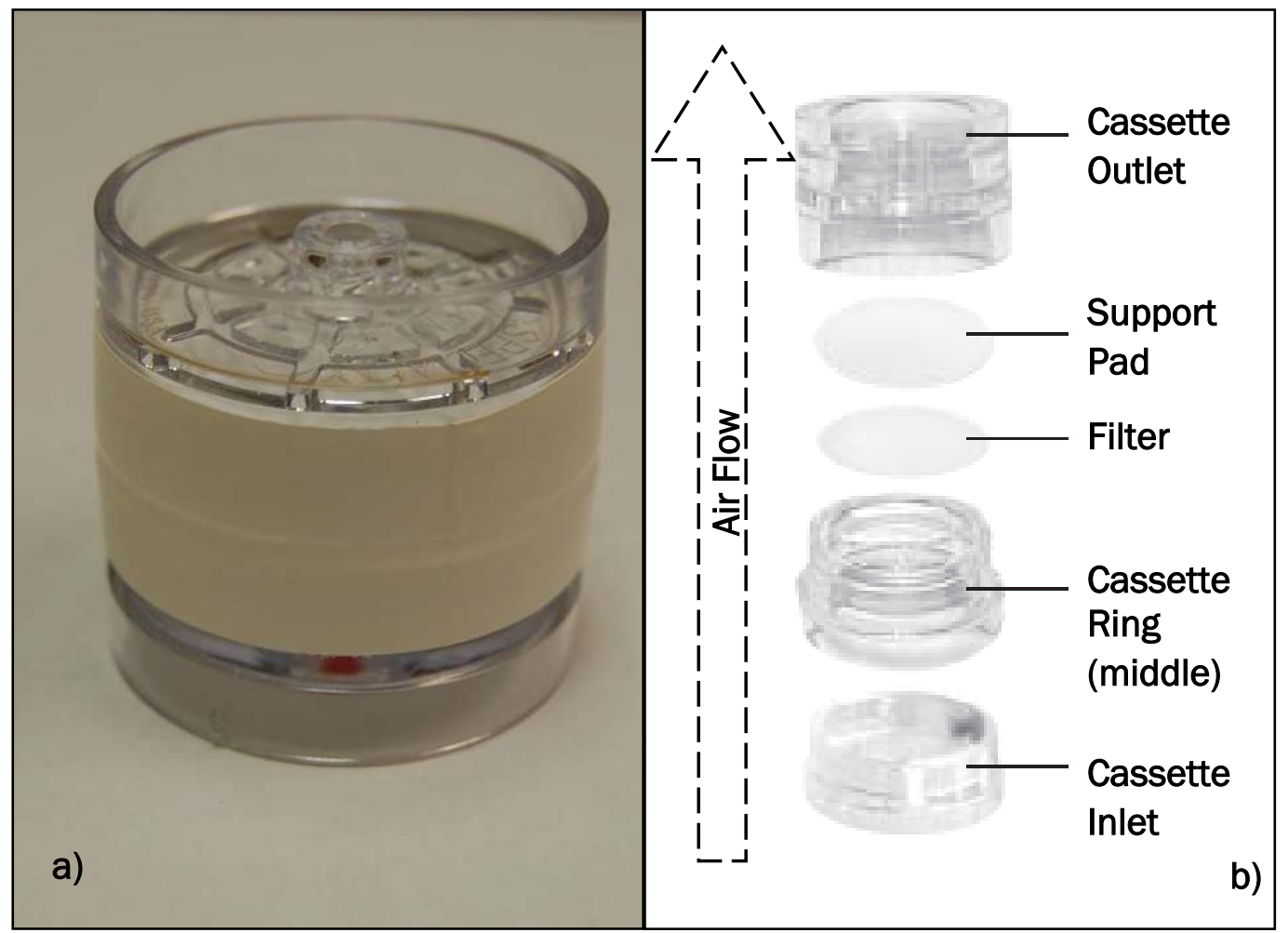

Figure 7. Sorbent tube sampler.

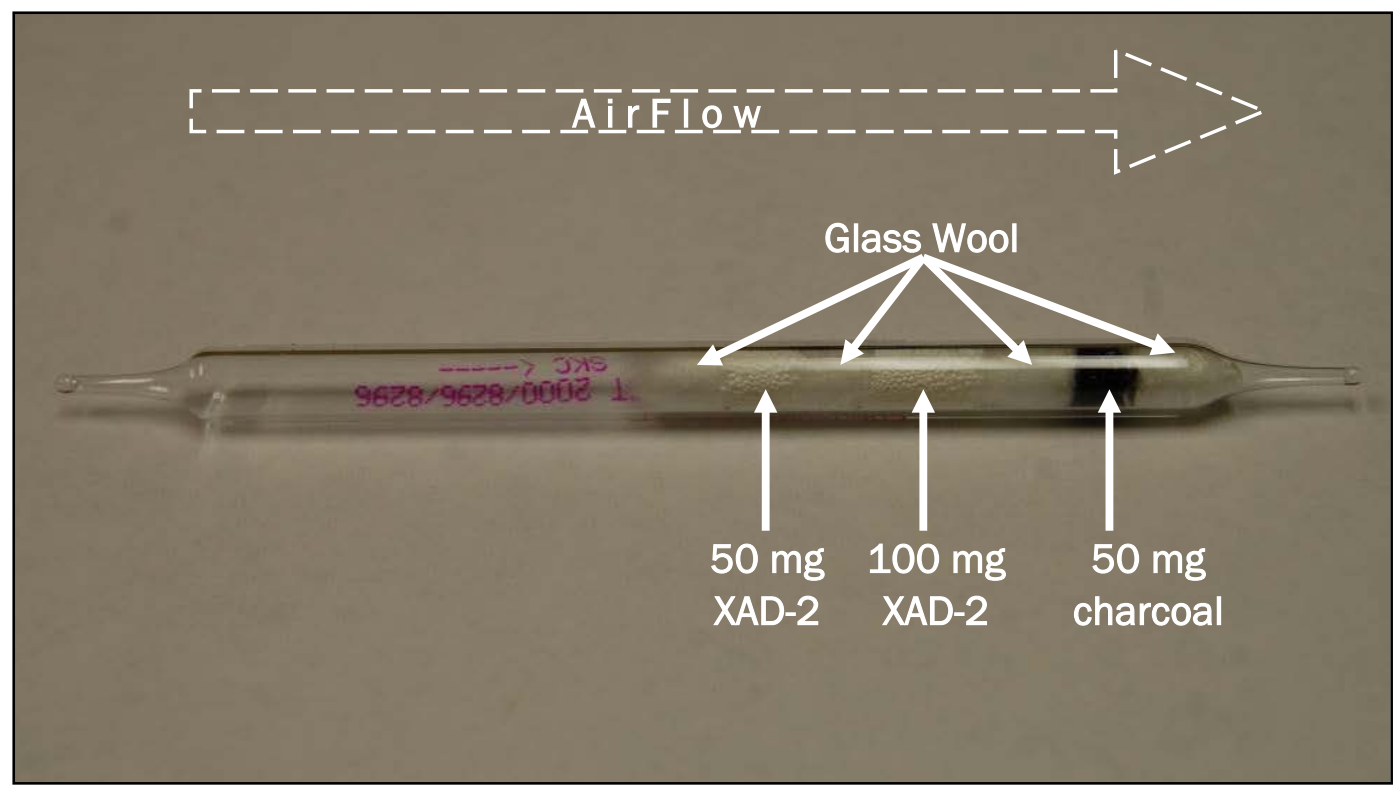

The two samplers were connected in series using Tygon ${ }^{\circledR}$ tubing (Dichloromethane rinsed) (Figure 8) so that the air would enter through the NIOSH 5042 sampler first and then through the sorbent tube. Tygon ${ }^{\circledR}$ tubing was also used to connect the sample train to the pump. Figure 9 shows a typical worker wearing the sampling equipment. 
Figure 8. Sampling train connected in series.

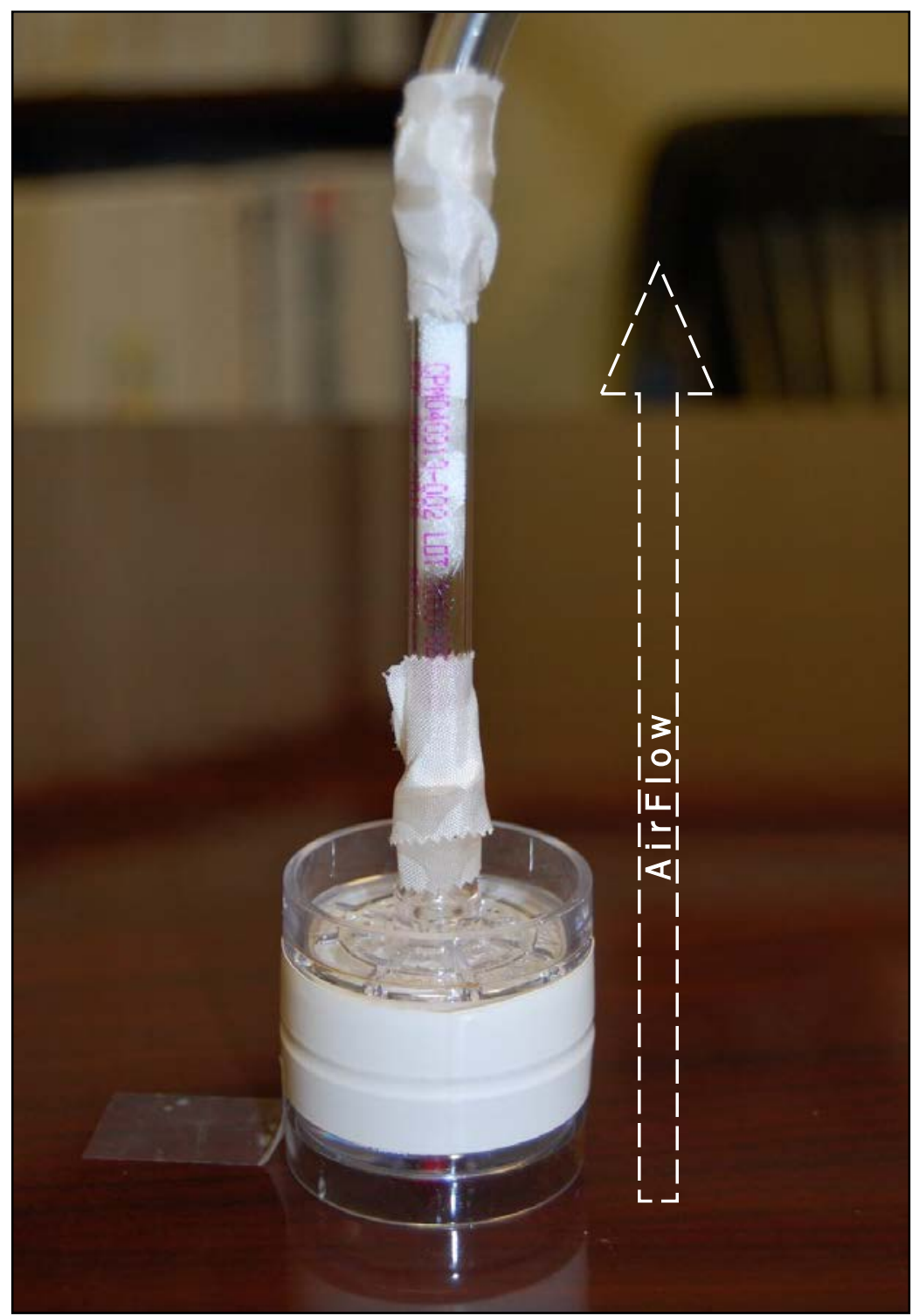

\subsubsection{Monitoring procedures}

Emissions tests were conducted according to the updated WMA TWG protocol (Prowell et al. 2014). Within a given test site, controlled variables included asphalt binder type and source; RAP/RAS usage and source; aggregate type and source; anti-stripping agent or other additives; and paving equipment. No diesel oil was used as a release agent during this study in order to focus the assessment only on the asphalt emissions. Paving machines were equipped with properly functioning engineering controls, which have a main purpose of reducing worker exposures to asphalt fumes and excessive temperatures. 
Figure 9. Typical sampler configuration on worker.

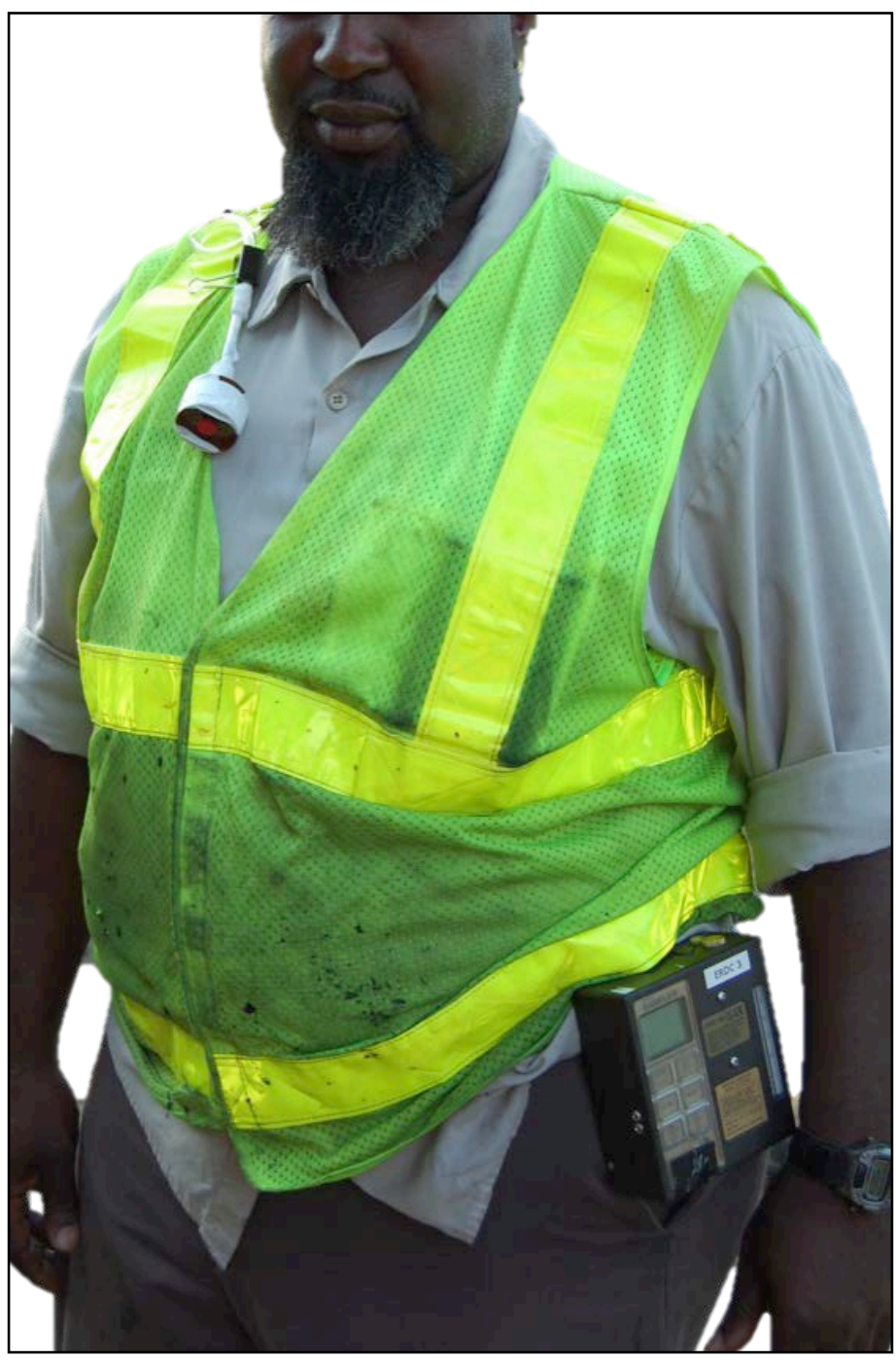

Mix temperatures (both in the hopper and on the mat as it exited the screed strike area) were monitored and recorded approximately every $60 \mathrm{~min}$ during the test period with a hand-held temperature infrared thermometer. Weather-related information was also collected and documented at least four times during the sampling period. This information included wind speed and direction, air temperature, humidity, and other weather related comments and is available in Appendix A.

At each test site, five workers, including paver operators, screed operators, roller operators, and material transfer vehicle (MTV) operators, were monitored during the placement of each mix. The workers were monitored using air sampling pumps operating at a flow rate of $2.0+0.2 \mathrm{~L} / \mathrm{min}$. The pumps were calibrated to this flow rate pre-shift and re-measured post shift 
using the electronic calibrator. Times were recorded when the pumps were started, during smoking breaks, and at the end of each mix placement, when the pumps were removed from the workers. The sample collection times varied based on the shift for each worker. It is important to note that the pumps were turned off while workers smoked to avoid any negative effects on the emissions results.

One background sample positioned upwind of the paving operation was collected each day. Descriptive data were collected on potential confounders from the site, e.g., vehicle exhaust, construction dust, releasing/ cleaning agents, and any other potential background exposures and are available in Appendix A. Field blanks were also collected (one per day for the sorbent tube and five per day for the NIOSH 5042 sampler) to account for contaminant loadings on the sampling media that may have resulted from accumulative field and laboratory activities. Figures 10 and 11 show the location of background samples relative to the paving operations at Test Sites 1 and 2, respectively. At the end of each day/ mix, all the samples were protected from light by wrapping them with foil and were refrigerated prior to shipping to the laboratory for analysis.

\subsection{Sample analysis procedures}

The analytical portion of this study was conducted by Heritage Research Group, Indianapolis, IN. Samples were analyzed using three methods, i.e., 1) NIOSH Method 5042 (NIOSH 1998), Total Organic Matter (TOM) method (Kriech et al. 2002), and asphalt-fume fluorescence (AFF) analysis (Osborn et al. 2001).

\subsubsection{Total Particulates and Benzene Soluble Fraction}

NIOSH Method 5042, Measurements of Total Particulates (TP) and Benzene Soluble Fraction (BSF), was used to analyze the filter portion of the sampling train. This method quantifies asphalt worker exposure for airborne total particulates and the benzene soluble fraction BSF. TP refers to the nonspecific gravimetric amount of organic and inorganic particles and represents the total dust that is collected on the filter that passes through the 4-mm inlet of the sample cassette. Each sample was collected on a pre-weighed 37-mm PTFE membrane filter (NIOSH sampler). The samples were re-weighed post sampling, and the concentration of TP was calculated using these weights, the average weight of the field blanks, and the total air volume sampled. 
Figure 10. Typical background sample layout at Site 1.

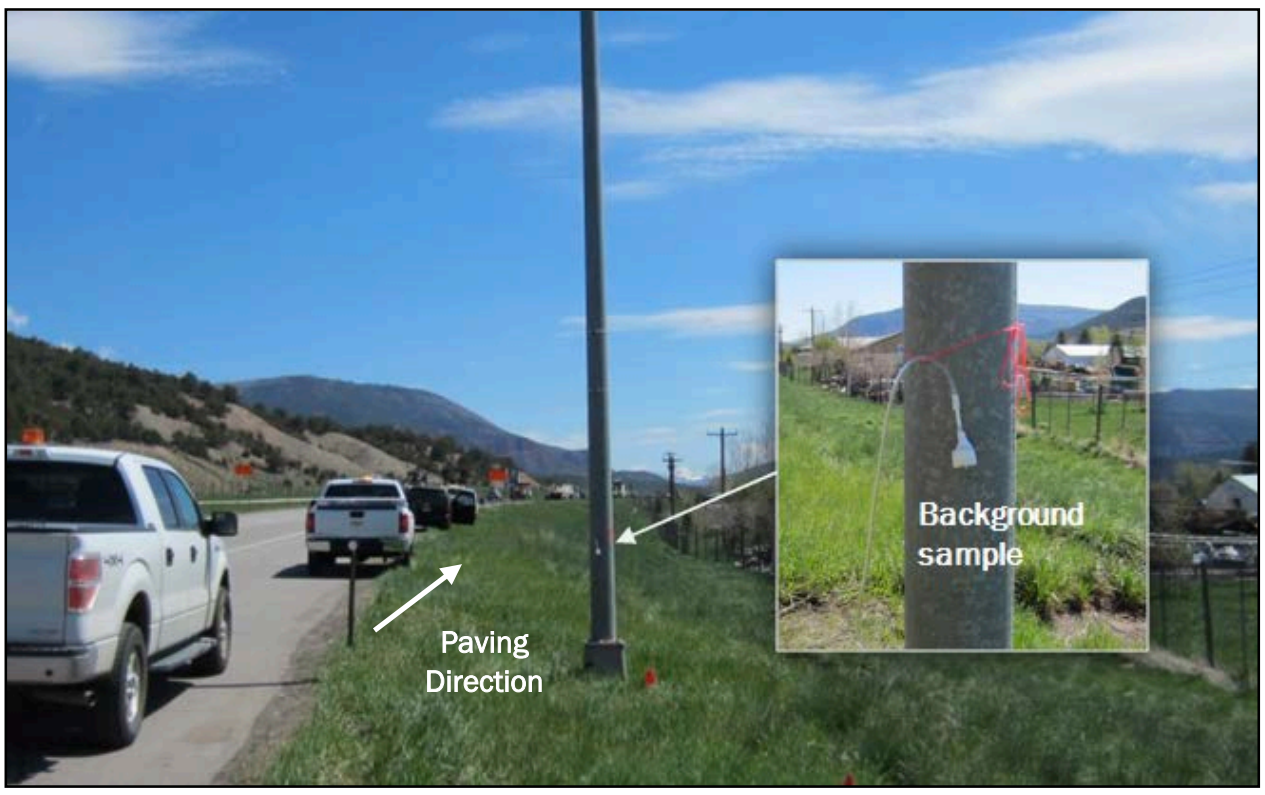

Figure 11. Background sample set up at Test Site 2.

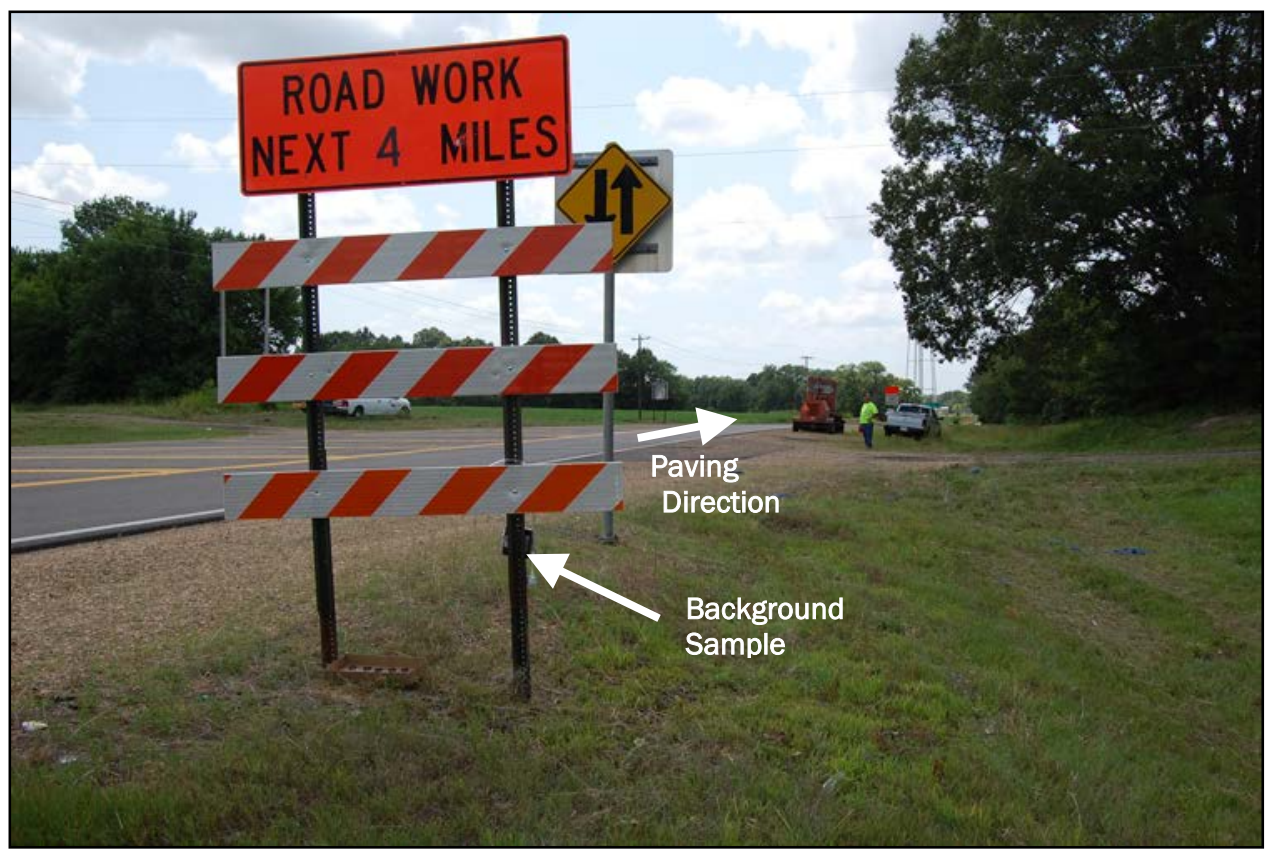

After determination of TP, each filter was extracted with benzene for the determination of BSF. BSF is the gravimetric amount of the TP that is soluble in benzene. Filters were submerged with benzene, and the soluble parts were weighed to determine the amount of BSF. BSF is also nonspecific and does not differentiate between sources of exposure. BSF is theoretically $100 \%$ of the organic fraction of the total particulate including aliphatic and aromatic compounds. 


\subsubsection{Total Organic Matter}

Gas Chromatography with Flame Ionization Detection (GC/ FID) was used to analyze the sorption tube portion of the sampling train. This method quantifies the TOM providing the amount and composition of fume collected using a modified SW846-8015B method (EPA 1996). This test provided the amount and chromatographic profile of these exposures. Quantification of the TOM was achieved by comparison of the most similar standard(s) to the pattern detected from the collected samples. In this case, kerosene was the standard used for all samples. All TOM extracts from air samples were analyzed using this technique, which provided valuable qualitative information relative to the source and nature of the exposures.

\subsubsection{Fluorescence analysis}

Fluorescence analysis was also performed on the total asphalt-fume samples for all air monitoring samples using a Perkin Elmer Luminescence Spectrometer LS50B following the asphalt-fume fluorescence test protocol outlined in Osborn et al. (2001). This test was designed to optimize response to the potentially carcinogenic portion of asphalt emissions. The method consisted of a screening to optically isolate the 4-6 ring polycyclic aromatic compounds (PACs). These PACs are believed to be responsible for carcinogenic activity. If the TOM was below the detection limit, then the fluorescence test was not needed. However, if the TOM was quantifiable, then it was used in the calculation of the fluorescence result.

Fluorescence results were calculated in two ways in this study, i.e., fluorescence concentrations in air ( $\mu \mathrm{g} / \mathrm{m}^{3}$ as Diphenylanthracene (DPA)) and fluorescence response per gram of fume in $1 \mathrm{~mL}(\mathrm{EU} / \mathrm{g})$. Both factors are important to consider in optimizing a healthy work environment.

\subsection{Results}

The complete results for all the sample analyses are in Appendix B. The average mix temperatures measured behind the screed at each test site are summarized in Table 6. Even though the HMA temperature at both test sites was similar and both plants used foaming to produce WMA, the placement temperature of WMA was higher in Mississippi than in Colorado. Therefore, the temperature difference between HMA and WMA was lower in Mississippi $\left(7^{\circ} \mathrm{C}\right)$ than in Colorado $\left(12^{\circ} \mathrm{C}\right)$. 
Table 6. Average mix temperatures for both test sites.

\begin{tabular}{|c|l|l|l|}
\hline $\begin{array}{c}\text { Test } \\
\text { Site }\end{array}$ & Mix Type & $\begin{array}{l}\text { Mix Temperature } \\
\text { Behind Screed }\left({ }^{\circ} \mathrm{C}\right)\end{array}$ & $\begin{array}{l}\text { Difference } \\
\left({ }^{\circ} \mathrm{C}\right)\end{array}$ \\
\hline \multirow{2}{*}{1} & $20 \%$ RAP HMA & 138 & Reference \\
\cline { 2 - 4 } & $20 \%$ RAP WMA & 126 & 12 \\
\hline \multirow{2}{*}{2} & $15 \%$ RAP HMA & 139 & Reference \\
\cline { 2 - 4 } & $15 \%$ RAP WMA & 132 & 7 \\
\hline
\end{tabular}

\subsubsection{Total Particulates and Benzene Soluble Fraction}

TP results are presented in Figures 12 and 13 for Test Sites 1 and 2, respectively. The total concentrations of TP measured during HMA and WMA placement operations are presented for each worker. At Test Site 1, the range of individual exposures to TP was $0.17-0.85 \mathrm{mg} / \mathrm{m}^{3}$, with an average exposure of $0.36 \mathrm{mg} / \mathrm{m}^{3}$. The workers with the highest exposures to TP were the screedmen during placement of both HMA and WMA. The left screedman was exposed to TP concentrations larger than the NIOSH recommended exposure limit (REL) of $0.5 \mathrm{mg} / \mathrm{m}^{3}$. However, the average exposure to TP for this test site was under the NIOSH REL. At Test Site 2, the range of individual exposures to TP was $0.12-2.26 \mathrm{mg} / \mathrm{m}^{3}$ with an average exposure of $0.71 \mathrm{mg} / \mathrm{m}^{3}$. In this case, the MTV operator had the highest exposure to TP during the placement of the HMA $\left(2.26 \mathrm{mg} / \mathrm{m}^{3}\right)$, which exceeded the NIOSH REL. When WMA was placed at Test Site 2, the right screedman had the highest exposure to TP $\left(0.72 \mathrm{mg} / \mathrm{m}^{3}\right)$, and it also exceeded NIOSH REL.

On average, TP concentrations at Test Site 1 during WMA placement were higher than those during HMA placement. At Test Site 2, the opposite was observed. It is important to note that since TP is just the dust that was collected on the filter, results did not and were not expected to correlate with changes in asphalt-placement temperature.

BSF results are presented in Figures 14 and 15 for Test Sites 1 and 2, respectively. The difference in concentration of BSF between WMA and HMA varied per worker at Test Site 1; however, on average the overall exposure to BSF at this test site was the same during the placement of HMA and WMA. The range of individual exposures to BSF was 0.01$0.08 \mathrm{mg} / \mathrm{m}^{3}$, with an average exposure of $0.036 \mathrm{mg} / \mathrm{m}^{3}$. At this test site, the workers with the highest exposure to BSF during HMA placement were the screedmen. During WMA placement, the roller operator received the 
highest concentration of BSF. This was unexpected because the wind always blew in the same direction of the paving operations, blowing emissions away from the paving line (west to east).

Figure 12. Worker exposure to TP during WMA and HMA placement at Test Site 1.

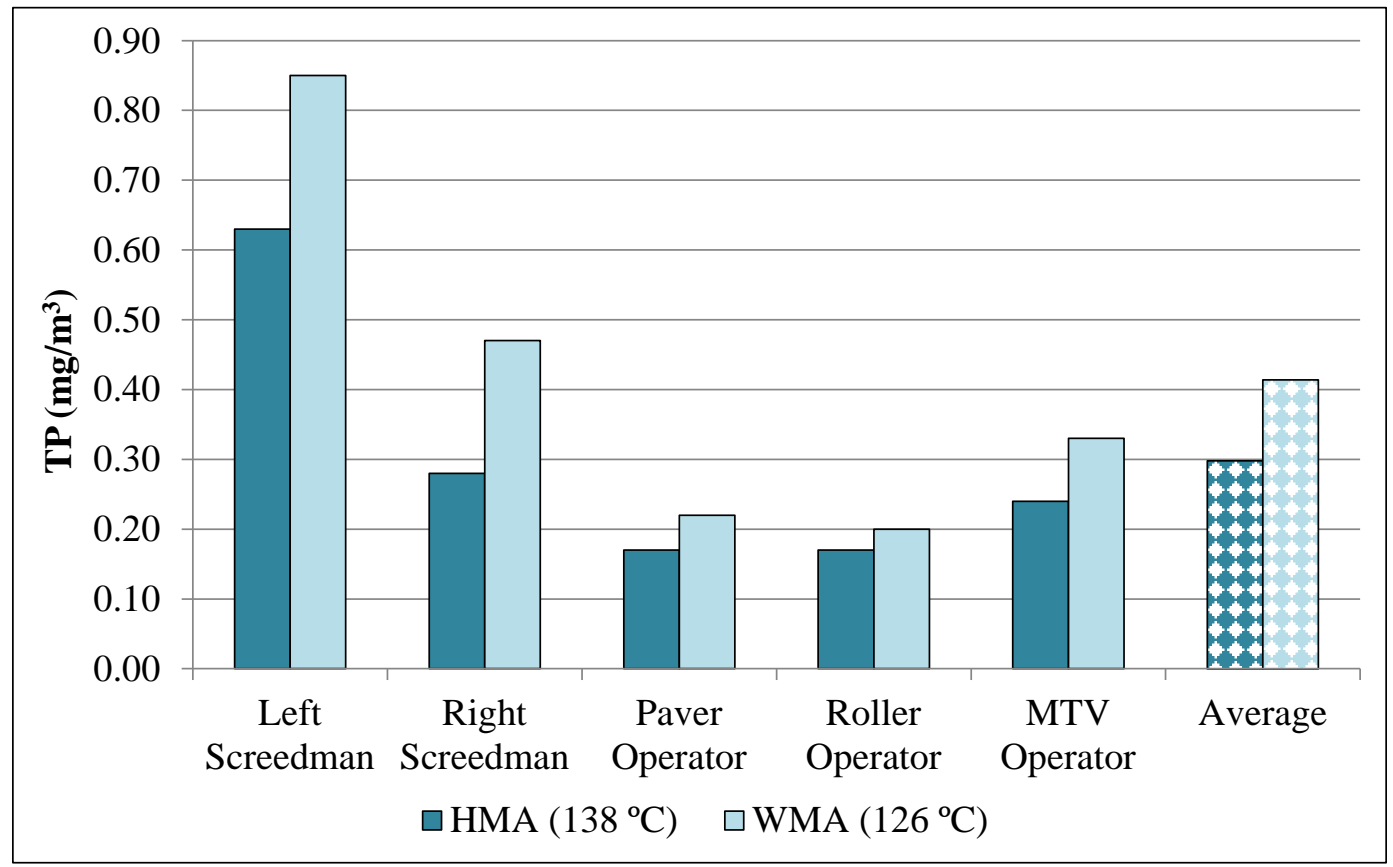

Figure 13. Worker exposure to TP during WMA and HMA placement at Test Site 2.

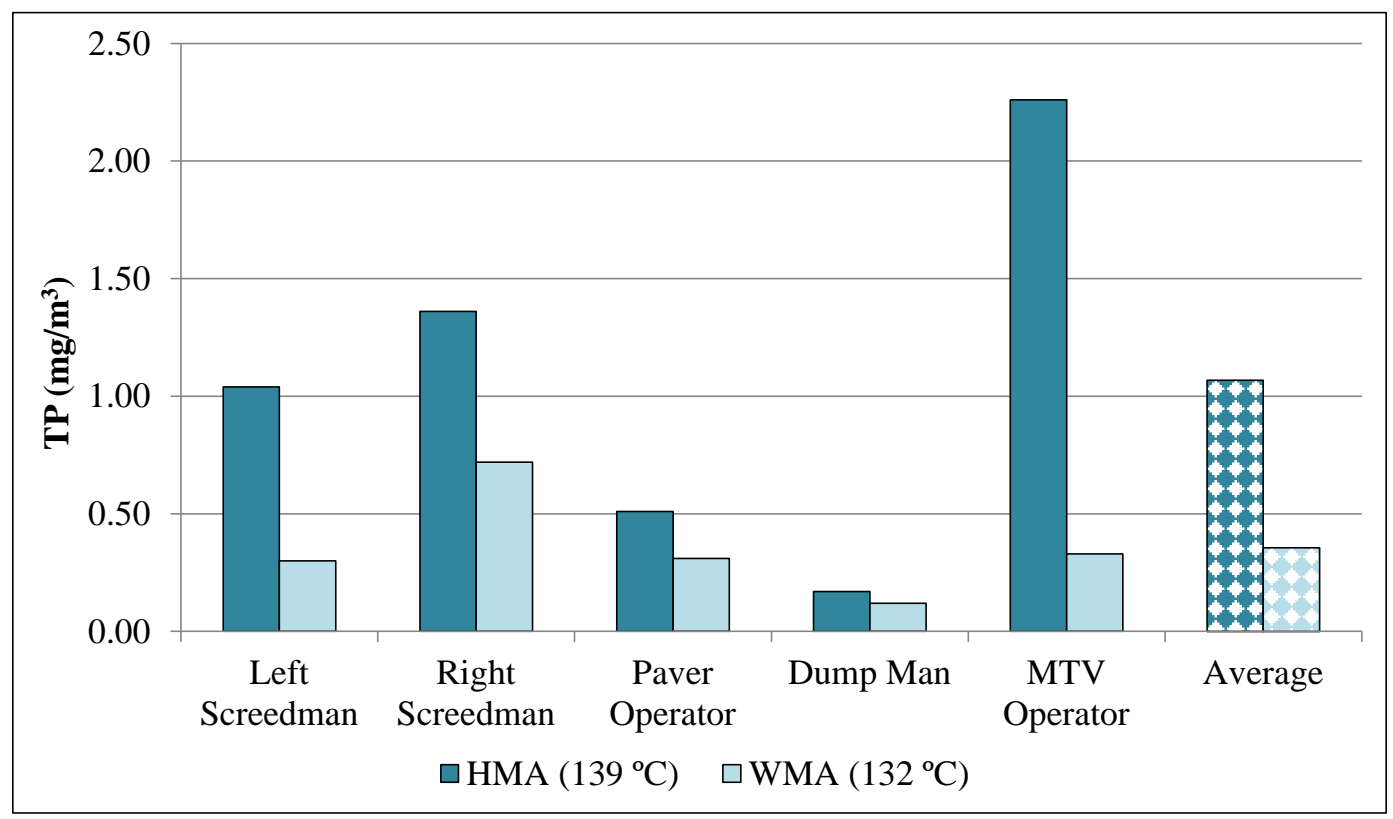


Figure 14. Worker exposure to BSF during WMA and HMA placement at Test Site 1.

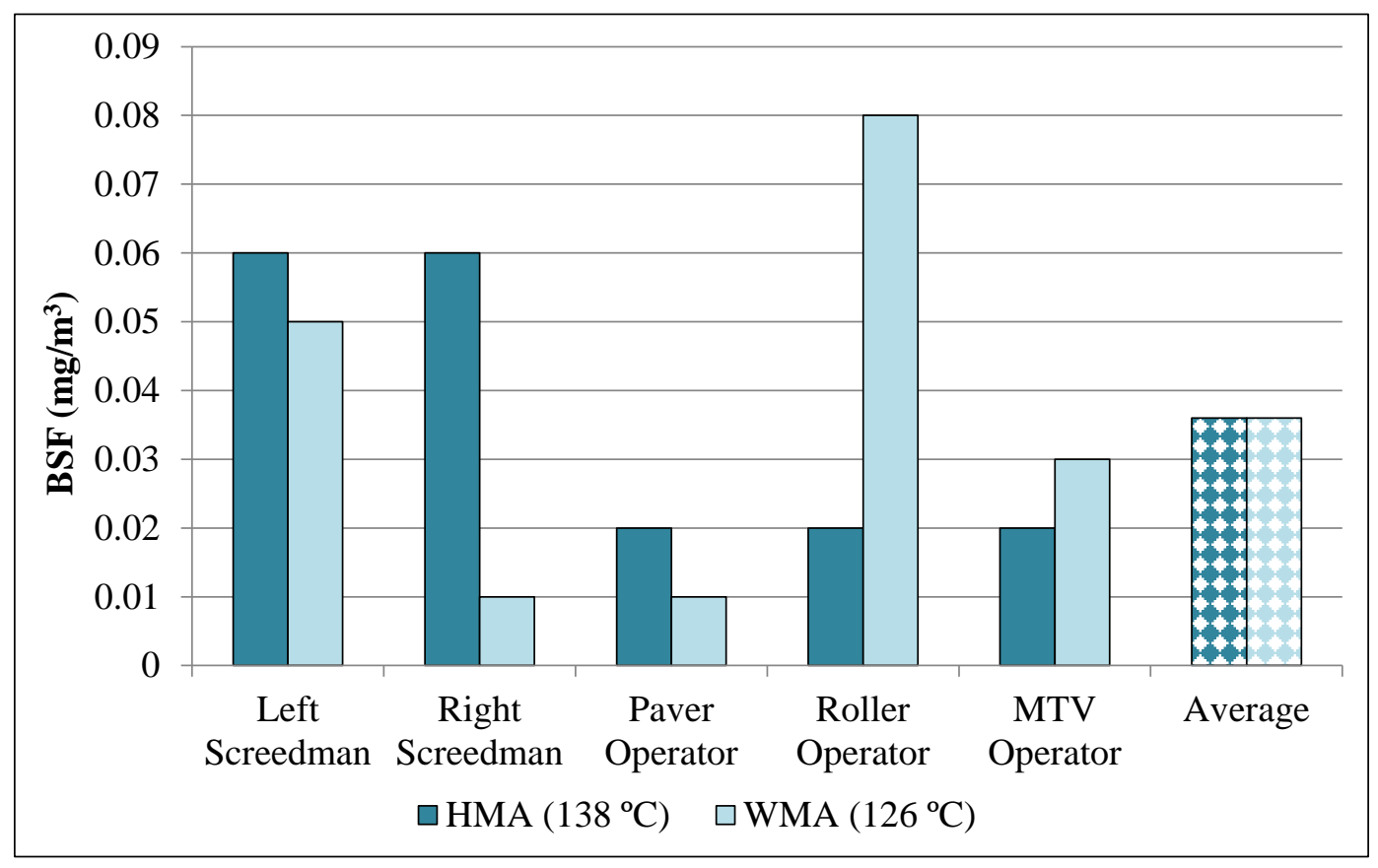

Figure 15. Worker exposure to BSF during WMA and HMA placement at Test Site 2.

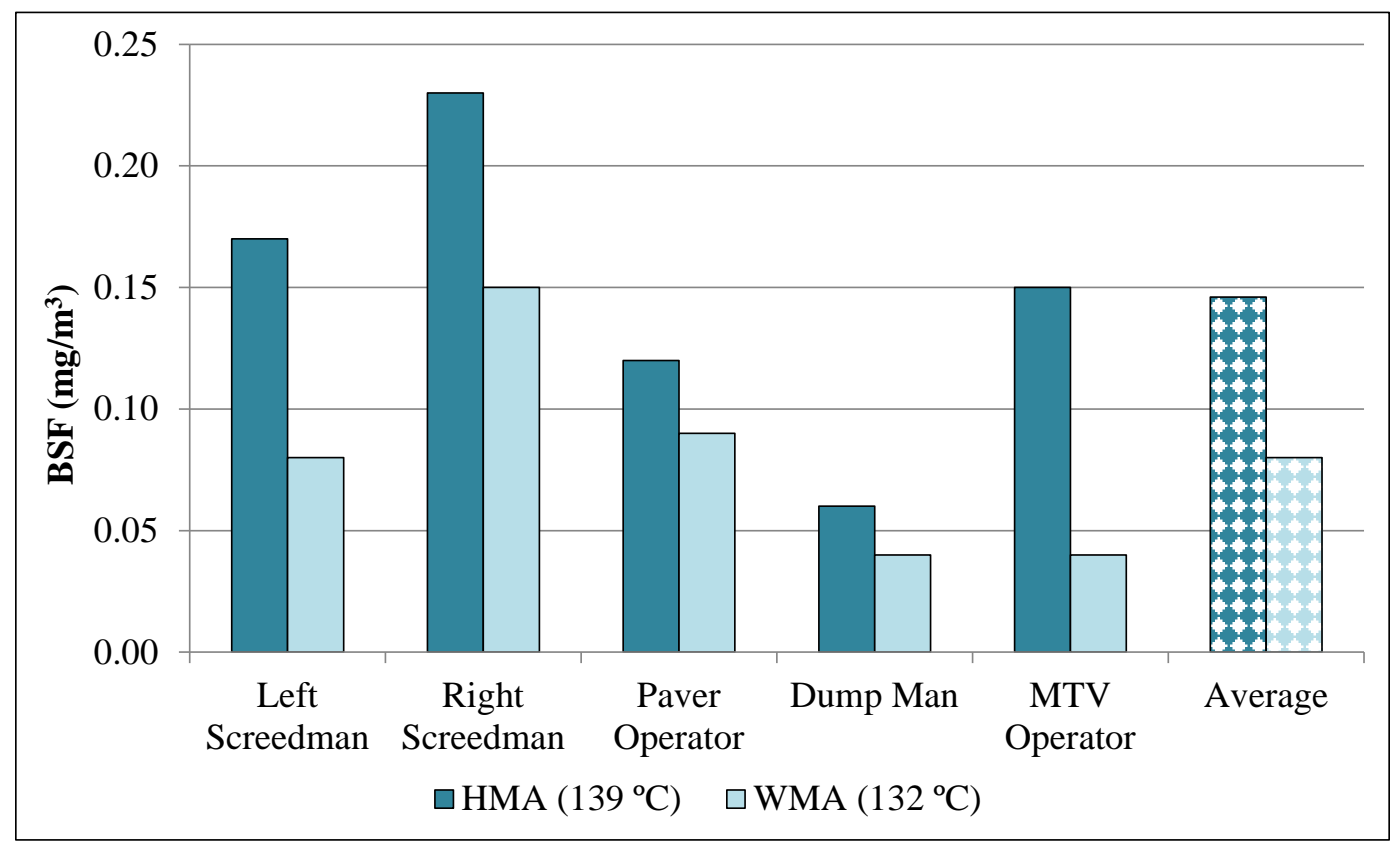

At Test Site 2, BSF concentrations were lower during WMA placement than during HMA placement, and the average exposures show the same effect. The range of individual exposures to BSF was $0.04-0.23 \mathrm{mg} / \mathrm{m}^{3}$, with an average exposure of $0.11 \mathrm{mg} / \mathrm{m}^{3}$. At this test site, the workers with the highest exposure to BSF during HMA placement were the screedmen, although the MTV operator's exposure to BSF was almost at the samelevel 
as the screedmen. During WMA placement, the screedmen and the paver operator received the highest concentration of BSF. At this test site, cross winds during both placements blew the emissions across the paving line and away from the workers on the left side of the paving line (i.e., dump man).

\subsubsection{Total Organic Matter}

TOM results from GC/ FID are presented in Figures 16 and 17 for Test Sites 1 and 2, respectively. GC/ FID Chromatograms are shown in Appendix C where the $x$-axis represents the elution time in minutes and the y-axis represents the intensity in $\mathrm{mV}$. Included are chromatograms for a simulated distillation standard, a kerosene standard, and one chromatogram example per test site.

At Test Site 1, TOM concentrations were higher during the placement of HMA. The left screedman and the MTV operator had the highest concentrations of TOM, which could be reasonable considering the fact that the emissions blew away from the paver to the front of the paving line, thus towards the MTV. The range of individual exposures to TOM was $0.05-0.45 \mathrm{mg} / \mathrm{m}^{3}$ with an average exposure of $0.20 \mathrm{mg} / \mathrm{m}^{3}$.

Figure 16. Worker exposure to TOM during WMA and HMA placement at Test Site 1.

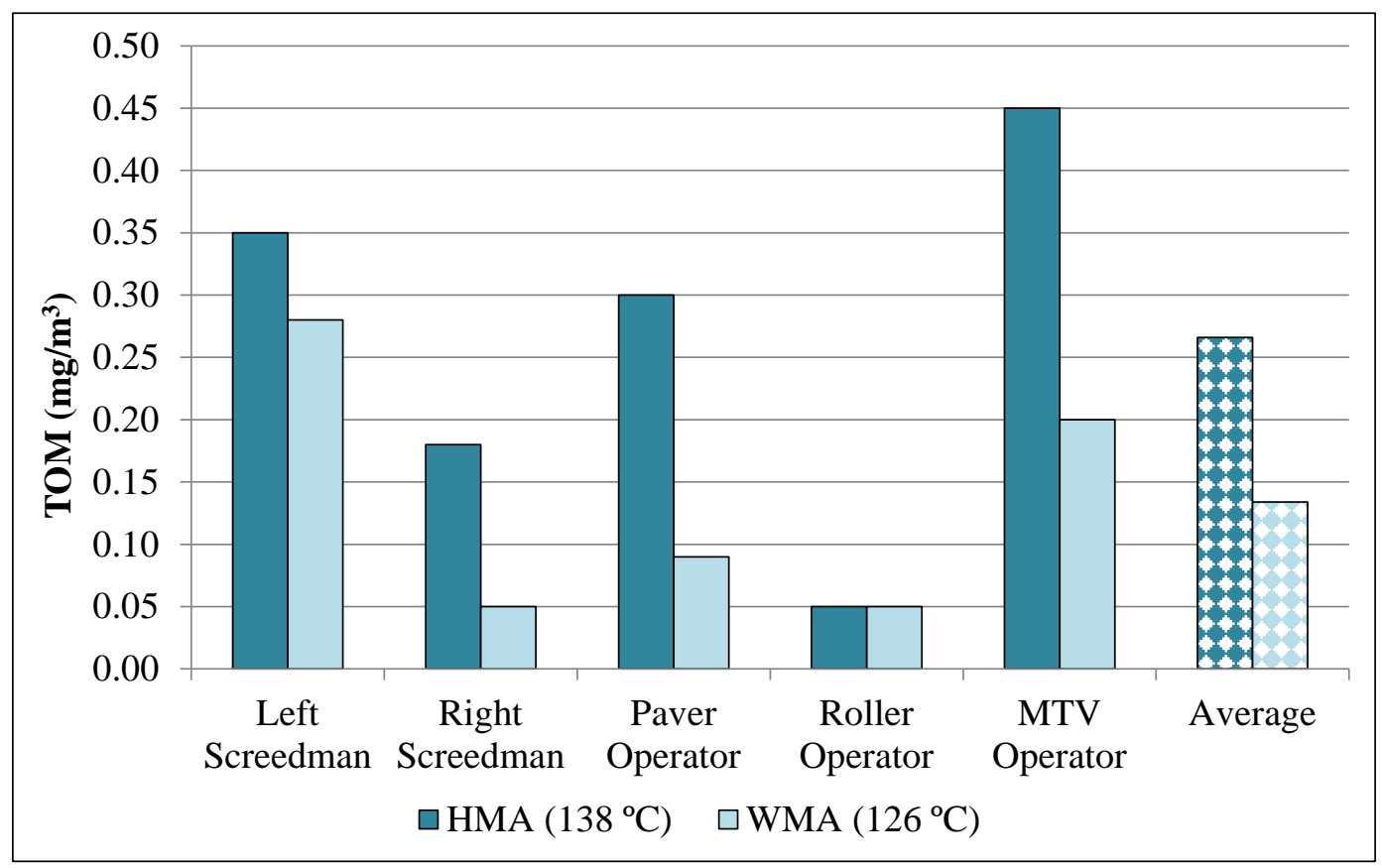


Figure 17. Worker exposure to TOM during WMA and HMA placement at Test Site 2.

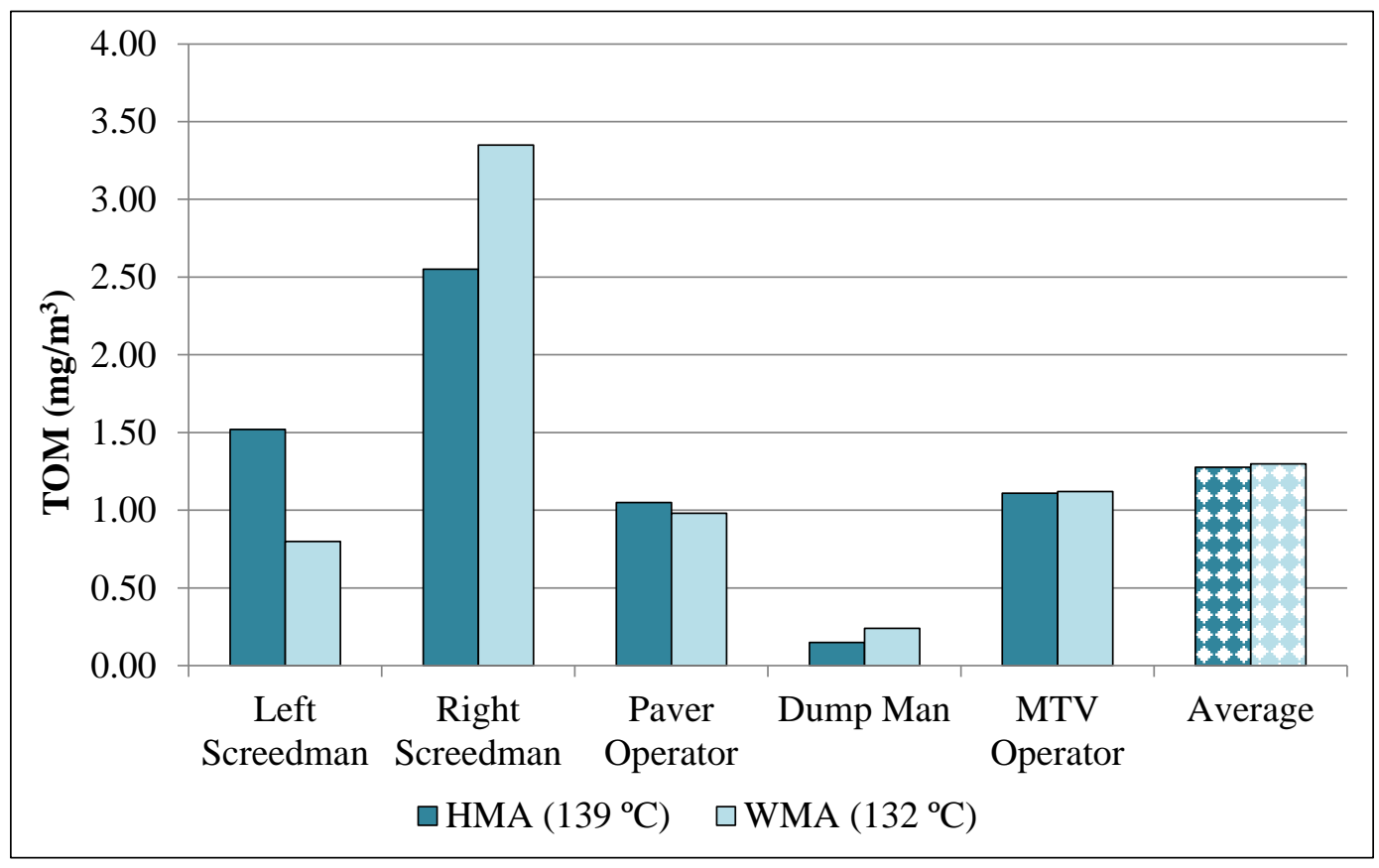

On average at Test Site 2, TOM concentrations were similar for both HMA and WMA. The placement temperature difference between HMA and WMA at this test site was small; therefore, no vast differences in the exposures between HMA and WMA were expected. The right screedman had the highest exposure to TOM during both placements. The range of individual exposures to TOM at this test site was $0.15-3.35 \mathrm{mg} / \mathrm{m}^{3}$ with an average exposure of $1.29 \mathrm{mg} / \mathrm{m}^{3}$.

\subsubsection{Fluorescence analysis}

Fluorescence results represent the amount of 4-6 ring PACs (both parent and alkylated compounds) present in the fumes. Results are shown in Figures 18 and 19 for concentrations in air at Test Sites 1 and 2, respectively, and in Figures 20 and 21 for concentrations in EU/g at Test Sites 1 and 2, respectively.

At Test Site 1, the MTV operator showed the highest concentrations of PACs, while at Test Site 2 the highest PACs were measured from the screedmen. The MTV operator was also exposed to high PACs at Test Site 2. The range of individual exposures to PACs as DPA at Test Site 1 was 0.01$0.09 \mathrm{mg} / \mathrm{m}^{3}$ with an average exposure of $0.04 \mathrm{mg} / \mathrm{m}^{3}$. At Test Site 2 , this range was $0.01-0.13 \mathrm{mg} / \mathrm{m}^{3}$ with an average exposure of $0.07 \mathrm{mg} / \mathrm{m}^{3}$. The PACs' concentrations as DPA were slightly higher at Test Site 2 than at Test 
Figure 18. FLU-PACs reported as $\mu \mathrm{g} / \mathrm{m}^{3}$ as DPA for WMA and HMA at Test Site 1.

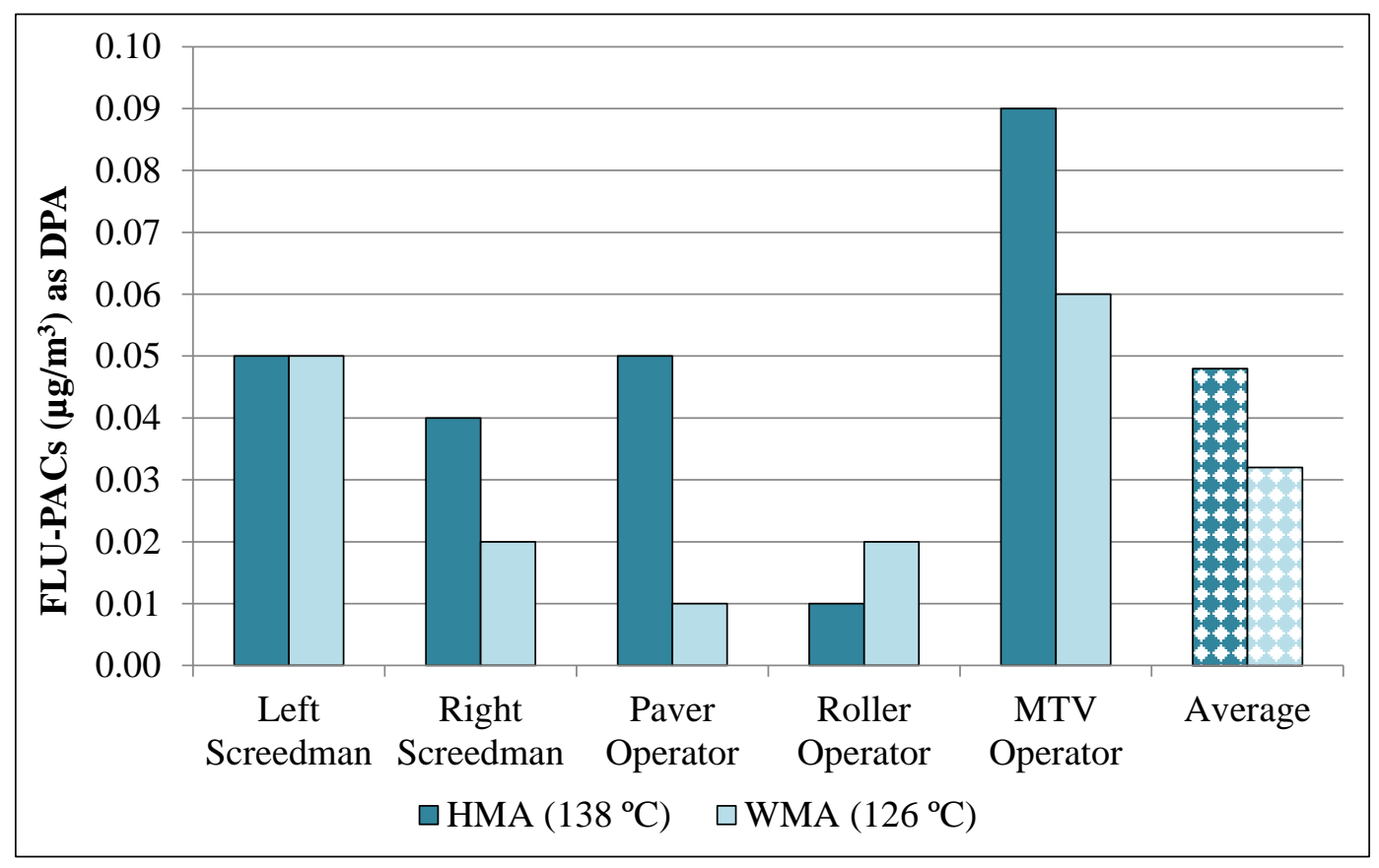

Figure 19. FLU-PACs reported as $\mu \mathrm{g} / \mathrm{m}^{3}$ as DPA for WMA and HMA at Test Site 2.

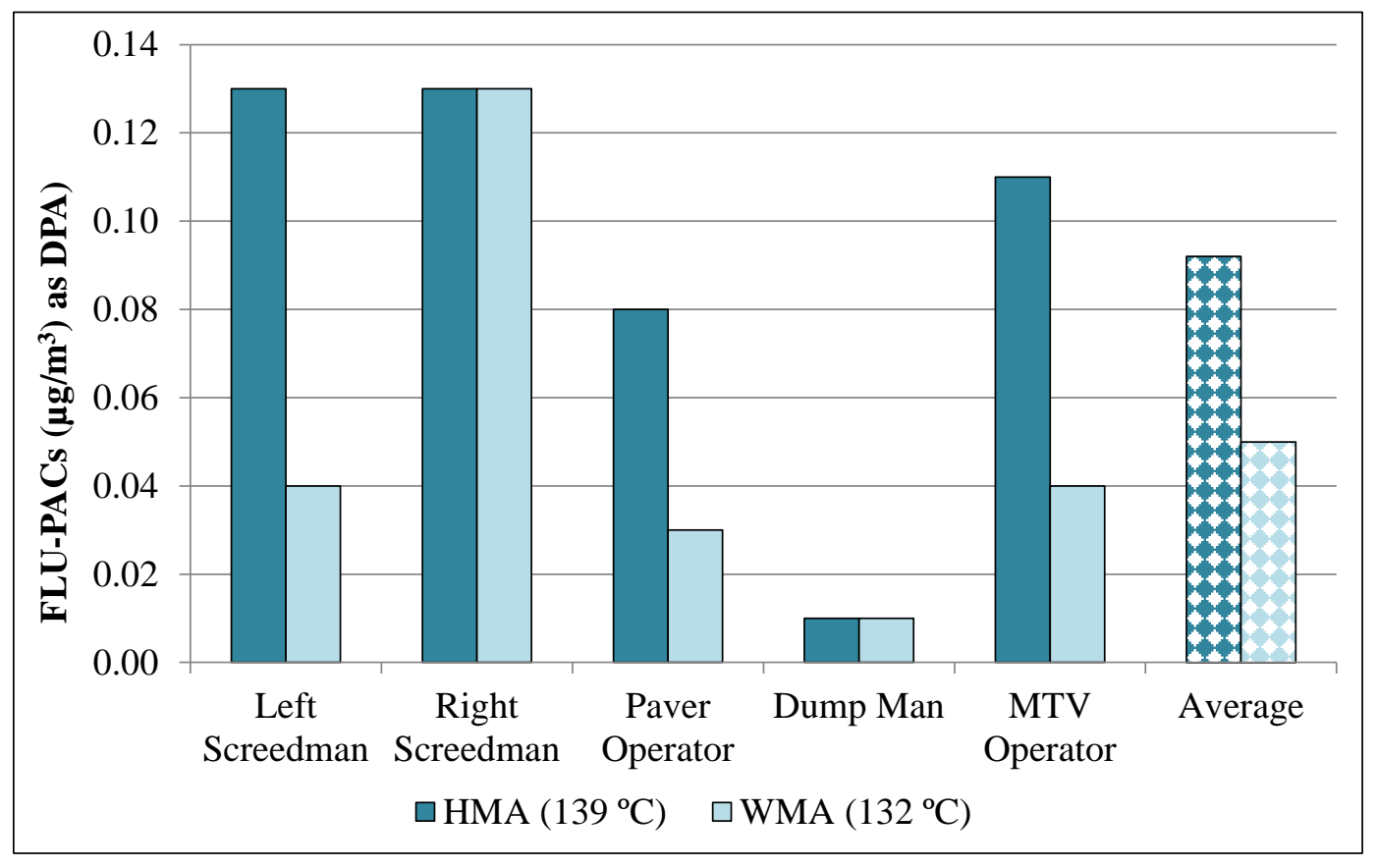


Figure 20. FLU-PACs reported as (EU/g ADJ) for WMA and HMA at Test Site 1.

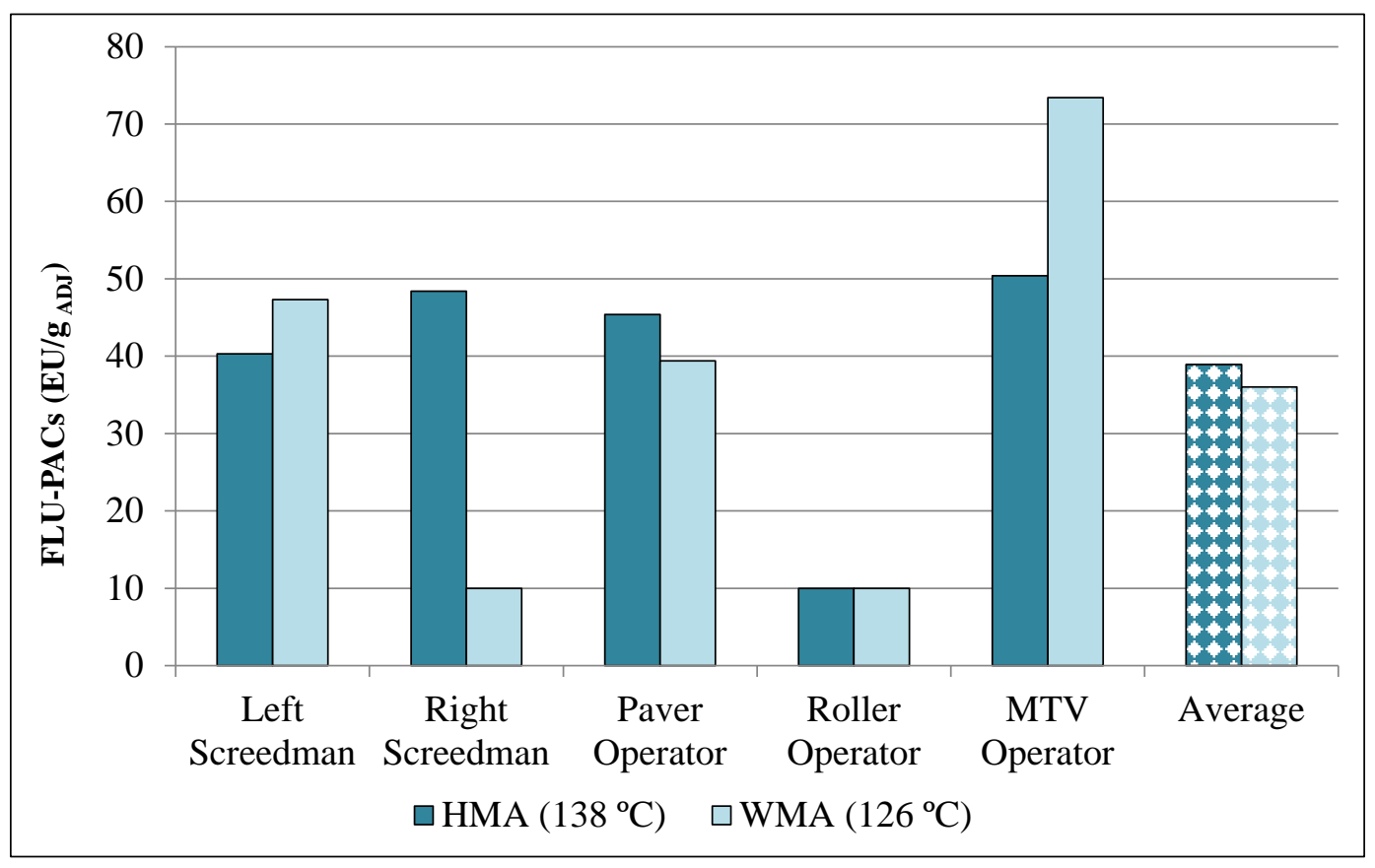

Figure 21. FLU-PACs reported as (EU/g ADJ) for WMA and HMA at Test Site 2.

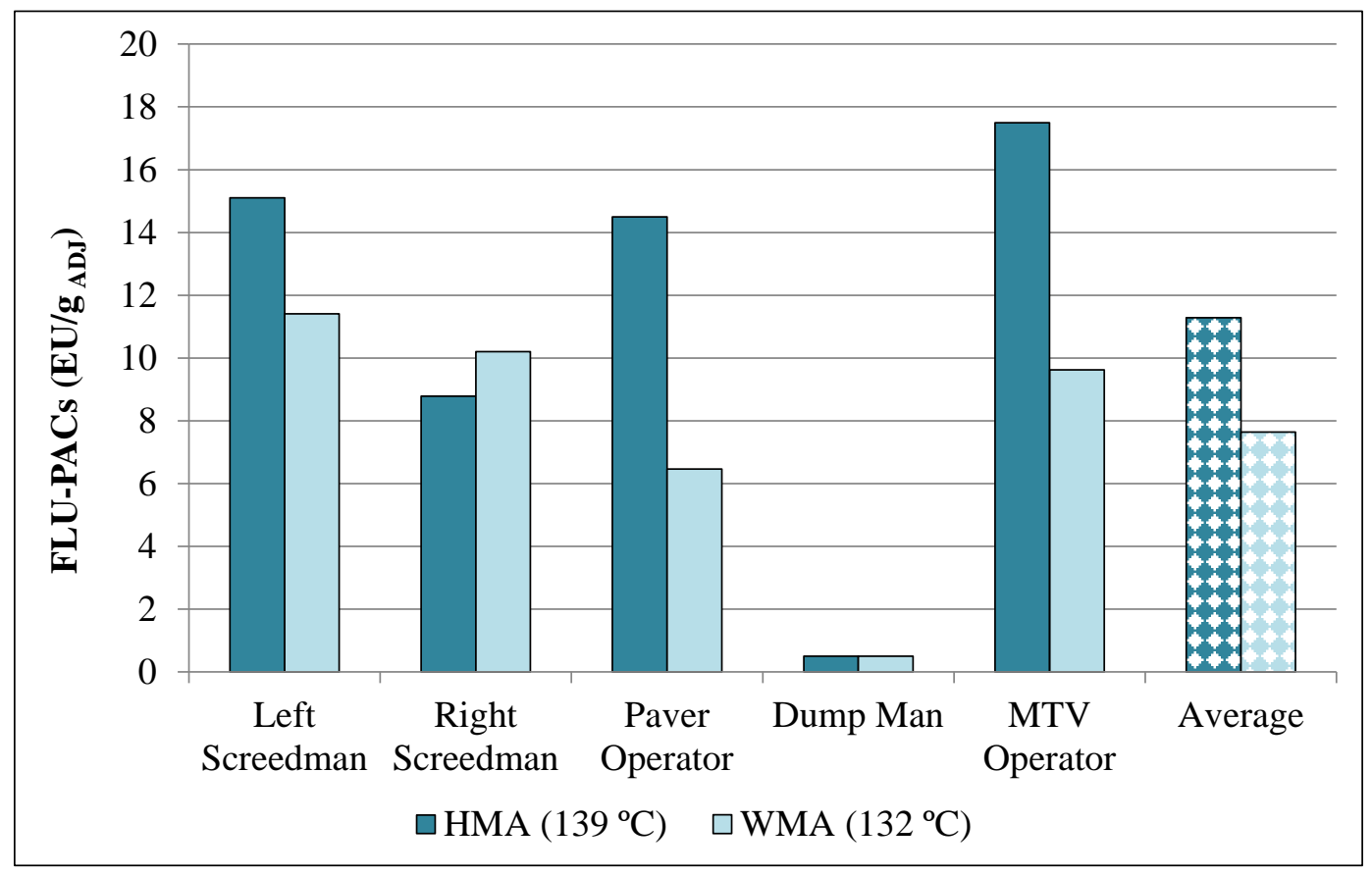

Site 1. There is a more evident difference in the concentrations of PACs as $\mathrm{EU} / \mathrm{g}$ ADJ between both test sites. The range of exposure to PACs as EU/ $g$ ADJ at Test Site 1 was $10.0-73.4 \mathrm{mg} / \mathrm{m}^{3}$ with an average exposure of $37.5 \mathrm{mg} / \mathrm{m}^{3}$. At Test Site 2, this range was $0.5-17.5 \mathrm{mg} / \mathrm{m}^{3}$ with an average exposure of $9.5 \mathrm{mg} / \mathrm{m}^{3}$. This noticeable difference between test sites could have been 
related to a combination of factors that include, but are not limited to, asphalt binder source, asphalt binder grade, RAP content, and/ or placement temperature.

\subsubsection{Emission Reductions}

Figures 22 through 26 show the average exposures to TP, BSF, TOM, and the FLU-PACs as DPA and EU/ $g$ ADJ from both test sites during HMA and WMA placement. At Test Site 1, emissions were reduced when WMA was used compared to HMA except for TP but, as mentioned before, no correlations were expected with application temperature. The percent reduction in the different emissions measured ranged from 0 to $50 \%$ at Test Site 1 . At Test Site 2, all emissions were reduced with the use of WMA except TOM. However, the increase in TOM was by only $1.7 \%$. This slight increase could also have been influenced by test variability. Also, the placement temperature difference between HMA and WMA at this test site was relatively small; therefore, no vast differences in the exposures between HMA and WMA were expected. However, the reduction in the other emissions measured at Test Site 2 ranged from 32\% to 67\%. This shows the effect of other factors in asphalt emissions and also questions the appropriateness of some of the methods used for this type of comparison.

Figure 22. Average site results comparing TP emissions of WMA and HMA.

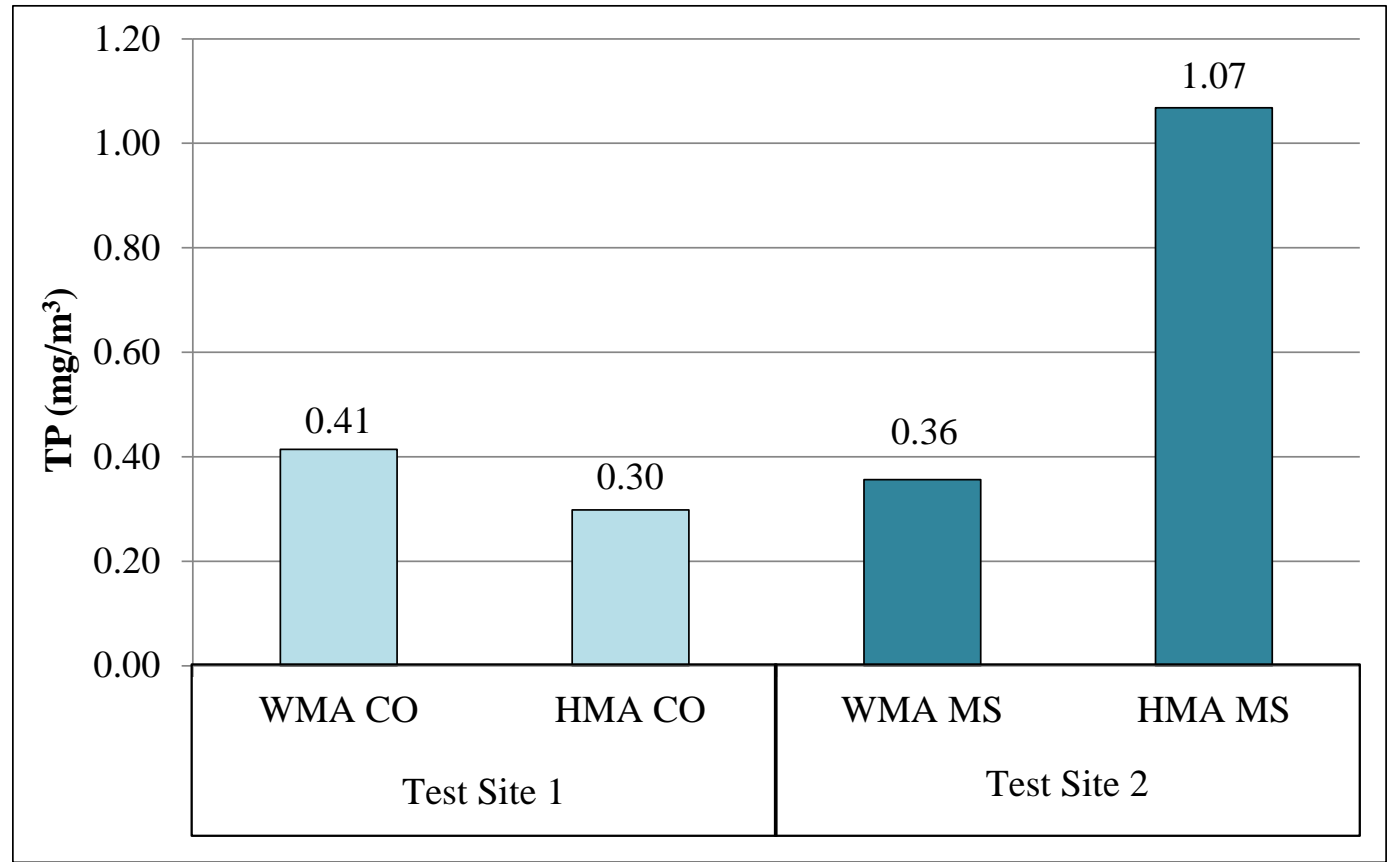


Figure 23. Average site results comparing BSF emissions of WMA and HMA.

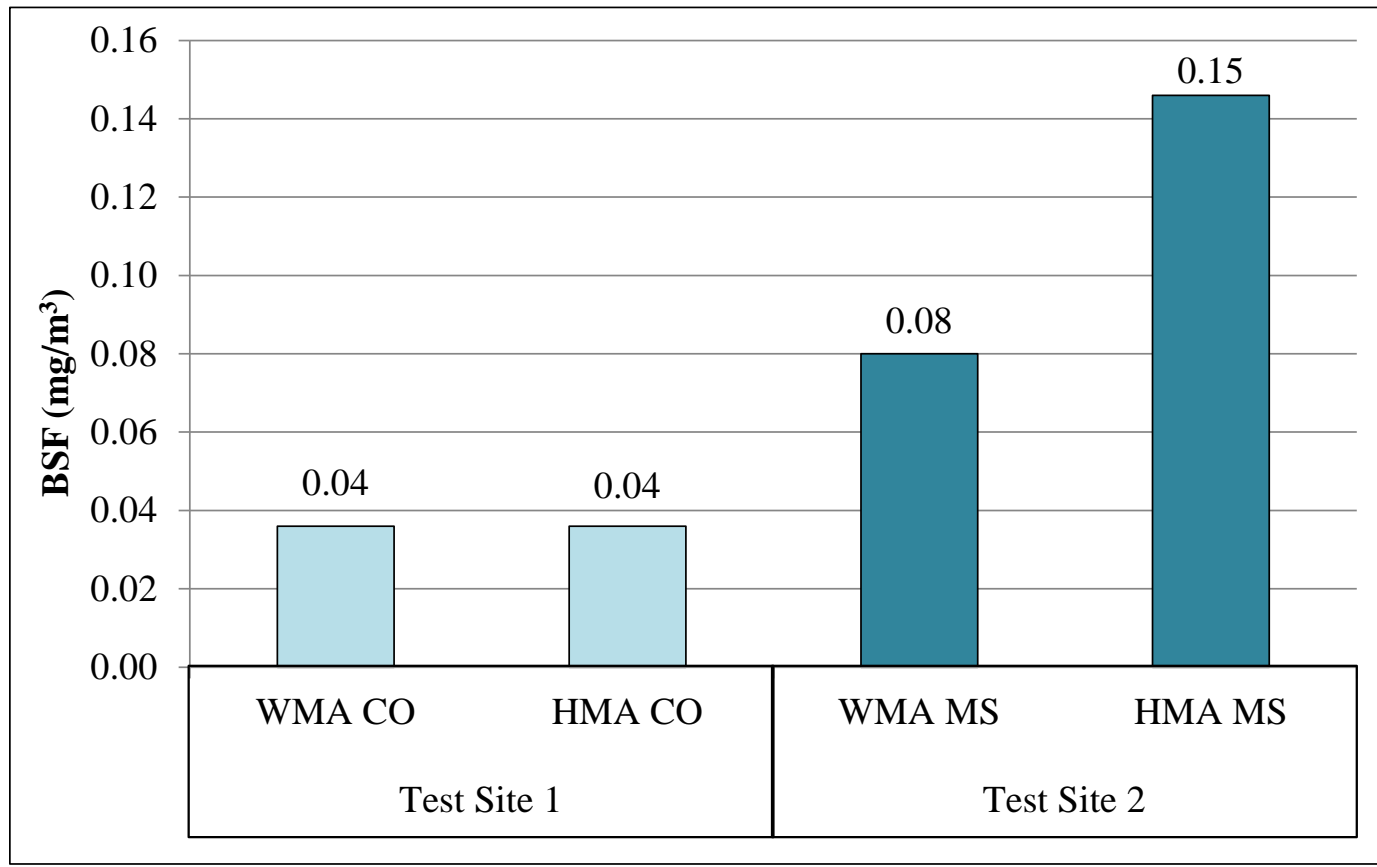

Figure 24. Average site results comparing TOM emissions of WMA and HMA.

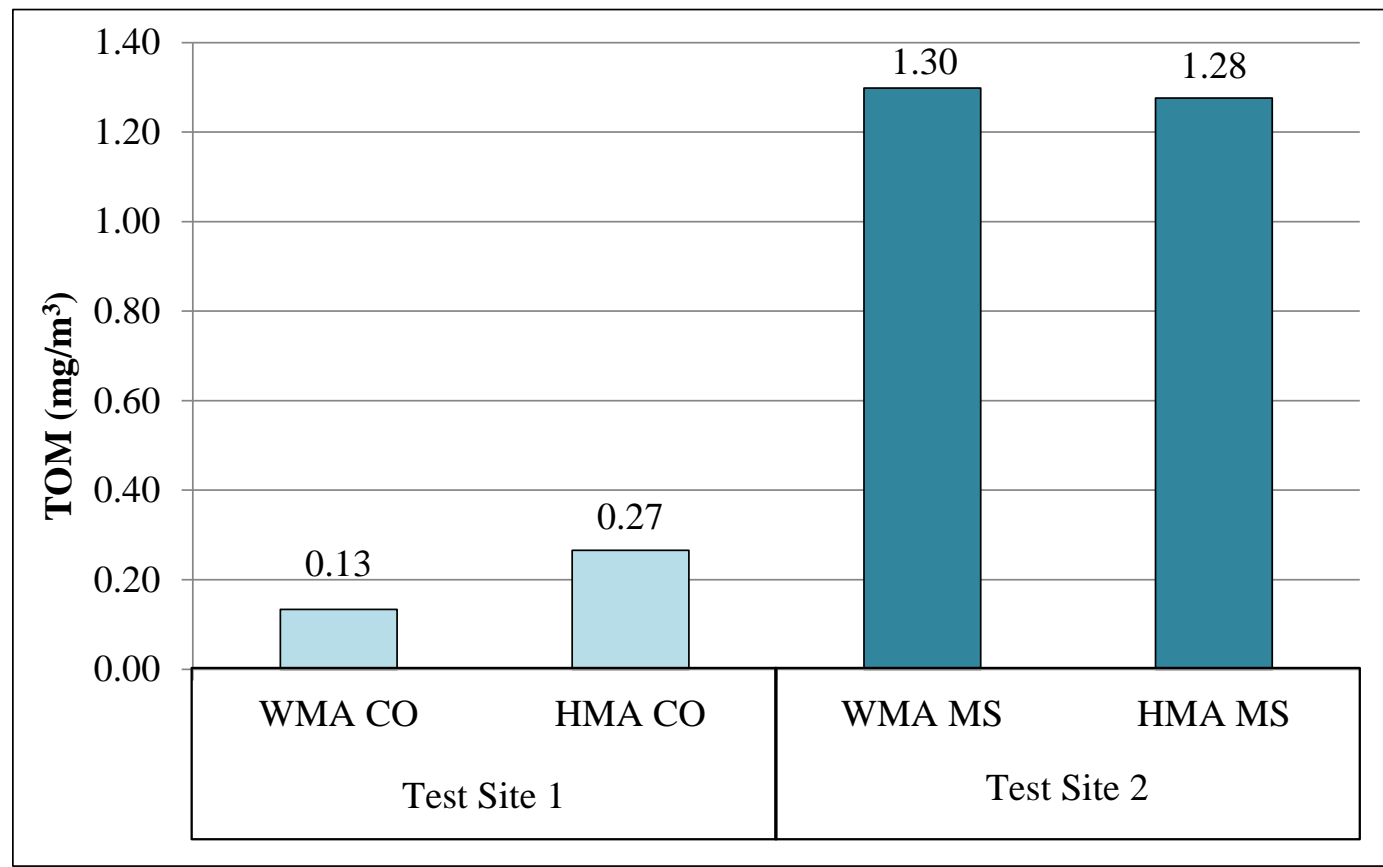


Figure 25. Average site results comparing fluorescence results $\left(\mu \mathrm{g} / \mathrm{m}^{3}\right.$ as DPA) of WMA and HMA.

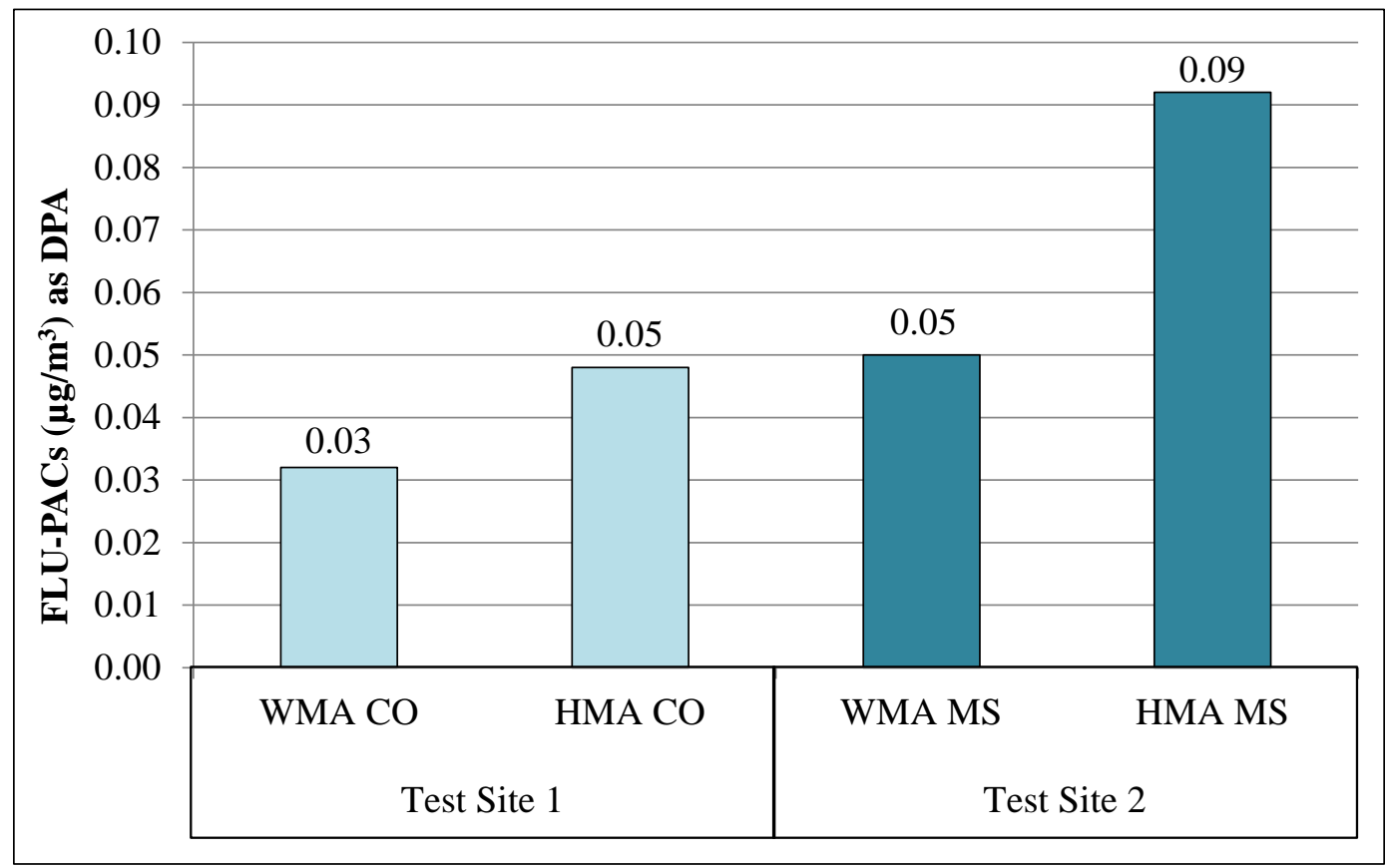

Figure 26. Average site results comparing fluorescence results (EU/g $A D J)$ of WMA and HMA.

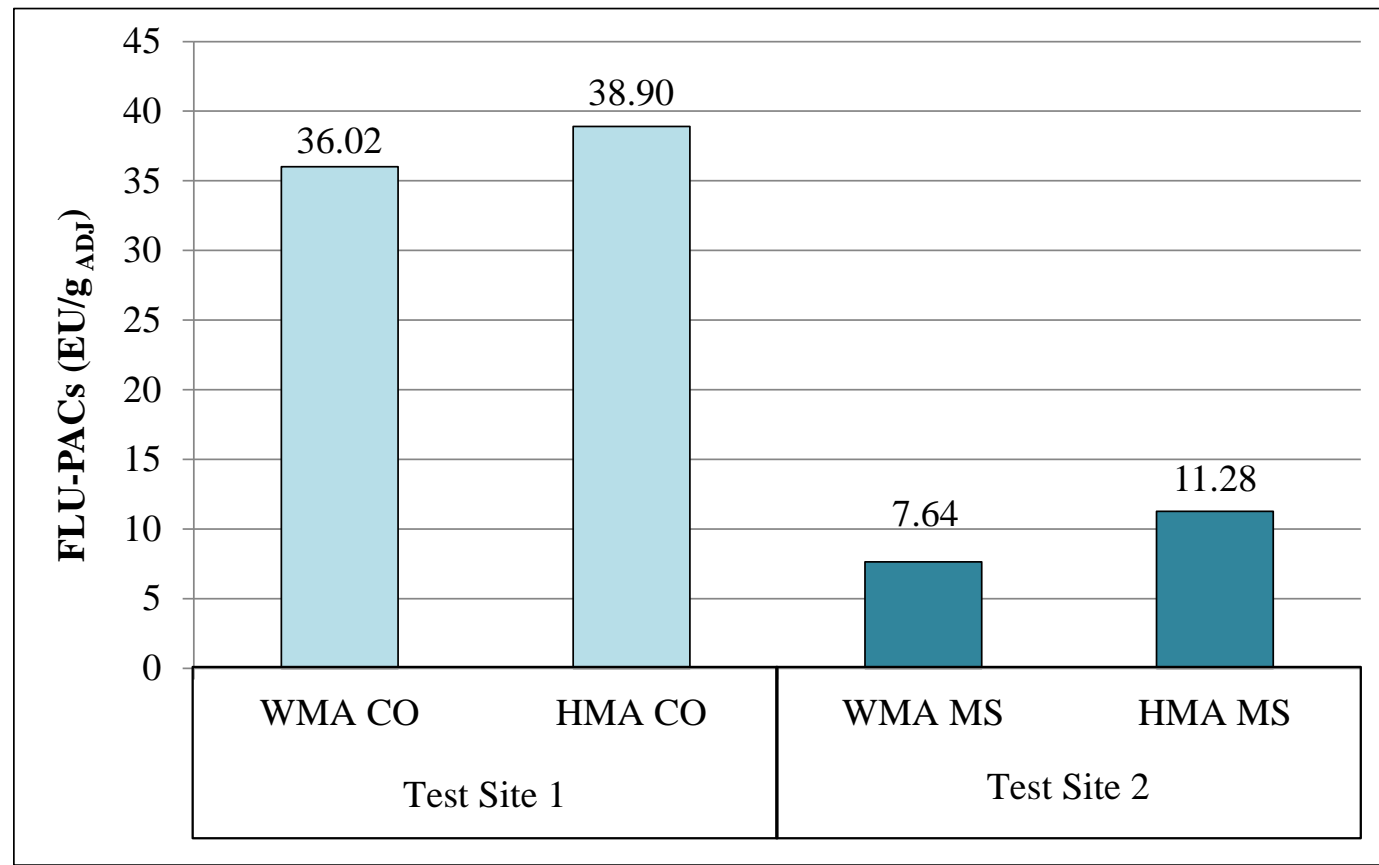

Figure 27 presents the average percent reduction in emissions associated with the use of WMA compared to HMA for each test site. Mixed results were observed throughout. For example, no reduction in BSF concentrations was observed at Test Site 1 with the use of WMA, while at Test Site 2 a reduction of $45 \%$ was observed. On the other hand, the TOM concentrations 
at Test Site 1 reduced by $50 \%$, while in Test Site 2 they were increased by $2 \%$. The fluorescence-analysis results showed reductions in PACs at both test sites. These kind of mixed results are typical in field observations that depend on different variables that cannot be controlled at the same time. In this type of investigations, factors such as construction logistics, landscape, and weather, among others, can affect the results in one way or another. However, it is important to note that, for this investigation, those variables that could be controlled; i.e., asphalt binder grade, RAP content, aggregate type and gradation, etc., were consistent between each WMA and its corresponding HMA. Therefore, mixed results are attributed to external factors that affect the sampling process.

Figure 27. Average emission reductions comparing WMA and HMA per test site.

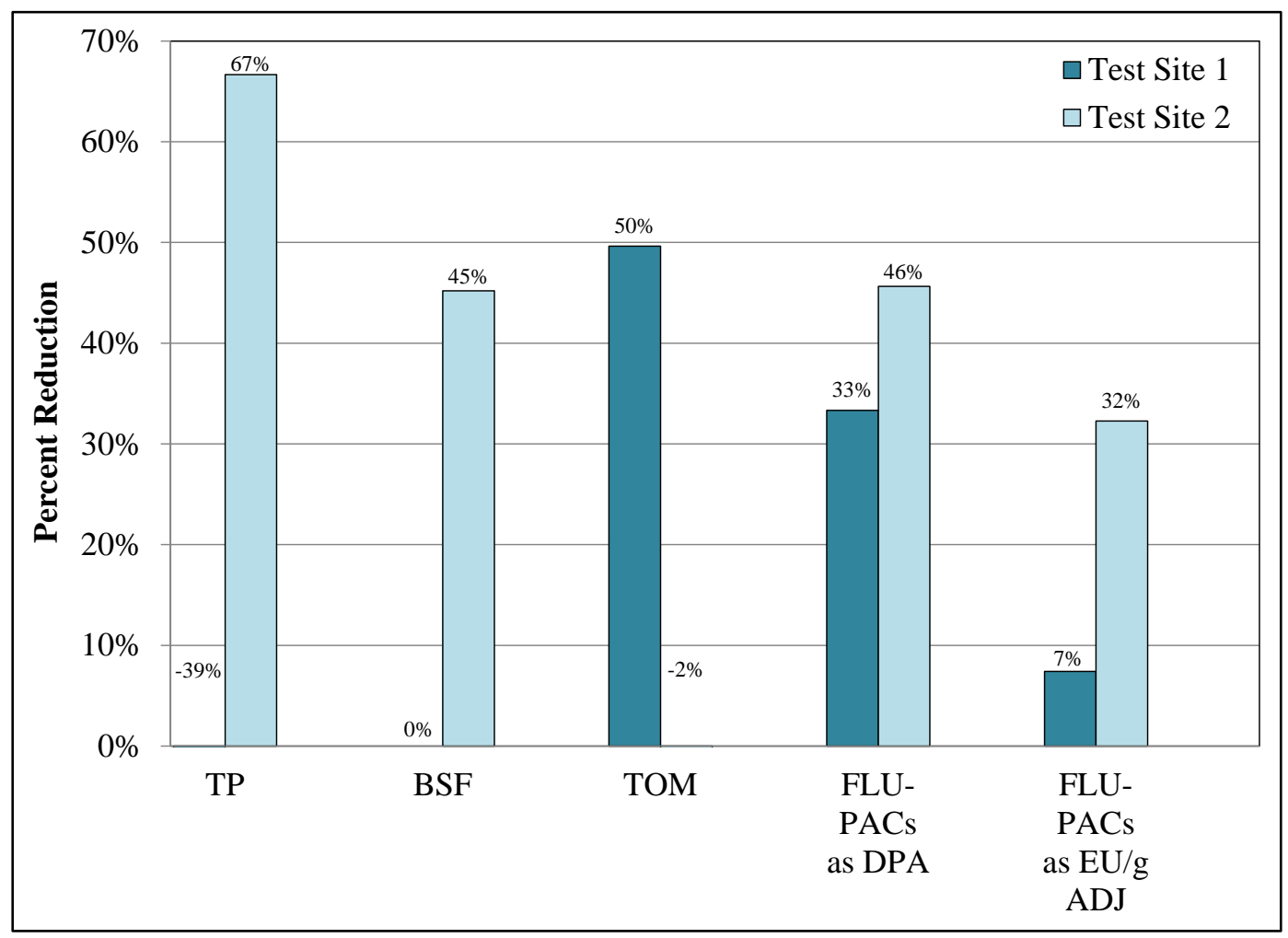




\section{Discussion}

\subsection{Literature review main findings}

The literature extensively supports that a reduction in asphalt temperatures reduces the emissions during the production and placement of asphalt mixes. Produced at temperatures typically $30^{\circ} \mathrm{C}$ lower than conventional HMA, WMA technologies play an important role in reducing the environmental and safety impacts of the asphalt industry.

Several techniques are available for measuring asphalt emissions during production and placement operations, and this variety complicates the process of quantifying potential reductions in emissions associated with the use of WMA compared to conventional HMA. Also, some techniques, such as the use of NIOSH 5042, for analyzing personal exposure samples are not appropriate for this purpose because the results are typically under detectable limits, which hinder quantitative comparisons between WMA and HMA. This was the main motivation for researchers to work on improving the current WMA TWG protocol for measuring asphalt emissions under NCHRP project 9-47a (Prowell et al. 2014). The updated protocol includes procedures for both stack emissions testing and measurement of workers' exposure to asphalt fumes during placement. However, limited data have been collected so far using this protocol.

In general, the WMA reductions in stack emissions found in the literature range up to $40 \%$ for $\mathrm{CO}_{2}, 55 \%$ for $\mathrm{SO}_{2}, 70 \%$ for $\mathrm{NO}_{x}, 50 \%$ for $\mathrm{VOCs}$, and $30 \%$ for $\mathrm{CO}$. The reductions found in the literature in workers' exposures during placement ranged up to $50 \%$ for VOCs and PAHs and $33 \%$ for TOM. Most of the studies reported BSF readings below detection limits.

\subsection{Field testing}

The study presented in this report used the updated WMA TWG protocol to measure emissions during asphalt placement of WMA and HMA at two different projects. Emission reductions were observed at both test sites. The average reductions in all the emissions measured ranged up to $67 \%$. Reductions in BSF ranged up to $45 \%$ and similarly reductions in TOM ranged up to $50 \%$. Reductions in PACs ranged up to $46 \%$. These numbers are within the range of reductions that was found in the literature. 


\subsection{General guidance for quantifying emissions reductions}

In general, the updated WMA TWG protocol (Prowell et al. 2014) for documenting WMA emissions is very helpful in providing guidance for quantifying emissions reductions and energy savings during asphalt production and placement. This protocol should be used in more projects to extend the database on emissions reductions associated to WMA. It is specific on what tests need to be performed to complete stack emissions testing and provides guidance on the costs for these tests. It also provides guidance on how to measure energy reductions during asphalt production.

To measure emissions during asphalt placement, the updated WMA TWG protocol recommends using two methods for sample analysis, i.e., NIOSH 5042 in conjunction with TOM (Kriech et al. 2002). The literature suggests that using NIOSH 5042 generally prevents quantitative comparisons between HMA and WMA since most readings are below detectable limits. However, in this project, both methods were used and only one of 10 samples produced a BSF reading below the detection limit.

The use of the updated WMA TWG protocol is recommended as a primary tool for documenting emissions reductions of WMA compared to conventional HMA during production and placement. The test methods included in this protocol have been used in the past and have provided useful information. Additional data are needed to create a database with actual reduction quantities that can be used as guidance for future projects.

In addition, the fluorescence analysis (Osborn et al. 2001) is a great tool that can be used to evaluate the workers' exposure to the potentially carcinogenic portion of asphalt emissions in order to optimize a healthy work environment. It is also a good tool to determine reductions in exposure to PACs associated with the use of WMA. However, this method is optional, and its use will depend on the extent of the investigation.

Finally, it is important to consider the factors in Table 7 and try to keep them as consistent as possible between HMA and WMA during emissions monitoring to make reasonable comparisons. 
Table 7. Important factors to consider when monitoring asphalt emissions.

\begin{tabular}{|l|l|}
\hline During Asphalt Production & During Asphalt Placement \\
\hline Plant type & Paving crew \\
Asphalt Source & Paving equipment \\
Aggregate type & Use of engineering controls \\
Aggregate moisture content & Paving direction \\
RAP/RAS content (if applicable) & Landscape \\
Use of additives (if applicable) & Weather conditions \\
\hline
\end{tabular}




\section{Conclusions and Recommendations}

\subsection{Conclusions}

The following conclusions resulted from a literature review and from the evaluation of the workers' exposures to asphalt emissions during placement of WMA and HMA.

- The literature extensively supports that a reduction in asphalt temperatures reduces the emissions during the production and placement of asphalt mixes.

- Reductions found in the literature in stack emissions associated with the use of WMA range up to $40 \%$ for $\mathrm{CO}_{2}, 55 \%$ for $\mathrm{SO}_{2}, 70 \%$ for $\mathrm{NO}_{\mathrm{x}}$, $50 \%$ for VOCs, and $30 \%$ for CO.

- Reductions found in the literature in workers' exposures during placement ranged up to 50\% for VOCs and PAHs and 33\% for TOM. Most of the studies reported BSF readings below detection limits.

- From the field study, the use of WMA at both test sites resulted in lower placement temperatures compared to their corresponding HMA; this yielded reductions in BSF up to $45 \%$, in TOM exposures up to $50 \%$, and in PACs up to $46 \%$.

\subsection{Recommendations}

Based on the literature review and the field evaluation, the following is recommended.

- The use of the updated WMA TWG protocol (Prowell et al. 2014) is recommended as a primary tool for documenting emissions reductions of WMA compared to conventional HMA during production and placement.

- The use of fluorescence analysis (Osborn et al. 2001) is recommended as optional. This method provides additional information on the exposure to potential carcinogenic portions in asphalt fumes.

- Extensive testing and additional data are required to build a database of measured emissions reductions associated with the use of WMA that can be used as guidance during the selection of these technologies as an alternative to conventional HMA. 


\section{References}

Cavallari, J ., L. V. Osborn, J . E. Snawder, A. J . Kriech, L. D. Olsen, R. F. Herrick, and M. D. McClean. 2011. Predictors of dermal exposures to polycyclic aromatic compounds among hot-mix asphalt paving workers. Annals of Occupational Hygiene 56(2):125-37.

D’ Angelo, J ., E. Harm, J . Bartoszek, G. Baumgardner, M. Corrigan, J . Cowsert, T. Harman, M. J amshidi, W. J ones, D. Newcomb, B. Prowell, R. Sines, and B. Yeaton. 2008. Warm-mix asphalt: European practice. Report No. FHWA-PL08-007. Washington, DC: Federal Highway Administration.

Davidson, J . K., and R. Pedlow. 2007. In Reducing Paving Emissions Using Warm Mix Technology, Proceedings Vol. LII. Canadian Technical Asphalt Association.

Diefenderfer, S. D., K. K. McGhee, and B. M. Donaldson. 2007. Installation of warm mix asphalt projects in Virginia. Final Report, VTRC 07-R25. Charlottesville, VA: Virginia Transportation Research Council.

Frank, B., B. D. Prowell, G. C. Hurley, and R. C. West. 2011. Warm mix asphalt (WMA) emissions reductions and energy savings." $2^{\text {nd }}$ International Conference on Warm Mix Asphalt. St. Louis, MO.

German Bitumen Forum. 2006. Progress report 2006: The German bitumen forum, Edition 2. Heinrich Lauck GmbH, Germany.

Hurley, G. C., B. D. Prowell, and A. N. Kvasnak. 2010. Wisconsin field trial of warm mix asphalt technologies: Construction summary. NCAT Report No. 10-04. Auburn, AL: National Center for Asphalt Technology.

Kriech, A. J., J . T. Kurek, H. L. Wissel, L. V. Osborn, and G. R. Blackburn. 2002. Evaluation of worker exposure to asphalt paving fumes using traditional and nontraditional techniques. American Industrial Hygiene Association J ournal 63(5):628-635.

Kriech, A. J ., L. V. Osborn, J . E. Snawder, L. D. Olsen, R. F. Herrick, J . M. Cavallari, M. D. MoClean, and G. R. Blackburn. 2011. Study design and methods to investigate inhalation and dermal exposure to polycyclic aromatic compounds and urinary metabolites from asphalt paving workers: Research conducted through partnership. Polycyclic Aromatic Compounds 31(4):243-269.

Lange, C. R., and M. Stroup-Gardiner. 2007. Temperature dependent chemical specific emission rates of aromatics and polyaromatic hydrocarbons (PAHs) in bitumen fume. J ournal of Occupational Environmental Hygiene 4(s1):72-6.

McClean, M. D., L. V. Osborn, J . E. Snawder, A. J . Kriech, L. D. Olsen, R. F. Herrick, and J. M. Cavallari. 2011. J ob characteristics and exposure routes associated with biomarkers polycyclic aromatic compound exposure among asphalt paving workers. Annals of Occupational Hygiene 48(6):565-578 
Middleton, B., and R. W. Forfylow. 2008. An evaluation of warm mix asphalt produced with the double barrel green process. 7th International Conference on Managing Pavement Assets (ICMPA). Calgary.

NIOSH. 1997. Engineering control guidelines for hot mix asphalt pavers. U.S. Department of Health and Human Services: National Institute for Occupational Safety and Health.

. 2001. Hazard review: Health effects of occupational exposure to asphalt. DHHS (NIOSH) Publication No. 2001-110. U.S. Department of Health and Human Services: National Institute for Occupational Safety and Health.

. 1998. Benzene solubles fraction and total particulate (asphalt fume): Method 5042. In NIOSH manual of analytical methods, $4^{\text {th }}$ edition, $2^{\text {nd }}$ supplement, ed. $\mathrm{P}$ M. Eller and M. E. Cassinelli. DHHS (NIOSH) Publication No. 98-119. U.S. Department of Health and Human Services: National Institute for Occupational Safety and Health.

NPI. 1999. Emission estimation technique manual for hot mix asphalt manufacturing. Canberra, Australia: National Pollutant Inventory.

Occupational Safety and Health Administration (OSHA). 2014. Asphalt fumes. https://www.osha.gov/SLTC/asphaltfumes.

Osborn, L. V., J . T. Kurek, A. J . Kriech, and F. M. Fehsenfeld. 2001. Luminescence spectroscopy as a screening tool for the potential carcinogenicity of asphalt fumes. J ournal of Environmental Monitoring 3:185-190.

Prowell, B. D., G. C. Hurley, and B. Frank. 2012. Warm-mix asphalt: Best practices. Landham, MD: National Asphalt Pavement Association (NAPA).

Prowell, B. D., A. Kvasnak, G. Hurley, R. West, T. Kriech, L. Osborn, B. Frank, K. Peregrine, and D. J ones. 2009. Engineering properties, emissions, and field performance of warm-mix asphalt technologies. Draft Interim Report - NCHRP 9-47A, December. Washington, DC: National Cooperative Highway Research Program.

Prowell, B. D., B. Frank, L. V. Osborn, T. Kriech, and R. West. 2014. Effects of WMA on plant energy and rmissions and worker exposures to respirable fumes. NCHRP 947A Final Report, Vol. 2 (in preparation). Washington, DC: National Cooperative Highway Research Program.

U.S. Environmental Protection Agency (EPA). 1996. Method SW846-8015B, nonhalogenated organics using GC/ FID. In U.S. EPA test methods for evaluating solid waste, physical/chemical method. SW846, 3rd rev. ed. Washington, DC: Environmental Protection Agency. 
Appendix A: Field Notes 


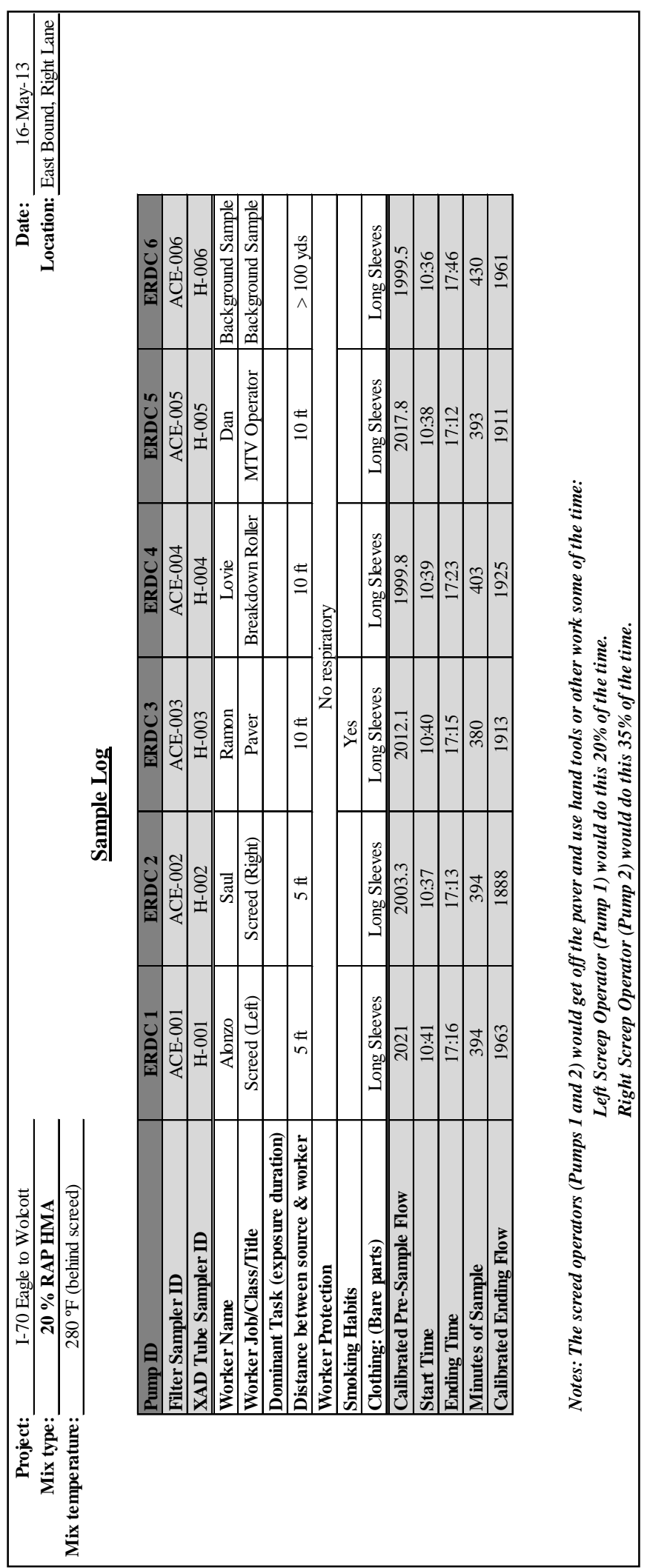


Project: I-70 Eagle to Wolcott

Date: May 16, 2013

Mix Type: 20\% RAP HMA

\begin{tabular}{|c|c|}
\hline \multicolumn{2}{|c|}{ Process/Material/Equipment Related Conditions } \\
\hline Paving direction & East on I-70 \\
\hline Machinery type & Paver + MTV \\
\hline Engineering controls (e.g. ventilation) & none \\
\hline Production rate (tons/day) & $150 \mathrm{TPH}$ \\
\hline Paved area, layer thickness \& length & 2 in. $x 12 \mathrm{ft}$ \\
\hline $\begin{array}{l}\text { Average application temperature/observed } \\
\text { emissions }\end{array}$ & $280^{\circ} \mathrm{F}$ \\
\hline Asphalt binder type & $64-28$ \\
\hline Mix type, binder content & 20\% RAP, HMA, $5.2 \%$ AC \\
\hline Used tack coat in priming road surface? & Yes \\
\hline Additional sources of contaminants & $\begin{array}{l}\text { Exhaust from passing vehicles } \\
\text { in other lane }\end{array}$ \\
\hline Release agent & $\begin{array}{c}\text { diesel on tools, non-diesel in } \\
\text { trucks } \\
\end{array}$ \\
\hline Fuel type used to power machinery & diesel \\
\hline \multicolumn{2}{|c|}{ Location Conditions } \\
\hline $\begin{array}{l}\text { Worksite geometry (countryside or city, degree } \\
\text { of enclosure) }\end{array}$ & Countryside \\
\hline Traffic & Heavy ( 10\% trcuks) \\
\hline
\end{tabular}




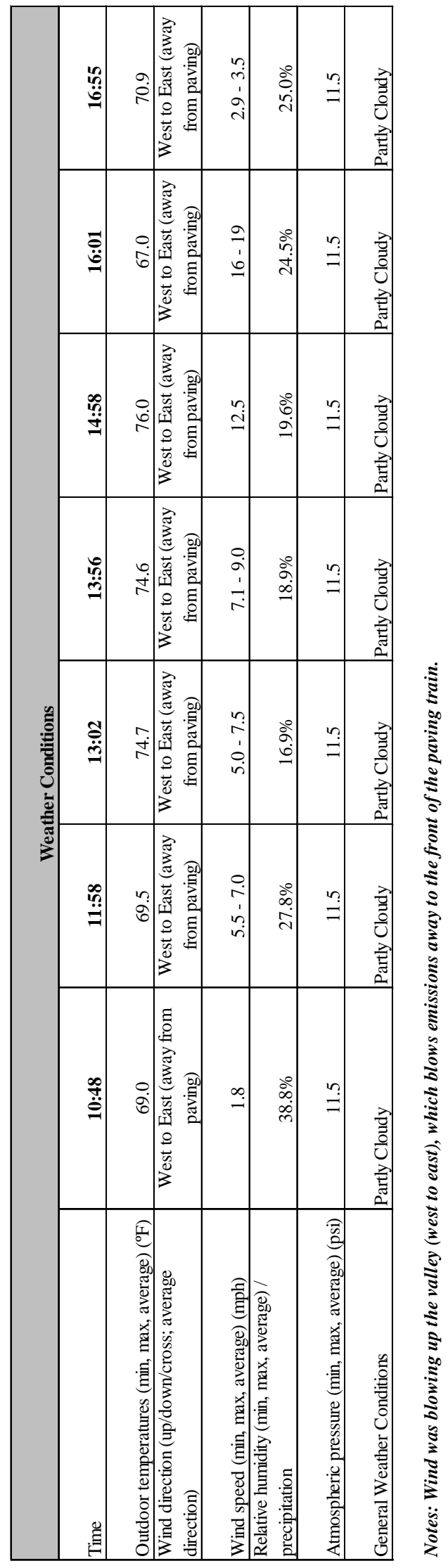




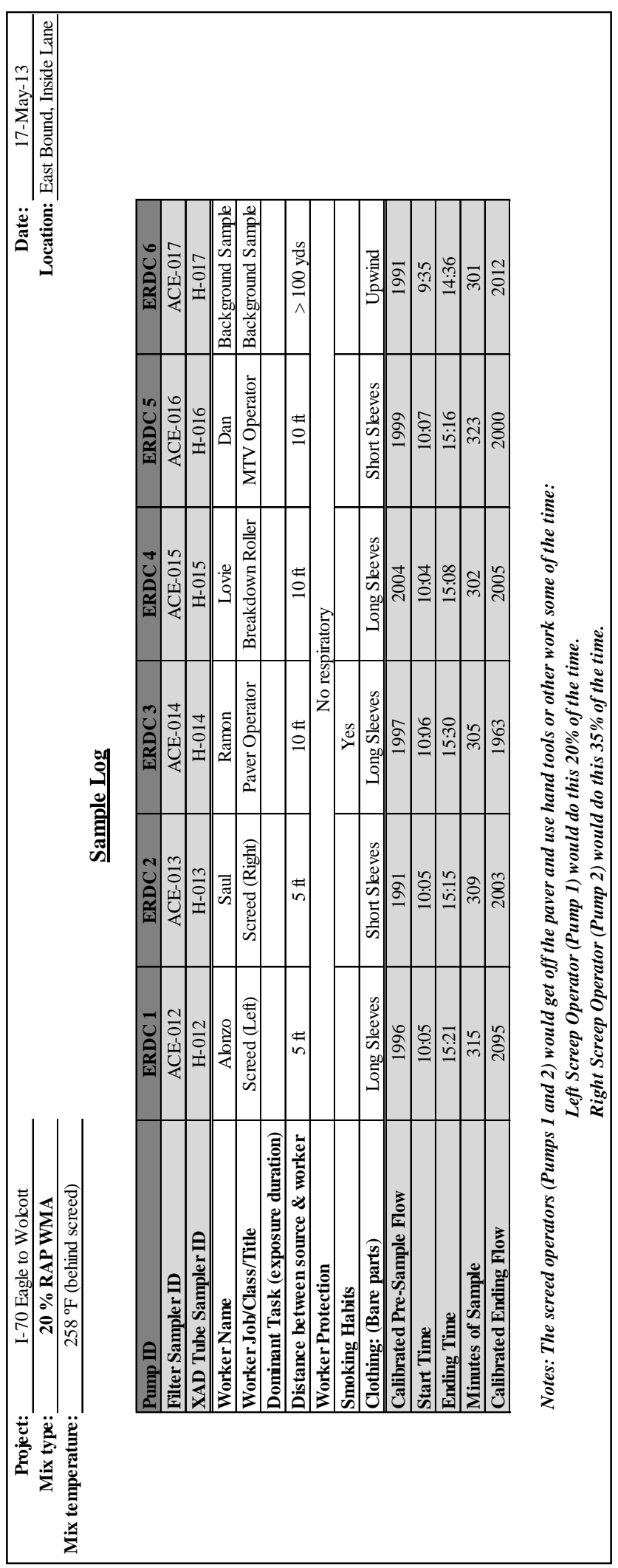


Project: I-70 Eagle to Wolcott

Date: May 17, 2013

Mix Type: 20\% RAP WMA

\begin{tabular}{|c|c|}
\hline \multicolumn{2}{|c|}{ Process/Material/Equipment Related Conditions } \\
\hline Paving direction & East on I-70 \\
\hline Machinery type & Paver + MTV \\
\hline Engineering controls (e.g. ventilation) & none \\
\hline Production rate (tons/day) & $150 \mathrm{TPH}$ \\
\hline Paved area, layer thickness \& length & 2 in. $x 12 \mathrm{ft}$ \\
\hline $\begin{array}{l}\text { Average application temperature/observed } \\
\text { emissions }\end{array}$ & $258^{\circ} \mathrm{F}$ \\
\hline Asphalt binder type & $64-28$ \\
\hline Mix type, binder content & $20 \%$ RAP, WMA, $5.2 \%$ AC \\
\hline Used tack coat in priming road surface? & Yes \\
\hline Additional sources of contaminants & \begin{tabular}{|c|}
$\begin{array}{c}\text { Exhaust from passing vehicles } \\
\text { in other lane }\end{array}$ \\
\end{tabular} \\
\hline Release agent & $\begin{array}{l}\text { diesel on tools, non-diesel in } \\
\text { trucks } \\
\end{array}$ \\
\hline Fuel type used to power machinery & diesel \\
\hline \multicolumn{2}{|c|}{ Location Conditions } \\
\hline $\begin{array}{l}\text { Worksite geometry (countryside or city, degree } \\
\text { of enclosure) }\end{array}$ & Countryside \\
\hline Traffic & Heavy ( 10\% trcuks) \\
\hline
\end{tabular}




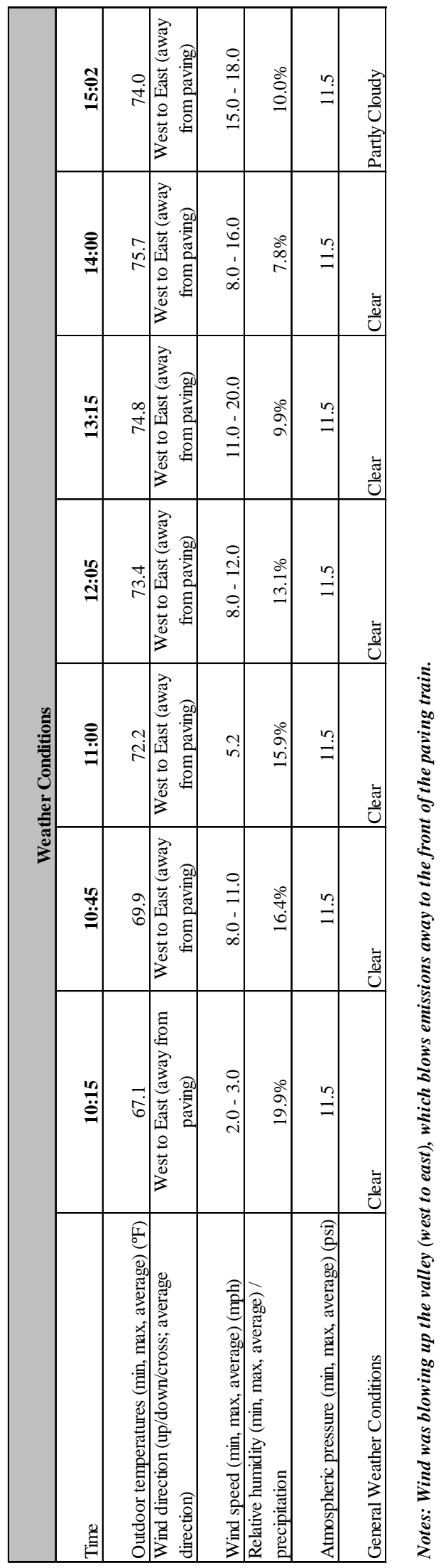




\section{Appendix B: Test Data}

Table B1. Total particulate (TP) data from Test Site 1.

\begin{tabular}{|c|c|c|c|c|c|c|}
\hline \multicolumn{7}{|c|}{ HMA $\left(280^{\circ} \mathrm{F}\right)$} \\
\hline $\begin{array}{l}\text { Sample } \\
\text { ID }\end{array}$ & Description & $\begin{array}{l}\text { Volume of } \\
\text { Air (L) }\end{array}$ & $\begin{array}{l}\text { TP } \\
\left(\mathrm{mg} / \mathrm{m}^{3}\right)\end{array}$ & STD. Dev. & LOD & LOQ \\
\hline ACE-01 & Left Screedman & 784.85 & 0.63 & \multirow{11}{*}{5.96} & \multirow{11}{*}{17.88} & \multirow{11}{*}{59.60} \\
\hline ACE-02 & Right Screedman & 766.59 & 0.28 & & & \\
\hline ACE-03 & Paver Operator & 745.77 & 0.17 & & & \\
\hline ACE-04 & Roller Operator & 790.85 & 0.17 & & & \\
\hline ACE-05 & MTV Operator & 772.01 & 0.24 & & & \\
\hline ACE-06 & Background Sample & 851.51 & 0.07 & & & \\
\hline ACE-07 & \multicolumn{3}{|c|}{ Field Blank } & & & \\
\hline ACE-08 & \multicolumn{3}{|c|}{ Field Blank } & & & \\
\hline ACE-09 & \multicolumn{3}{|c|}{ Field Blank } & & & \\
\hline ACE-10 & \multicolumn{3}{|c|}{ Field Blank } & & & \\
\hline ACE-11 & \multicolumn{3}{|c|}{ Field Blank } & & & \\
\hline \multicolumn{7}{|c|}{ WMA $\left(258^{\circ} \mathrm{F}\right)$} \\
\hline $\begin{array}{l}\text { Sample } \\
\text { ID }\end{array}$ & Description & $\begin{array}{l}\text { Volume of } \\
\text { Air (L) }\end{array}$ & $\begin{array}{l}\mathrm{TP} \\
\left(\mathrm{mg} / \mathrm{m}^{3}\right)\end{array}$ & STD. Dev. & LOD & LOQ \\
\hline ACE-12 & Left Screedman & 644.33 & 0.85 & \multirow{11}{*}{8.09} & \multirow{11}{*}{24.28} & \multirow{11}{*}{80.93} \\
\hline ACE-13 & Right Screedman & 617.07 & 0.47 & & & \\
\hline ACE-14 & Paver Operator & 603.90 & 0.22 & & & \\
\hline ACE-15 & Roller Operator & 605.36 & 0.20 & & & \\
\hline ACE-16 & MTV Operator & 645.84 & 0.33 & & & \\
\hline ACE-17 & Background Sample & 602.45 & 0.16 & & & \\
\hline ACE-18 & \multicolumn{3}{|c|}{ Field Blank } & & & \\
\hline ACE-19 & \multicolumn{3}{|c|}{ Field Blank } & & & \\
\hline ACE-20 & \multicolumn{3}{|c|}{ Field Blank } & & & \\
\hline ACE-21 & \multicolumn{3}{|c|}{ Field Blank } & & & \\
\hline ACE-22 & \multicolumn{3}{|c|}{ Field Blank } & & & \\
\hline
\end{tabular}


Table B2. Total particulate (TP) data from Test Site 2.

\begin{tabular}{|c|c|c|c|c|c|c|}
\hline \multicolumn{7}{|c|}{ HMA $\left(283^{\circ} \mathrm{F}\right)$} \\
\hline $\begin{array}{l}\text { Sample } \\
\text { ID }\end{array}$ & Description & $\begin{array}{l}\text { Volume of } \\
\text { Air (L) }\end{array}$ & $\begin{array}{l}\mathrm{TP} \\
\left(\mathrm{mg} / \mathrm{m}^{3}\right)\end{array}$ & STD. Dev. & LOD & LOQ \\
\hline ACE-12 & Paver Operator & 636.01 & 0.51 & \multirow{11}{*}{0.002} & \multirow{11}{*}{0.01} & \multirow{11}{*}{0.02} \\
\hline ACE-13 & Right Screedman & 591.02 & 1.36 & & & \\
\hline ACE-14 & Left Screedman & 609.75 & 1.04 & & & \\
\hline ACE-15 & MTV Operator & 582.54 & 2.26 & & & \\
\hline ACE-16 & Dump Man & 614.89 & 0.17 & & & \\
\hline ACE-17 & Background Sample & 718.76 & 0.44 & & & \\
\hline ACE-18 & \multicolumn{3}{|c|}{ Field Blank } & & & \\
\hline ACE-19 & \multicolumn{3}{|c|}{ Field Blank } & & & \\
\hline ACE-20 & \multicolumn{3}{|c|}{ Field Blank } & & & \\
\hline ACE-21 & \multicolumn{3}{|c|}{ Field Blank } & & & \\
\hline ACE-22 & \multicolumn{3}{|c|}{ Field Blank } & & & \\
\hline \multicolumn{7}{|c|}{ WMA $\left(270^{\circ} \mathrm{F}\right)$} \\
\hline $\begin{array}{l}\text { Sample } \\
\text { ID }\end{array}$ & Description & $\begin{array}{l}\text { Volume of } \\
\text { Air (L) }\end{array}$ & $\begin{array}{l}\mathrm{TP} \\
\left(\mathrm{mg} / \mathrm{m}^{3}\right)\end{array}$ & STD. Dev. & LOD & LOQ \\
\hline ACE-01 & Paver Operator & 754.7 & 0.31 & \multirow{11}{*}{0.001} & \multirow{11}{*}{0.003} & \multirow{11}{*}{0.01} \\
\hline ACE-02 & Right Screedman & 870.17 & 0.72 & & & \\
\hline ACE-03 & Left Screedman & 741.75 & 0.30 & & & \\
\hline ACE-04 & MTV Operator & 789.14 & 0.33 & & & \\
\hline ACE-05 & Dump Man & 769.47 & 0.12 & & & \\
\hline ACE-06 & Background Sample & 891.57 & 0.25 & & & \\
\hline ACE-07 & \multicolumn{3}{|c|}{ Field Blank } & & & \\
\hline ACE-08 & \multicolumn{3}{|c|}{ Field Blank } & & & \\
\hline ACE-09 & \multicolumn{3}{|c|}{ Field Blank } & & & \\
\hline ACE-10 & \multicolumn{3}{|c|}{ Field Blank } & & & \\
\hline ACE-11 & \multicolumn{3}{|c|}{ Field Blank } & & & \\
\hline
\end{tabular}


Table B3. Benzene soluble fraction (BSF) data from Test Site 1.

\begin{tabular}{|c|c|c|c|}
\hline \multicolumn{4}{|c|}{$\mathrm{HMA}\left(280^{\circ} \mathrm{F}\right)$} \\
\hline $\begin{array}{l}\text { Sample } \\
\text { ID }\end{array}$ & Description & $\begin{array}{l}\text { Volume } \\
\text { of Air (L) }\end{array}$ & $\begin{array}{l}\text { BSF } \\
\left(\mathrm{mg} / \mathrm{m}^{3}\right)\end{array}$ \\
\hline ACE-01 & Left Screedman & 784.85 & 0.06 \\
\hline ACE-02 & Right Screedman & 766.59 & 0.06 \\
\hline ACE-03 & Paver Operator & 745.77 & 0.02 \\
\hline ACE-04 & Roller Operator & 790.85 & 0.02 \\
\hline ACE-05 & MTV Operator & 772.01 & 0.02 \\
\hline ACE-06 & Background Sample & 851.51 & BDL \\
\hline ACE-07 & \multicolumn{3}{|c|}{ Field Blank } \\
\hline ACE-08 & \multicolumn{3}{|c|}{ Field Blank } \\
\hline ACE-09 & \multicolumn{3}{|c|}{ Field Blank } \\
\hline ACE-10 & \multicolumn{3}{|c|}{ Field Blank } \\
\hline ACE-11 & \multicolumn{3}{|c|}{ Field Blank } \\
\hline \multicolumn{4}{|c|}{ WMA $\left(258^{\circ} \mathrm{F}\right)$} \\
\hline $\begin{array}{l}\text { Sample } \\
\text { ID }\end{array}$ & Description & $\begin{array}{l}\text { Volume } \\
\text { of Air (L) }\end{array}$ & $\begin{array}{l}\text { BSF } \\
\left(\mathrm{mg} / \mathrm{m}^{3}\right)\end{array}$ \\
\hline ACE-12 & Left Screedman & 644.33 & 0.05 \\
\hline ACE-13 & Right Screedman & 617.07 & 0.01 \\
\hline ACE-14 & Paver Operator & $\begin{array}{r}\text { Not } \\
\text { available }\end{array}$ & 0.01 \\
\hline ACE-15 & Roller Operator & 605.36 & 0.08 \\
\hline ACE-16 & MTV Operator & 645.84 & 0.03 \\
\hline ACE-17 & Background Sample & 602.45 & 0.02 \\
\hline ACE-18 & \multicolumn{3}{|c|}{ Field Blank } \\
\hline ACE-19 & \multicolumn{3}{|c|}{ Field Blank } \\
\hline ACE-20 & \multicolumn{3}{|c|}{ Field Blank } \\
\hline ACE-21 & \multicolumn{3}{|c|}{ Field Blank } \\
\hline ACE-22 & \multicolumn{3}{|c|}{ Field Blank } \\
\hline
\end{tabular}

$\mathrm{BDL}=$ below detection limit 
Table B4. Benzene soluble fraction (BSF) data from Test

Site 2.

\begin{tabular}{|c|c|c|c|}
\hline \multicolumn{4}{|c|}{ HMA $\left(283^{\circ} \mathrm{F}\right)$} \\
\hline $\begin{array}{l}\text { Sample } \\
\text { ID }\end{array}$ & Description & $\begin{array}{l}\text { Volume } \\
\text { of Air (L) }\end{array}$ & $\begin{array}{l}\text { BSF } \\
\left(\mathrm{mg} / \mathrm{m}^{3}\right)\end{array}$ \\
\hline ACE-12 & Paver Operator & 636.01 & 0.12 \\
\hline ACE-13 & Right Screedman & 591.02 & 0.23 \\
\hline ACE-14 & Left Screedman & 609.75 & 0.17 \\
\hline ACE-15 & MTV Operator & 582.54 & 0.15 \\
\hline ACE-16 & Dump Man & 614.89 & 0.06 \\
\hline ACE-17 & Background Sample & 718.76 & 0.07 \\
\hline ACE-18 & \multicolumn{3}{|c|}{ Field Blank } \\
\hline ACE-19 & \multicolumn{3}{|c|}{ Field Blank } \\
\hline ACE-20 & \multicolumn{3}{|c|}{ Field Blank } \\
\hline ACE-21 & \multicolumn{3}{|c|}{ Field Blank } \\
\hline ACE-22 & \multicolumn{3}{|c|}{ Field Blank } \\
\hline \multicolumn{4}{|c|}{ WMA $\left(270^{\circ} \mathrm{F}\right)$} \\
\hline $\begin{array}{l}\text { Sample } \\
\text { ID }\end{array}$ & Description & $\begin{array}{l}\text { Volume } \\
\text { of Air (L) }\end{array}$ & $\begin{array}{l}\text { BSF } \\
\left(\mathrm{mg} / \mathrm{m}^{3}\right)\end{array}$ \\
\hline ACE-01 & Paver Operator & 754.70 & 0.09 \\
\hline ACE-02 & Right Screedman & 870.17 & 0.15 \\
\hline ACE-03 & Left Screedman & 741.75 & 0.08 \\
\hline ACE-04 & MTV Operator & 789.14 & 0.04 \\
\hline ACE-05 & Dump Man & 769.47 & 0.04 \\
\hline ACE-06 & Background Sample & 891.57 & 0.04 \\
\hline ACE-07 & \multicolumn{3}{|c|}{ Field Blank } \\
\hline ACE-08 & \multicolumn{3}{|c|}{ Field Blank } \\
\hline ACE-09 & \multicolumn{3}{|c|}{ Field Blank } \\
\hline ACE-10 & \multicolumn{3}{|c|}{ Field Blank } \\
\hline ACE-11 & \multicolumn{3}{|c|}{ Field Blank } \\
\hline
\end{tabular}


Table B5. Total organic matter (TOM) data from Test Site 1.

\begin{tabular}{|l|l|r|r|}
\hline \multicolumn{5}{|c|}{ HMA (280 $\left.{ }^{\circ} \mathrm{F}\right)$} \\
\hline $\begin{array}{l}\text { Sample } \\
\text { ID }\end{array}$ & Description & $\begin{array}{l}\text { Volume } \\
\text { of Air (L) }\end{array}$ & $\begin{array}{l}\text { TOM } \\
\left(\mathrm{mg} / \mathrm{m}^{3}\right)\end{array}$ \\
\hline ACE-01 & Left Screedman & 784.85 & 0.35 \\
\hline ACE-02 & Right Screedman & 766.59 & 0.18 \\
\hline ACE-03 & Paver Operator & 745.77 & 0.30 \\
\hline ACE-04 & Roller Operator & 790.85 & 0.05 \\
\hline ACE-05 & MTV Operator & 772.01 & 0.45 \\
\hline ACE-06 & Background Sample & 851.51 & $\mathrm{BDL}$ \\
\hline ACE-07 & Field Blank & NA & $\mathrm{BDL}$ \\
\hline \multicolumn{4}{|c|}{ WMA (258 $\left.{ }^{\circ} \mathrm{F}\right)$} \\
\hline $\begin{array}{l}\text { Sample } \\
\text { ID }\end{array}$ & Description & $\begin{array}{l}\text { Volume } \\
\text { of Air (L) }\end{array}$ & $\begin{array}{l}\text { TOM } \\
\left(\mathrm{mg} / \mathrm{m}^{3}\right)\end{array}$ \\
\hline ACE-12 & Left Screedman & 644.33 & 0.28 \\
\hline ACE-13 & Right Screedman & 617.07 & 0.05 \\
\hline ACE-14 & Paver Operator & 603.90 & 0.09 \\
\hline ACE-15 & Roller Operator & 605.36 & 0.05 \\
\hline ACE-16 & MTV Operator & 645.84 & 0.20 \\
\hline ACE-17 & Background Sample & 602.45 & $\mathrm{BDL}$ \\
\hline ACE-18 & Field Blank & NA & $\mathrm{BDL}$ \\
\hline
\end{tabular}

$\mathrm{BDL}=$ below detection limit 
Table B6. Total organic matter (TOM) data from Test Site 2.

\begin{tabular}{|l|l|r|r|}
\hline \multicolumn{5}{|c|}{ HMA (283 $\left.{ }^{\circ} \mathrm{F}\right)$} \\
\hline $\begin{array}{l}\text { Sample } \\
\text { ID }\end{array}$ & Description & $\begin{array}{l}\text { Volume } \\
\text { of Air (L) }\end{array}$ & $\begin{array}{l}\text { TOM } \\
\left(\mathbf{m g} / \mathbf{m}^{3}\right)\end{array}$ \\
\hline ACE-12 & Paver Operator & 636.01 & 1.05 \\
\hline ACE-13 & Right Screedman & 591.02 & 2.55 \\
\hline ACE-14 & Left Screedman & 609.75 & 1.52 \\
\hline ACE-15 & MTV Operator & 582.54 & 1.11 \\
\hline ACE-16 & Dump Man & 614.89 & 0.15 \\
\hline ACE-17 & Background Sample & 718.76 & BDL \\
\hline ACE-18 & Field Blank & NA & BDL \\
\hline \multicolumn{4}{|c|}{ WMA (270 ${ }^{\circ}$ F) } \\
\hline \begin{tabular}{l|l|c|} 
Sample \\
ID
\end{tabular} & Description & Volume & TOM \\
\hline of Air (L) & (mg/m $\left.{ }^{3}\right)$ \\
\hline ACE-01 & Paver Operator & 754.7 & 0.98 \\
\hline ACE-02 & Right Screedman & 870.17 & 3.35 \\
\hline ACE-03 & Left Screedman & 741.75 & 0.8 \\
\hline ACE-04 & MTV Operator & 789.14 & 1.12 \\
\hline ACE-05 & Dump Man & 769.47 & 0.24 \\
\hline ACE-06 & Background Sample & 891.57 & BDL \\
\hline ACE-07 & Field Blank & NA & BDL \\
\hline
\end{tabular}

$\mathrm{BDL}=$ below detection limit 
Table B7. Fluorescence data from Test Site 1.

\begin{tabular}{|c|c|c|c|}
\hline \multicolumn{4}{|c|}{$\mathrm{HMA}\left(280^{\circ} \mathrm{F}\right)$} \\
\hline $\begin{array}{l}\text { Sample } \\
\text { ID }\end{array}$ & Description & $\begin{array}{l}\text { Result } \\
\text { EU/g }\end{array}$ & $\begin{array}{l}\mu \mathrm{g} / \mathrm{m}^{3} \\
\text { as DPA }\end{array}$ \\
\hline ACE-01 & Left Screedman & 40.30 & 0.05 \\
\hline ACE-02 & Right Screedman & 48.40 & 0.04 \\
\hline ACE-03 & Paver Operator & 45.40 & 0.05 \\
\hline ACE-04 & Roller Operator & 10.00 & 0.01 \\
\hline ACE-05 & MTV Operator & 50.40 & 0.09 \\
\hline ACE-06 & Background Sample & $\mathrm{BDL}$ & BDL \\
\hline ACE-07 & Field Blank & $\mathrm{BDL}$ & NA \\
\hline \multicolumn{4}{|c|}{ WMA $\left(258^{\circ} \mathrm{F}\right)$} \\
\hline $\begin{array}{l}\text { Sample } \\
\text { ID }\end{array}$ & Description & $\begin{array}{l}\text { Result } \\
\text { EU/g g }\end{array}$ & $\begin{array}{l}\mu \mathrm{g} / \mathrm{m}^{3} \\
\text { as DPA }\end{array}$ \\
\hline ACE-12 & Left Screedman & 47.30 & 0.05 \\
\hline ACE-13 & Right Screedman & 10.00 & 0.02 \\
\hline ACE-14 & Paver Operator & 39.40 & 0.01 \\
\hline ACE-15 & Roller Operator & 10.00 & 0.02 \\
\hline ACE-16 & MTV Operator & 73.40 & 0.06 \\
\hline ACE-17 & Background Sample & $\mathrm{BDL}$ & 0.01 \\
\hline ACE-18 & Field Blank & $\mathrm{BDL}$ & NA \\
\hline
\end{tabular}

$\mathrm{BDL}=$ below detection limit 
Table B8. Fluorescence data from Test Site 2.

\begin{tabular}{|c|c|c|c|}
\hline \multicolumn{4}{|c|}{$\mathrm{HMA}\left(283^{\circ} \mathrm{F}\right)$} \\
\hline $\begin{array}{l}\text { Sample } \\
\text { ID }\end{array}$ & Description & $\begin{array}{l}\text { Result } \\
\text { EU/g }\end{array}$ & $\begin{array}{l}\mu \mathrm{g} / \mathrm{m}^{3} \\
\text { as DPA }\end{array}$ \\
\hline ACE-12 & Paver Operator & 14.5 & 0.08 \\
\hline ACE-13 & Right Screedman & 8.78 & 0.13 \\
\hline ACE-14 & Left Screedman & 15.1 & 0.13 \\
\hline ACE-15 & MTV Operator & 17.5 & 0.11 \\
\hline ACE-16 & Dump Man & 0.5 & 0.01 \\
\hline ACE-17 & Background Sample & $\mathrm{BDL}$ & 0.03 \\
\hline ACE-18 & Field Blank & $\mathrm{BDL}$ & NA \\
\hline \multicolumn{4}{|c|}{ WMA $\left(270^{\circ} \mathrm{F}\right)$} \\
\hline $\begin{array}{l}\text { Sample } \\
\text { ID }\end{array}$ & Description & $\begin{array}{l}\text { Result } \\
\text { EU/g }\end{array}$ & $\begin{array}{l}\mu \mathrm{g} / \mathrm{m}^{3} \\
\text { as DPA }\end{array}$ \\
\hline ACE-01 & Paver Operator & 6.5 & 0.03 \\
\hline ACE-02 & Right Screedman & 10.2 & 0.13 \\
\hline ACE-03 & Left Screedman & 11.4 & 0.04 \\
\hline ACE-04 & MTV Operator & 9.62 & 0.04 \\
\hline ACE-05 & Dump Man & 0.5 & 0.01 \\
\hline ACE-06 & Background Sample & $\mathrm{BDL}$ & $\mathrm{BDL}$ \\
\hline ACE-07 & Field Blank & $\mathrm{BDL}$ & $\mathrm{NA}$ \\
\hline
\end{tabular}

$\mathrm{BDL}=$ below detection limit 


\section{Appendix C: Chromatograms}

Figure C1. GC/FID chromatogram of a kerosene calibration standard.

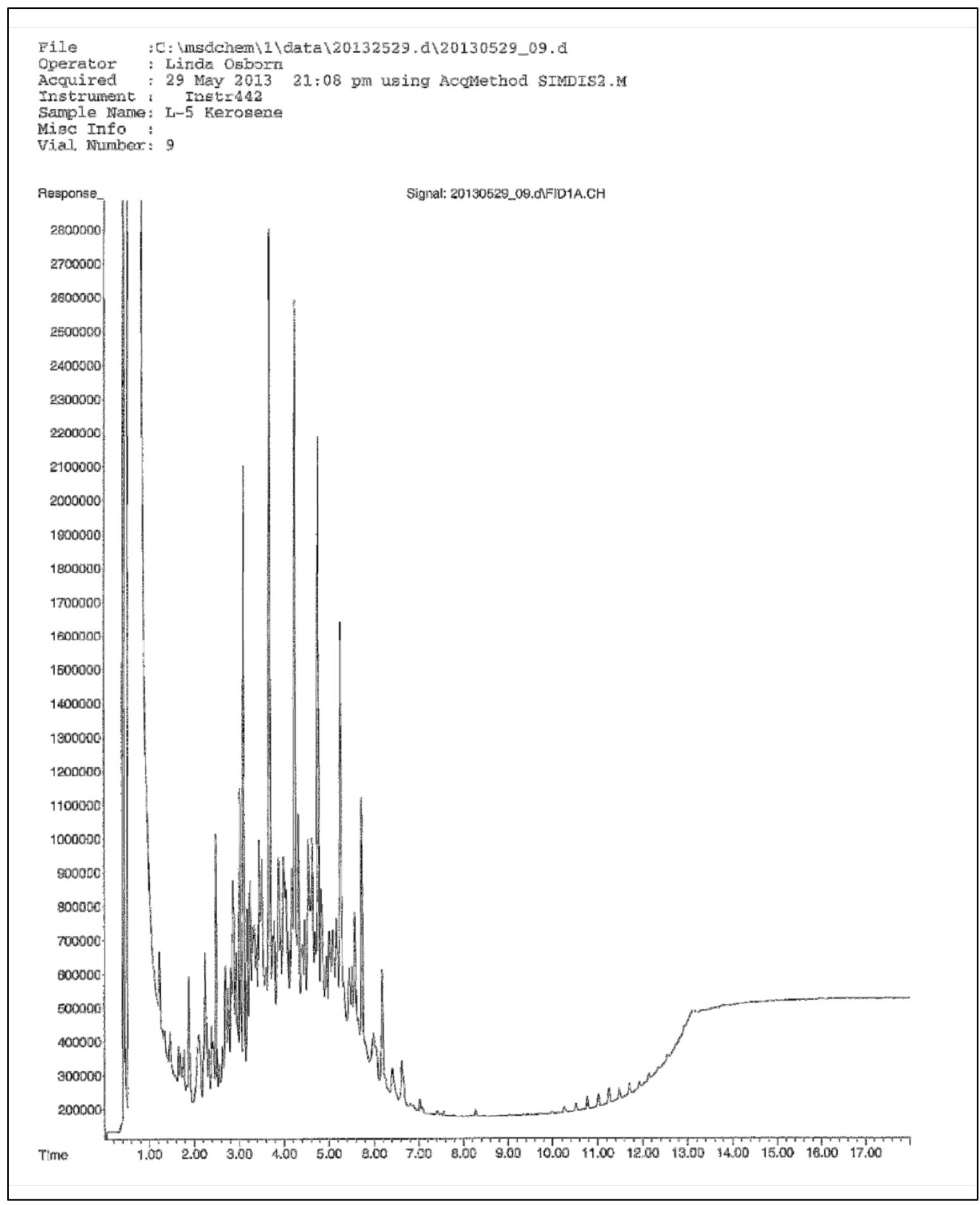


Figure C2. GC/FID chromatogram of a simulated distillation standard showing straight chain hydrocarbons from C-6 through C-44.

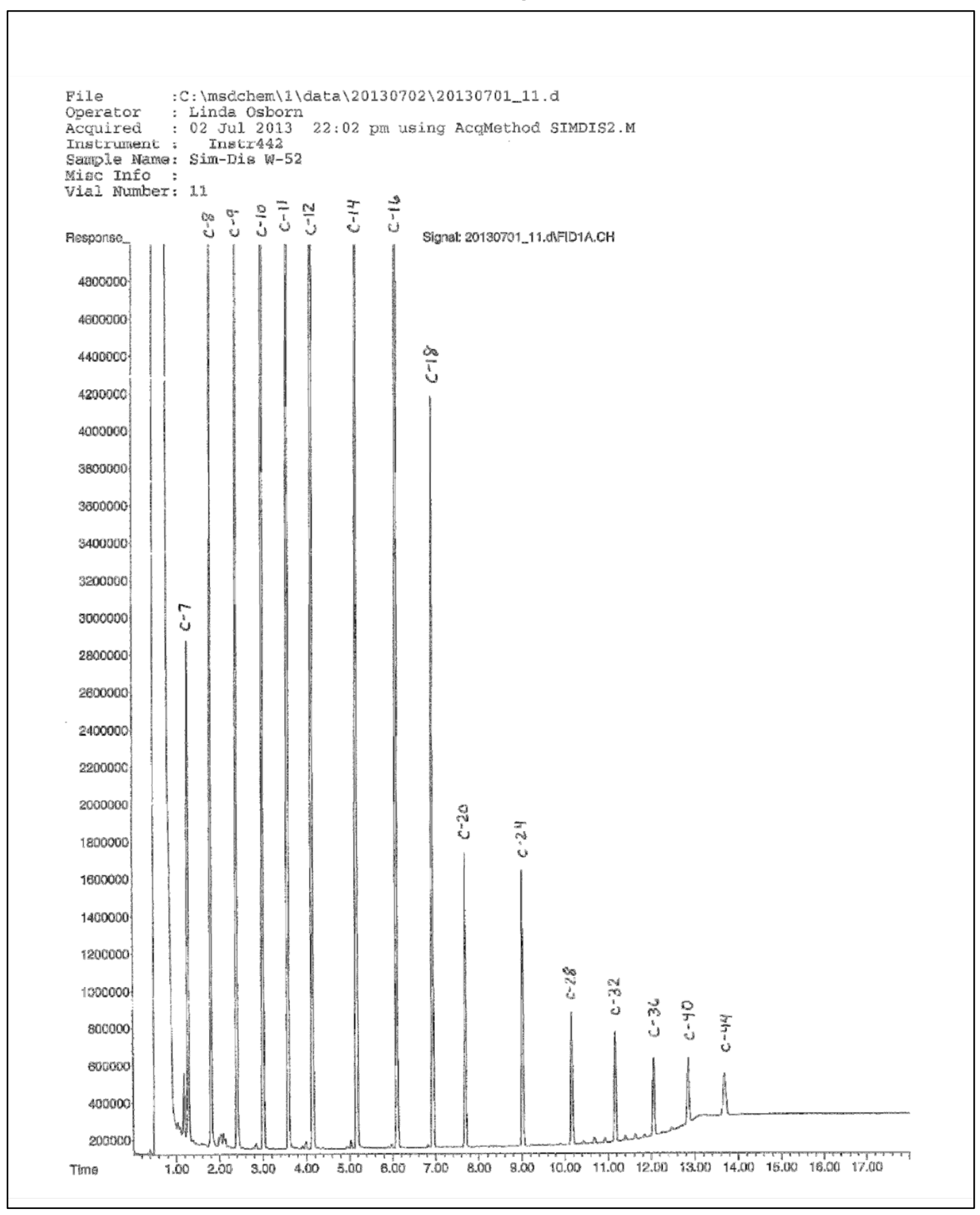


Figure C3. GC/FID chromatogram of a blank extract.

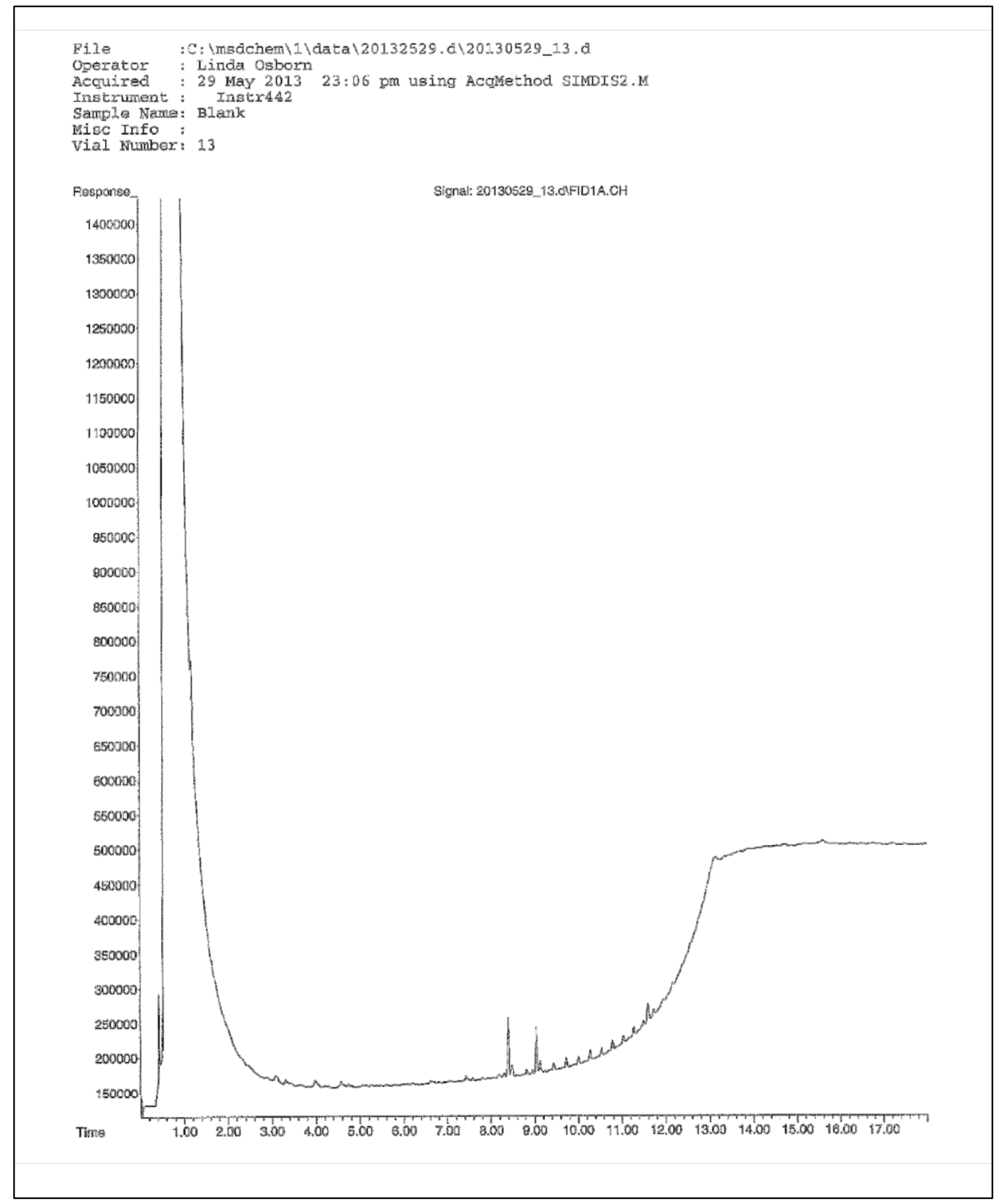


Figure C4. GC/FID chromatogram of TOM from one worker from Test Site 1.

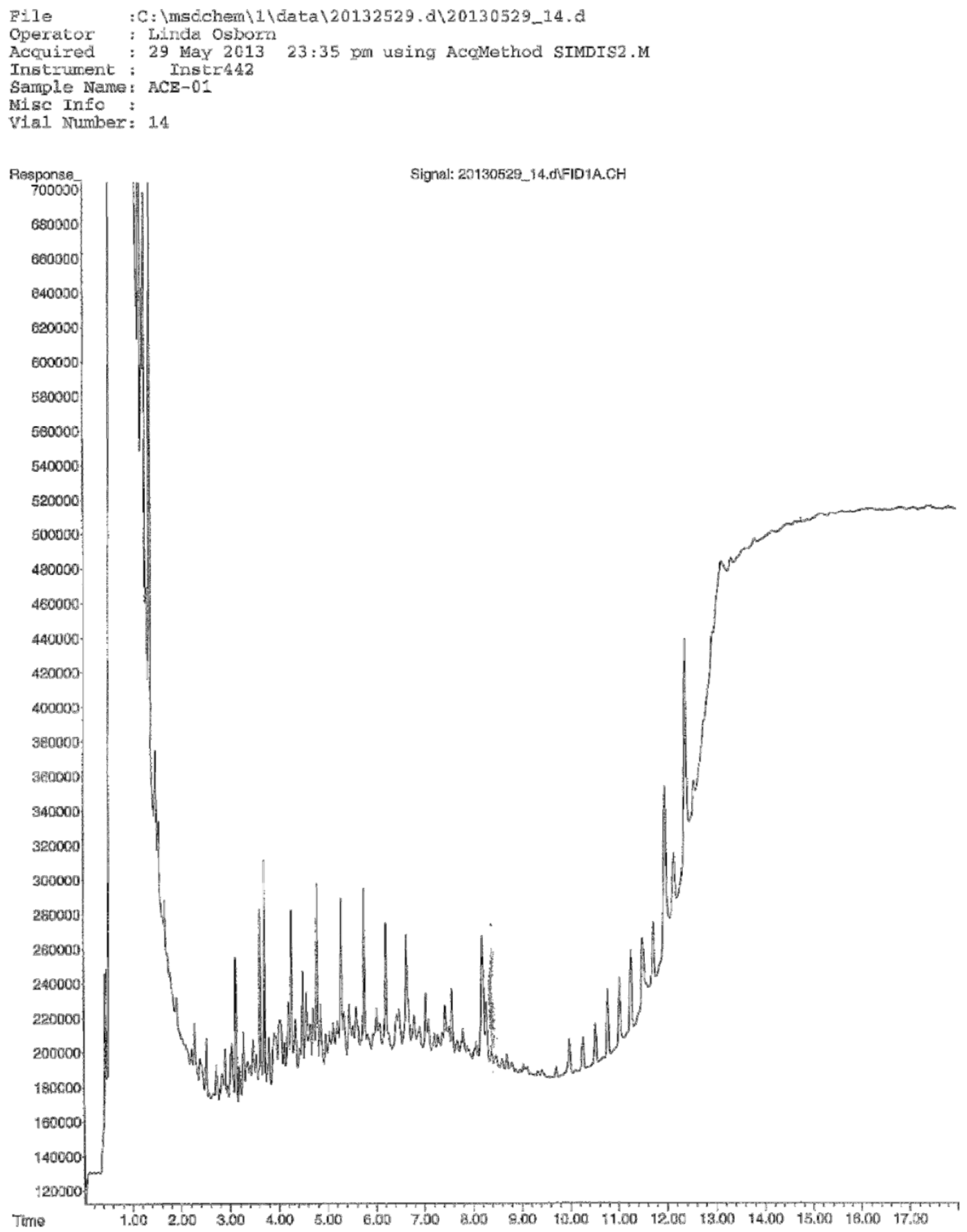


Figure C5. GC/FID chromatogram of TOM from one worker from Test Site 2.

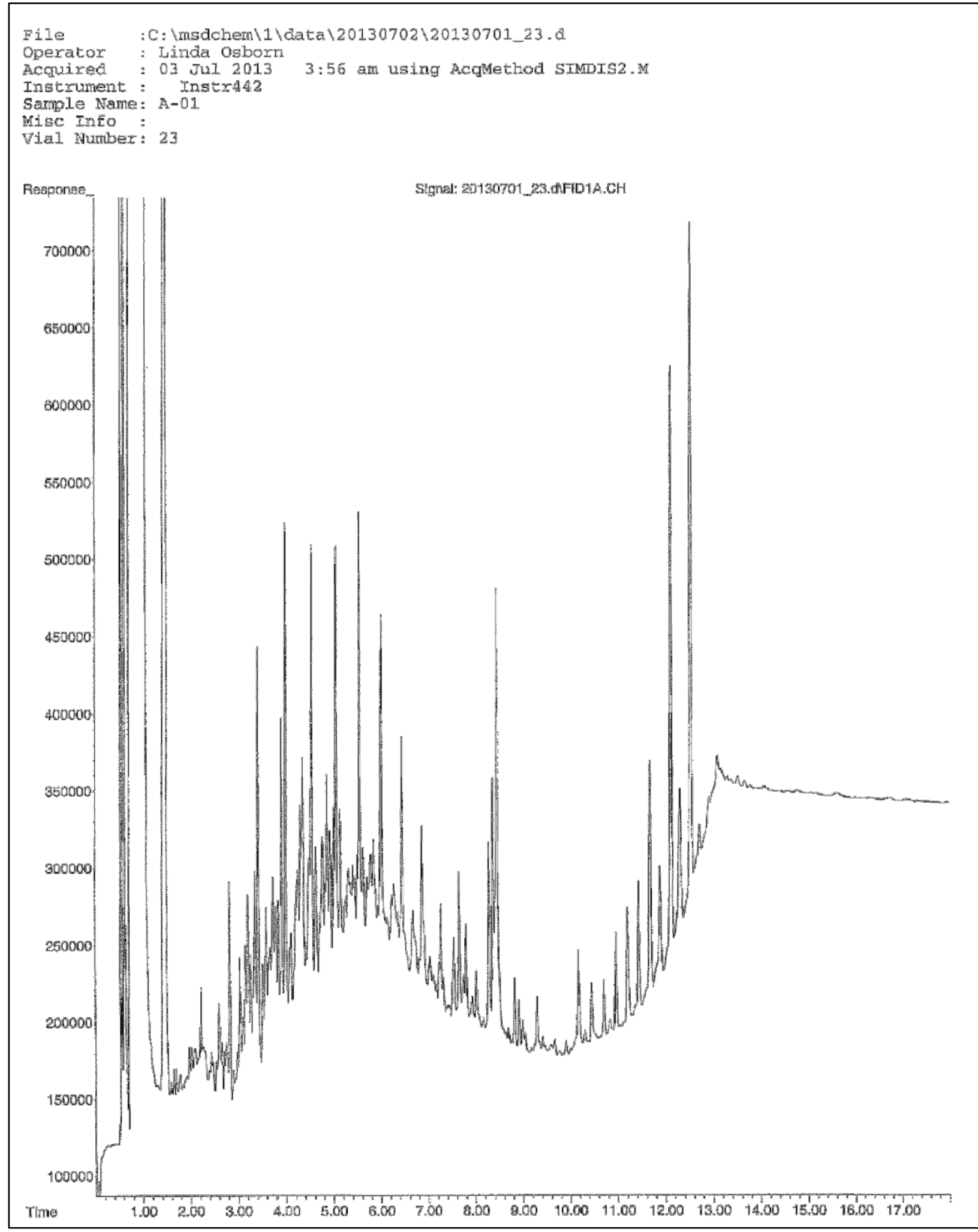




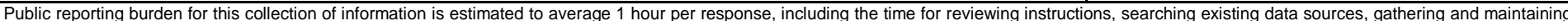

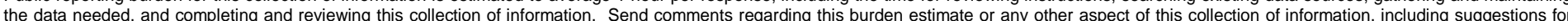

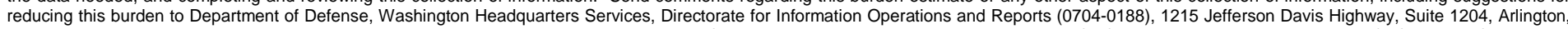

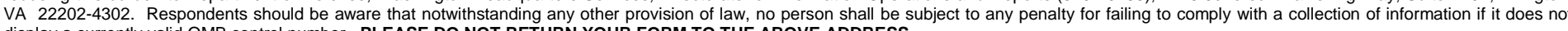
display a currently valid OMB control number. PLEASE DO NOT RETURN YOUR FORM TO THE ABOVE ADDRESS.
1. REPORT DATE (DD-MM-YYYY)
June 2014

\section{TITLE AND SUBTITLE}

Emissions Reductions Associated with the Use of Warm-Mix Asphalt as Compared to Hot-Mix Asphalt
3. DATES COVERED (From - To)

5a. CONTRACT NUMBER

5b. GRANT NUMBER

\section{AUTHOR(S)}

Mariely Mejias-Santiago and Linda V. Osborn

5c. PROGRAM ELEMENT NUMBER

5d. PROJECT NUMBER

5e. TASK NUMBER

5f. WORK UNIT NUMBER

\section{PERFORMING ORGANIZATION NAME(S) AND ADDRESS(ES)}

Geotechnical and Structures Laboratory

U.S. Army Engineer Research and Development Center

3909 Halls Ferry Road

Vicksburg, MS 39180-6199

\section{SPONSORING / MONITORING AGENCY NAME(S) AND ADDRESS(ES)}

U.S. Air Force Civil Engineer Center

139 Barnes Drive, Suite 1

Tyndall AFB,FL 32403-5319

8. PERFORMING ORGANIZATION REPORT
NUMBER

ERDC/GSL TR-14-19

10. SPONSOR/MONITOR'S ACRONYM(S)

AFCEC

11. SPONSOR/MONITOR'S REPORT NUMBER(S)

\section{DISTRIBUTION / AVAILABILITY STATEMENT}

Approved for public release; distribution is unlimited.

\section{SUPPLEMENTARY NOTES}

\section{ABSTRACT}

This report presents results from a literature review and field testing that were conducted with the main objective of developing guidance for documenting the reduction in emissions associated with the use of warm-mix asphalt (WMA) as compared to conventional hot-mix asphalt (HMA). The literature review presents current methods for estimating emissions during asphalt production, current protocols to measure and control emissions, and case studies where WMA emissions were measured and compared to HMA. Field testing was conducted during asphalt paving at two locations where a given mixture was placed as HMA and WMA. Workers' exposures to asphalt emissions were measured at each test site for both HMA and WMA. Data from both the literature and field testing provide averaged emissions reductions that range up to $70 \%$ for plant emissions and up to $50 \%$ for asphalt emissions during placement.

\section{SUBJECT TERMS}

Warm-mix asphalt

Stack emissions
Emissions

Worker exposure

Asphalt fumes

\begin{tabular}{|c|c|c|c|c|}
\hline \multicolumn{3}{|c|}{ 16. SECURITY CLASSIFICATION OF: } & \multirow{3}{*}{$\begin{array}{l}\text { 17. LIMITATION } \\
\text { OF ABSTRACT }\end{array}$} & \multirow{2}{*}{$\begin{array}{l}\text { 18. NUMBER } \\
\text { OF PAGES }\end{array}$} \\
\hline a. REPORT & b. ABSTRACT & c. THIS PAGE & & \\
\hline Unclassified & Unclassified & Unclassified & & 68 \\
\hline
\end{tabular}

19a. NAME OF RESPONSIBLE PERSON M. Mejias-Santiago

19b. TELEPHONE NUMBER (include area code) 